THE AUDITORY SYSTEM OF THE MINKE WHALE (BALAENOPTERA

ACUTOROSTRATA): A POTENTIAL FATTY SOUND RECEPTION PATHWAY

IN A MYSTICETE CETACEAN

By

\title{
Maya Yamato
}

A.B., Princeton University, 2007

Submitted in partial fulfillment of the requirements for the degree of

Doctor of Philosophy

at the
MASSACHUSETTS INSTITUTE OF TECHNOLOGY
and the
WOODS HOLE OCEANOGRAPHIC INSTITUTION

September 2012

(C) 2012 Maya Yamato

ARCHIVES

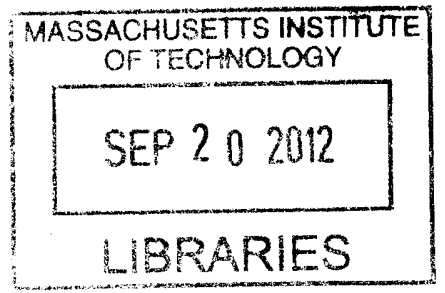

All rights reserved.

The author hereby grants to MIT and WHOI permission to reproduce and to distribute publicly paper and electronic copies of this thesis document in whole or in part in any medium now known or hereafter created.

Signature of Author
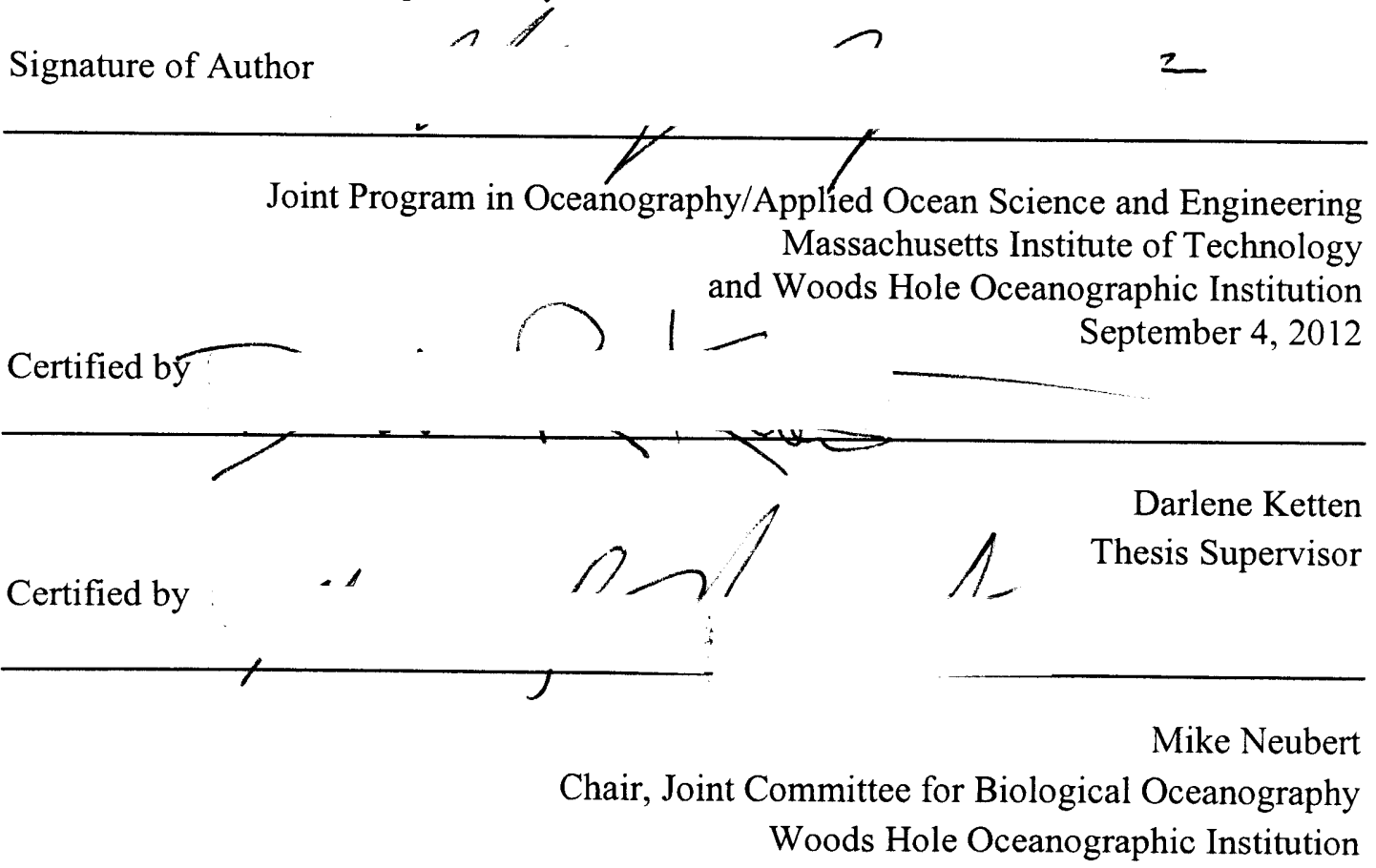

The auditory system of the minke whale (Balaenoptera acutorostrata): a potential fatty sound reception pathway in a mysticete cetacean

by

Maya Yamato

Submitted to the MIT-WHOI Joint Program in Oceanography / Applied Ocean Science and Engineering on September 4, 2012 in Partial Fulfillment of the Requirements for the Degree of Doctor of Philosophy in Biological Oceanography

\begin{abstract}
Despite widespread concerns about the effects of anthropogenic noise on baleen whales (suborder Mysticeti), we lack basic information about their auditory physiology for comprehensive risk assessments. Hearing ranges and sensitivities could be measured if customized equipment and methods were developed based on how baleen whales receive sound. However, sound reception pathways in baleen whales are currently unknown. This thesis presents an integrative approach to understanding hearing in baleen whales through dissections, biomedical imaging, biochemical analyses, and modeling sound propagation through a whale head using the Finite Element Method (FEM). We focused on the minke whale (Balaenoptera acutorostrata) because it is one of the smallest and most abundant mysticete species, reducing logistical difficulties for dissections and experiments. We discovered a large, well-formed fat body extending from the blubber region to the ears and contacting the ossicles. Although odontocetes, or toothed whales, are thought to use specialized "acoustic fats" for sound reception, no such tissues had been described for mysticetes to date. Our study indicates that the basic morphology and biochemical composition of the minke whale "ear fats" are very different from those of odontocete acoustic fats. However, the odontocete and mysticete fatty tissues share some characteristics, such as being conserved even during starvation, containing fewer dietary signals compared to blubber, and having well-defined attachments to the tympano-periotic complex, which houses the middle and inner ears. FE models of the whale head indicated that the ear fats caused a slight increase in the total pressure magnitude by the ears, and this focusing effect could be attributed to the low density and low sound speed of the ear fats in the models. Fatty tissues are known to have lower densities and sound speeds than other types of soft tissues, which may explain why they are an important component of the auditory system of odontocetes, and perhaps mysticete cetaceans as well. In an aquatic habitat where the pinna and air-filled ear canal are no longer effective at collecting and focusing sound towards the ears, we propose that both odontocete and mysticete cetaceans have incorporated fatty tissues into their auditory systems for underwater sound reception.
\end{abstract}

Thesis supervisor: Dr. Darlene Ketten

Title: Senior Scientist, Department of Biology, Woods Hole Oceanographic Institution 


\section{Acknowledgements}

This thesis would not have been possible without the support of numerous individuals who have contributed their time and efforts into helping me over the past 5 years as a graduate student. First and foremost I would like to thank my thesis advisor, Dr. Darlene Ketten, for providing me with numerous resources and opportunities that enabled me to develop and pursue my own research interests. I will always be grateful for her support and mentorship, beginning in 2005 when she took me in to her lab group as an undergraduate fellow. Members of my thesis committee were also indispensable for the execution of my thesis. Dr. Heather Koopman of UNC Wilmington provided me with exceptional and insightful feedback throughout this process and was my primary mentor for Chapter 3. Dr. Gonzalo Feijoo of Siemens AG provided me with the tools and knowledge necessary for Chapter 4, and Dr. Dennis Freeman of MIT and Dr. Peter Tyack of WHOI and the University of St. Andrews also provided their valuable expertise.

Several individuals have also served as unofficial mentors during my time in the Joint Program. My thesis would not have been possible without the kind support of Scott Cramer and Julie Arruda of the Ketten Lab, who were incredibly tolerant of the numerous whale heads we handled together. Dr. Michael Moore of WHOI, who chaired both my thesis proposal defense and my thesis defense, was always available for advice whether we were in the MRF hallway or inside a dead whale. Dr. Aran Mooney of WHOI has been a great friend and mentor, and Dr. Joy Reidenberg of Mt. Sinai School of Medicine has kindly helped me with some of the dissections. Aleks Zosuls and Andrew Tubelli were fantastic collaborators.

I am so grateful to the staff of the IFAW Marine Mammal Rescue and Research Group and their countless volunteers, who have provided me with most of the specimens for this thesis. None of this work would have been possible without their dedication and commitment to the advancement of marine mammal science, in addition to their tireless rescue efforts. Special thanks to Misty Niemeyer, who also became a great friend with her smiling, positive influence. Additional thanks to everyone in MRF for their support and friendship over the past 5 years.

I would also like to thank the past and present members of the WHOI Academic Programs Office for their genuine support and making me feel at home in the Joint Program.

The past five years in the MIT-WHOI Joint Program were the most incredible years of my life, thanks to my awesome friends. While there are too many individuals to list on one page, special thanks to my housemates, Ann Allen and Kim Popendorf, and Carly Buchwald and Jeff Kaeli, who have been best friends since SSF ' 06 .

I would not be here today without my family, Suzuko, Saburo, and Masaru Yamato. Thank you for your support throughout the years. Finally, thanks to Greg Dietzen, my best friend and future husband, for providing me with encouragement, unwavering love, and true happiness.

This study was funded by the National Science Foundation Graduate Research Fellowship Program, WHOI Academic Programs Office, WHOI Ocean Life Institute Fellowship, Ocean Ventures Fund, WHOI Coastal Ocean Institute Award, WHOI Summer Student Fellowship, WHOI Minority Fellowship, the MIT Student Assistance Fund, the Joint Industry Program, the Marine Mammal Program of the Office of Naval Research, and the Naval Operations Energy and Environmental Readiness Division. 
Table of Contents

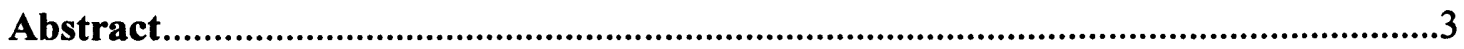

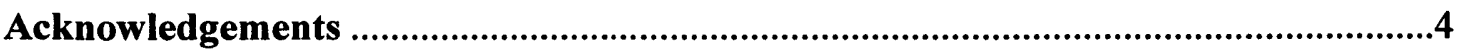

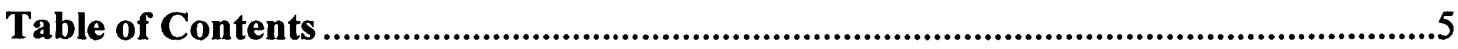

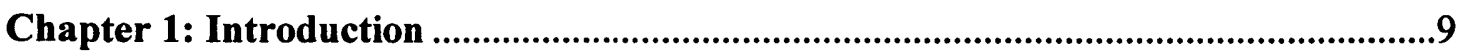

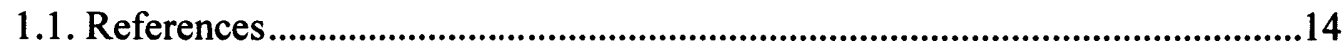

Chapter 2: Auditory anatomy of the minke whale .............................................17

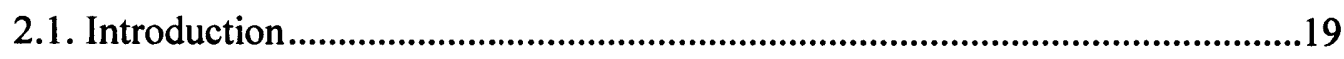

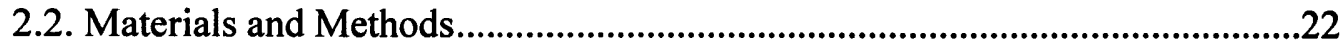

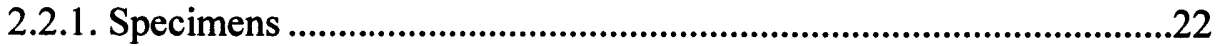

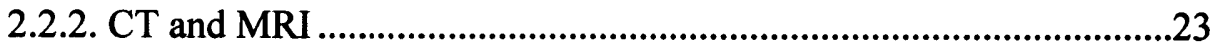

2.2.3. Three-dimensional reconstructions.................................................24

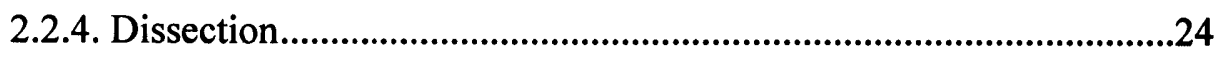

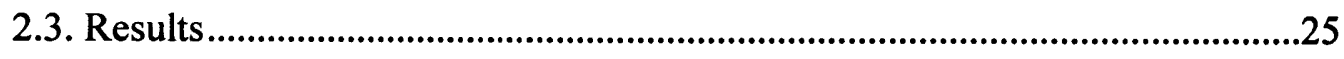

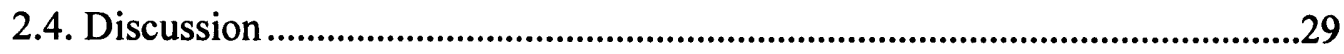

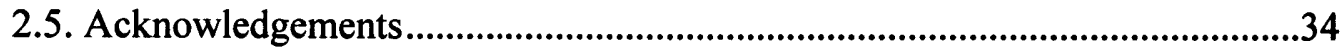

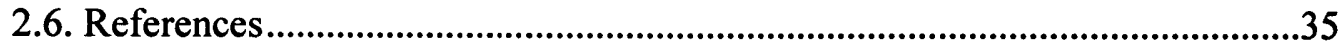

\section{Chapter 3: Morphology and lipid biochemistry of fats associated with}

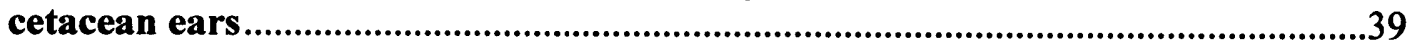

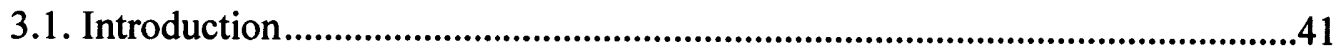

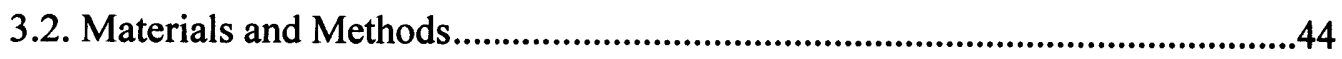

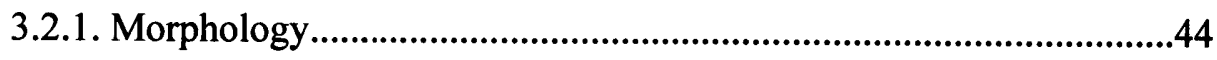

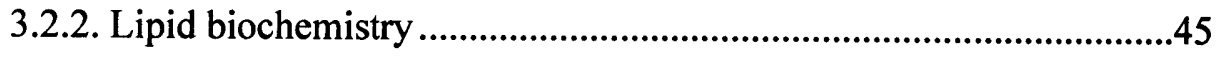

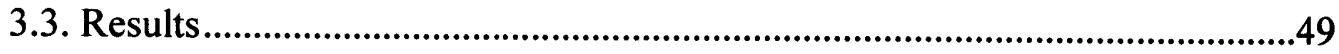

3.3.1. Morphology of the ear fats vs. odontocete acoustic fats.................49

3.3.2. Lipid composition of ear fats ......................................................55

3.3.2.1. Lipid content ................................................................52

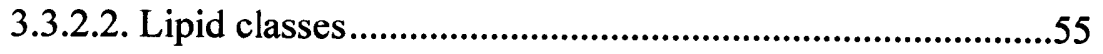


3.3.2.3. Fatty acid composition ..........................................................55

3.3.3. Comparison of ear fat lipid composition with odontocete

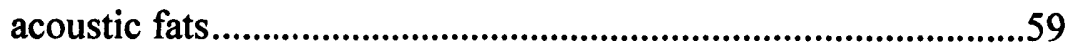

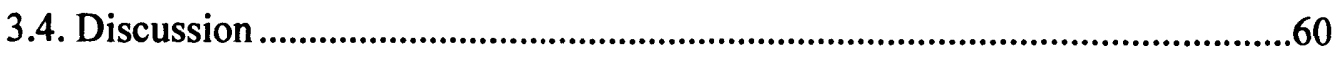

3.4.1. Morphology of the ear fats vs. odontocete acoustic fats...................60

3.4.2. Lipid composition of ear fats ............................................................61

3.4.2.1. Lipid content .......................................................................61

3.4.2.2. Lipid classes........................................................................64

3.4.2.3. Fatty acid composition ........................................................65

3.4.3. Comparison with odontocete acoustic fats .......................................66

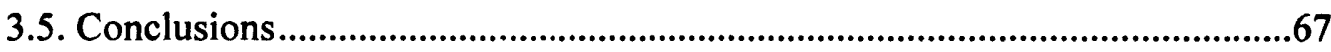

3.6. Acknowledgements.....................................................................................70

3.7. References.....................................................................................................

\section{Chapter 4: Modeling sound propagation through the minke whale head using the}

Finite Element Method (FEM) .....................................................................77

4.1. Introduction .............................................................................................79

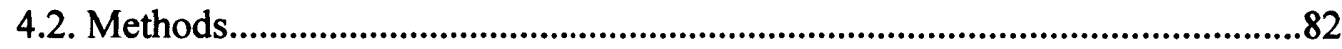

4.2.1. Model development ...........................................................................82

4.2.2. Material properties ...........................................................................83

4.2.3. FEM program ...................................................................................85

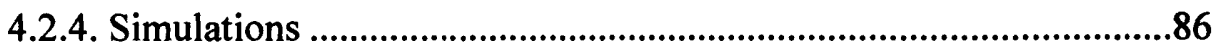

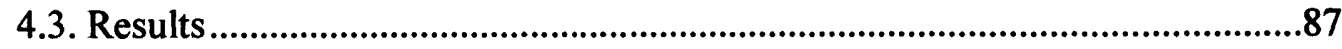

4.3.1. Density of ear fat samples...............................................................87

4.3.2. The basic model and effect of sound source location.......................89

4.3.3. The effect of air spaces ..................................................................93

4.3.4. The effect of bony structures ............................................................94

4.3.5. The role of ear fat...........................................................................97

4.3.6. Immersing the head in soft tissues................................................102 


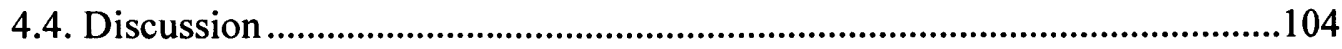

4.4.1. Density of ear fat samples........................................................104

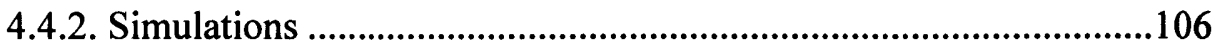

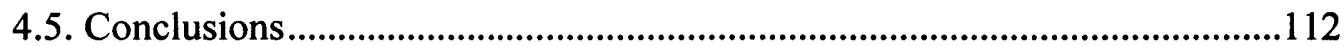

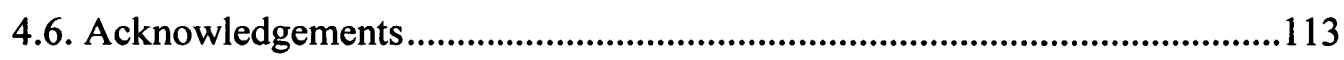

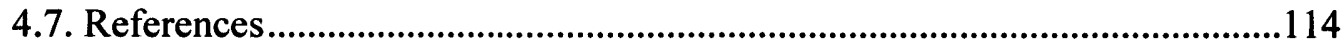

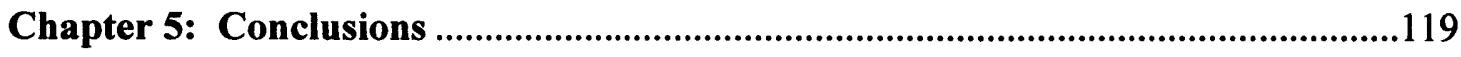

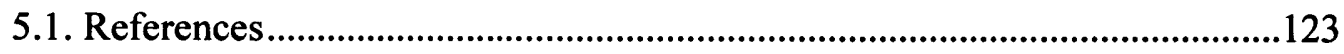

Appendix: CT scanning and three-dimensional visualization of the minke whale head: non-auditory structures ...........................................................125

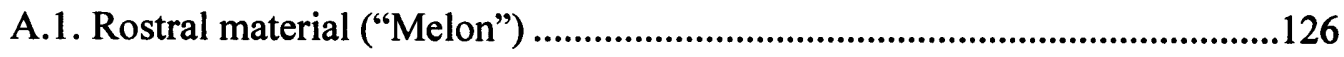

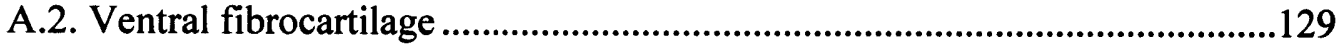

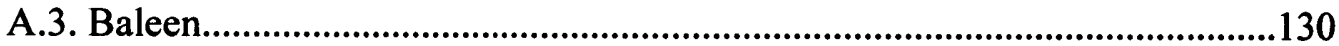

A.4. Pharyngo-tympanic (Eustachian) tube ....................................................132

A.5. Olfactory structures......................................................................134

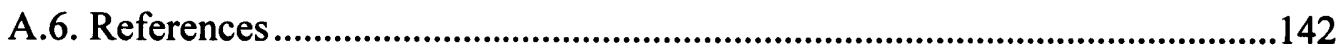


Chapter 1: Introduction 
Humans are increasingly altering the world's oceans. Overfishing, pollution, and ocean acidification are just a few of the anthropogenic threats that our oceans face today. Over the past several years, however, another source of concern has been developing among scientists, governments, and even the popular press: the effects of human-made noise on marine animals. This issue has been highlighted for cetaceans in particular not only because of their public appeal, but also because of their protected status and importance of hearing for their survival. In the aquatic habitat where light attenuates quickly, cetaceans evolved the ability to use sound for vital functions such as communication, navigation, and feeding. Odontocetes, or toothed whales, have acquired the ability to echolocate (McBride, 1947, in Scheville, 1956; Kellogg, 1958; Norris et al., 1961). Such sophisticated, specialized biosonar systems have not been demonstrated in mysticetes, or baleen whales, which is the other suborder of cetaceans. However, mysticetes produce low frequency sounds, which can travel over hundreds of kilometers in the ocean and perhaps farther in the Sound Fixing and Ranging channels ("deep sound channels") of the ocean (Cummings and Thompson, 1971; Payne and Webb, 1971; Tsuchiya et al., 2004).

There are many natural noise sources in the oceans, including crashing waves, earthquakes, and biological sounds. However, anthropogenic noises are becoming more ubiquitous. The most well-publicized of these noise sources is military sonar, which has been linked to several mass-strandings of primarily beaked whales (Frantzis, 1998; Balcomb and Claridge, 2001) and have evoked passionate responses from the public, environmental groups, and scientists (e.g., Parsons et al., 2008). However, commercial shipping is the dominant input of ambient noise in the oceans today, because of its universal presence and emission of long ranging, low frequency noises (Figure 1.1; Hildebrand, 2009). According to McDonald et al. (2006), there was a doubling of commercial vessels in the world's oceans between 1965 and 2003, leading to a 2.5 to 3 $\mathrm{dB}$ increase per decade in low frequency noises below $50 \mathrm{~Hz}$. Andrew et al. (2011) showed data consistent with a 8-10 dB increase in traffic noise from the mid-1960's to the present at multiple study sites, with a peak in the mid-1990's. 


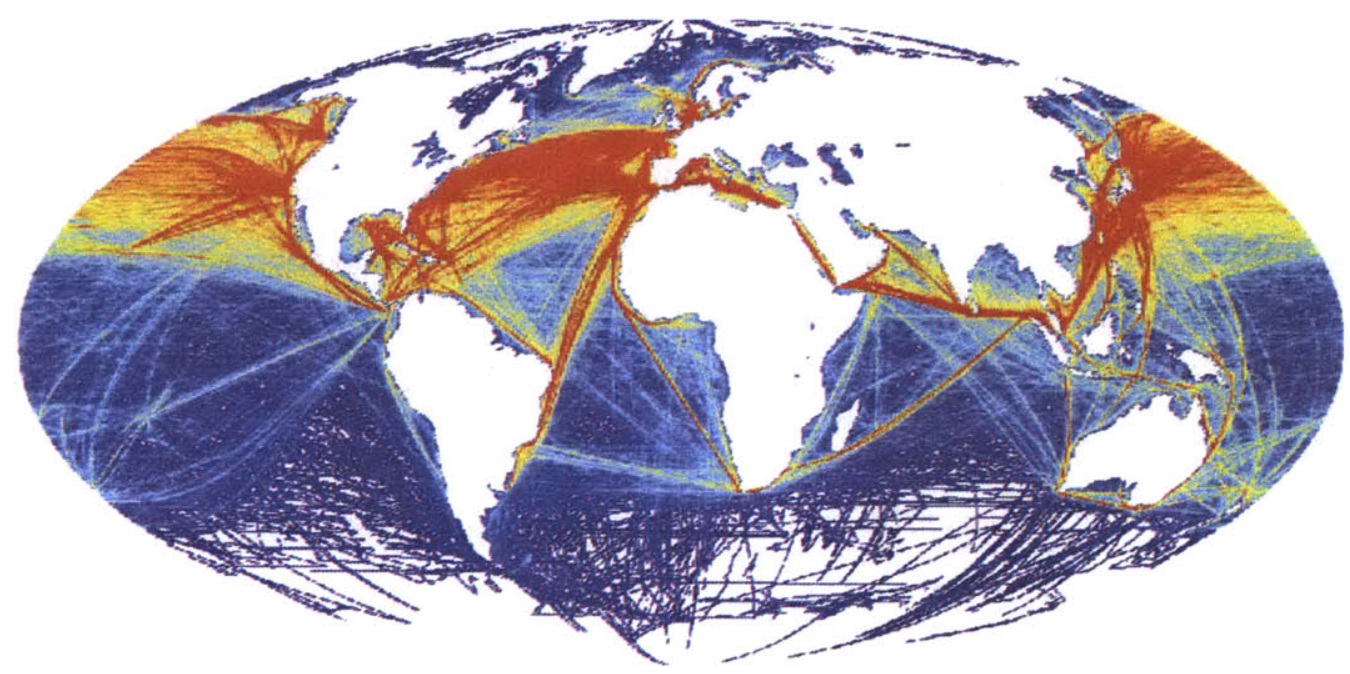

Figure 1.1. Global shipping activity. (National Center for Ecological Analysis and Synthesis, 2008. www.nceas.ucsb.edu/globalmarine/impacts)

The increased levels of low frequency anthropogenic noise are a particular concern for baleen whales, which are thought to be sensitive to low-frequency sounds. Many mysticete populations have already suffered drastic declines from human activities such as whaling and could be further endangered if anthropogenic noise results in behavioral disruption, hearing impairment, habitat abandonment, or reduced mating opportunities. For example, anthropogenic noise may mask mysticete vocalizations and reduce the range over which individuals can communicate with each other, compromising the ability to find mates or initiate cooperative feeding behaviors (Payne and Webb, 1971; Clark et al., 2009). Recent studies have found that the critically endangered North Atlantic right whales vocalize more loudly and at higher frequencies to compensate for increased levels of low frequency ambient noise (Parks et al., 2007; Parks et al., 2011). While the physiological costs of such efforts are unknown, there is also some evidence that shipping noise is linked to elevated levels of stress hormones in right whales (Rolland et al., 2012). Numerous studies have documented other responses of cetaceans to anthropogenic noise (see Richardson et al., 1995; Nowacek et al., 2007). 
One major knowledge gap in the effort to assess and mitigate the effects of human-made noise on baleen whales is the lack of knowledge about their auditory systems, hearing ranges, and hearing sensitivities. No study has successfully measured the auditory capacity of any mysticete species to date. This is in contrast to toothed whales, including dolphins and porpoises, for which behavioral and electrophysiological methods of testing hearing are well-established. In behavioral testing, a captive animal is trained to produce a certain response if it detects a sound stimulus. This stimulus can be altered in frequency or intensity to obtain a complete audiogram of the individual. This method is commonly used for testing human hearing, although human subjects do not require training and can verbally communicate the results. In electrophysiological testing, electrodes are used to detect auditory evoked potentials (AEP) or changes in brain wave patterns resulting from sound stimuli. As a sound stimulus of a particular frequency is presented at lower and lower intensities, there is a point at which a differentiable AEP is no longer detectable in the brain wave; this is the hearing threshold of the subject at the frequency being tested (Campbell et al., 1977).

There are several reasons why these forms of hearing studies have not been carried out on baleen whales. Baleen whales are rarely kept in captivity, have never been trained, and thus are not good candidates for behavioral testing. Electrophysiological testing is a potentially promising approach. The recent development of AEP techniques for studying marine mammal hearing has significantly advanced our knowledge of what many species hear. Two key advantages to using AEPs over conventional behavioral hearing studies are that they do not require trained animals and they can be employed outside of the laboratory. For example, AEPs have been used to successfully measure odontocete hearing in capture-release scenarios and in stranded animals (e.g., Nachtigall et al., 2005; Nachtigall et al., 2008; Finneran et al., 2009; Mann et al., 2010).

Although AEP testing is most likely the best method for obtaining accurate hearing ranges and sensitivities of large whales, there are some hurdles that must be overcome before it becomes a reality. Access to animals is a significant challenge; in 
cases where stranded or entangled animals are used, these situations will be rare and opportunistic. Even if there is a suitable opportunity, the Marine Mammal Protection Act requires a permitting process that may be lengthy and result in a rejection. In addition to these logistical challenges, another limitation for applying AEP techniques to baleen whales is that we do not know how baleen whales receive sounds. Baleen whale heads are very different from those of toothed whales, and there are large differences in both their skull and soft tissue anatomies. Although we have a relatively good understanding of the sound conduction pathways that channel sounds from the aquatic environment into a toothed whale's inner ears, even basic principles, such as whether baleen whales use soft tissue pathways or bone conduction to receive sounds, remain unclear. Such background knowledge is essential for designing appropriate AEP equipment and experimental setups for baleen whales.

This thesis aims to elucidate potential sound reception mechanisms in baleen whales through an interdisciplinary study combining anatomical, biomedical, biochemical, and engineering techniques. The minke whale (Balaenoptera acutorostrata) is used as a model species because it is one of the smallest baleen whale species, which reduces some of the logistical difficulties for dissections and experiments. Minke whales are also closely related to the other whales in the Balaenoptera genus, including endangered species such as the blue whale (Balaenoptera musculus), fin whale (Balaenoptera physalus), and sei whale (Balaenoptera borealis). Therefore an in-depth study of minke whales, which are relatively abundant and common in the world oceans, will provide a foundation for future research on their less frequently encountered and less tractable relatives. Results from this thesis will be an important first step towards advancing our knowledge on mysticete auditory systems and developing an appropriate knowledge base for effective conservation policies in the future. 


\subsection{References}

Andrew RK, Howe BM, Mercer JA. 2011. Long-time trends in ship traffic noise for four sites off the North American West Coast. The Journal of the Acoustical Society of America 129:642-651.

Balcomb K, Claridge DE. 2001. A mass stranding of cetaceans caused by naval sonar in the Bahamas. Bahamas Journal of Science 01/05 2-12.

Campbell FW, Atkinson J, Francis MR, Green DM. 1977. Estimation of Auditory Thresholds Using Evoked Potentials. Auditory Evoked Potentials in Man., in Psychopharmacology Correlates of EPs. Prog. Clin. Neurophysiol., vol.2., Ed. J. E. Desmedt, pp. 68-78

Clark CW, Ellison WT, Southall BL, Hatch L, Van Parijs SM, Frankel A, Ponirakis D. 2009. Acoustic masking in marine ecosystems: intuitions, analysis, and implication. Marine Ecology-Progress Series 395:201-222.

Cummings WC, Thompson PO. 1971. Underwater Sounds from the Blue Whale, Balaenoptera musculus. The Journal of the Acoustical Society of America 50:1193-1198.

Finneran JJ, Houser DS, Mase-Guthrie B, Ewing RY, Lingenfelser RG. 2009. Auditory evoked potentials in a stranded Gervais' beaked whale (Mesoplodon europaeus). Journal of the Acoustical Society of America 126:484-490.

Frantzis A. 1998. Does acoustic testing strand whales? Nature 392:29-29.

Hildebrand JA. 2009. Anthropogenic and natural sources of ambient noise in the ocean. Marine Ecology Progress Series 395:5-20.

Kellogg WN. 1958. Echo Ranging in the Porpoise. Science 128:982-988.

Mann D, Hill-Cook M, Manire C, Greenhow D, Montie E, Powell J, Wells R, Bauer G, Cunningham-Smith P, Lingenfelser R, DiGiovanni R, Stone A, Brodsky M, Stevens R, Kieffer G, Hoetjes P. 2010. Hearing Loss in Stranded Odontocete Dolphins and Whales. Plos One 5.

McDonald MA, Hildebrand JA, Wiggins SM. 2006. Increases in deep ocean ambient noise in the northeast Pacific west of San Nicolas Island, California. Journal of the Acoustical Society of America 120:711-718.

Nachtigall PE, Yuen MML, Mooney TA, Taylor KA. 2005. Hearing measurements from a stranded infant Risso's dolphin, Grampus griseus. Journal of Experimental Biology 208:4181-4188. 
Nachtigall PE, Mooney TA, Taylor KA, Miller LA, Rasmussen MH, Akamatsu T, Teilmann J, Linnenschmidt M, Vikingsson GA. 2008. Shipboard measurements of the hearing of the white-beaked dolphin Lagenorhynchus albirostris. Journal of Experimental Biology 211:642-647.

National Center for Ecological Analysis and Synthesis, 2008, A Global Map of Human Impacts to Marine Ecosystems: Commercial Activity (Shipping). www.nceas.ucsb.edu/globalmarine/impacts

Norris K. S, Prescott JH, Asa-Dorian PV, Perkins P. 1961. An Experimental Demonstration of Echo-Location Behavior in the Porpoise, Tursiops truncatus (Montagu). Biological Bulletin 120:163-176.

Nowacek DP, Thorne LH, Johnston DW, Tyack PL. 2007. Responses of cetaceans to anthropogenic noise. Mammal Review 37:81-115.

Parsons ECM, Dolman SJ, Wright AJ, Rose NA, Burns WCG. 2008. Navy sonar and cetaceans: Just how much does the gun need to smoke before we act? Marine Pollution Bulletin 56:1248-1257.

Parks SE, Clark CW, Tyack PL. 2007. Short- and long-term changes in right whale calling behavior: The potential effects of noise on acoustic communication. Journal of the Acoustical Society of America 122:3725-3731.

Parks SE, Johnson M, Nowacek D, Tyack PL. 2011. Individual right whales call louder in increased environmental noise. Biology Letters 7:33-35.

Payne R, Webb D. 1971. Orientation by means of long range acoustic signaling in baleen whales. Annals of the New York Academy of Sciences 188:110-141.

Richardson WJ, Greene CRJ, Malme CI, Thomson DH. 1995. Marine Mammals and Noise. New York: Academic Press.

Rolland RM, Parks SE, Hunt KE, Castellote M, Corkeron PJ, Nowacek DP, Wasser SK, Kraus SD. 2012. Evidence that ship noise increases stress in right whales. Proceedings of the Royal Society B-Biological Sciences 279:2363-2368.

Schevill WE, McBride AF. 1956. Evidence for echolocation by cetaceans. Deep Sea Research 3:153-154.

Tsuchiya T, Naoi J, Futa K, Kikuchi, T. 2004. Difference in simulated low-frequency sound propagation in the various species of baleen whale, Japanese Journal of Applied Physics 43(5B), 3193-3196. 
Chapter 2: The auditory anatomy of the minke whale

This chapter consists of the text and figures of a published article and is reprinted with permission from The Anatomical Record: Yamato M, Ketten DR, Arruda J, Cramer S, Moore K. 2012. The Auditory Anatomy of the Minke Whale (Balaenoptera acutorostrata): A Potential Fatty Sound Reception Pathway in a Baleen Whale. The Anatomical Record: Advances in Integrative Anatomy and Evolutionary Biology, vol. 295: 991-998. 


\begin{abstract}
Cetaceans possess highly derived auditory systems adapted for underwater hearing. Odontoceti (toothed whales) are thought to receive sound through specialized fat bodies that contact the tympano-periotic complex, the bones housing the middle and inner ears. However, sound reception pathways remain unknown in Mysticeti (baleen whales), which have very different cranial anatomies compared to odontocetes. Here, we report a potential fatty sound reception pathway in the minke whale (Balaenoptera acutorostrata), a mysticete of the balaenopterid family. The cephalic anatomy of seven minke whales was investigated using computerized tomography (CT) and magnetic resonance imaging (MRI), verified through dissections. Findings include a large, wellformed fat body lateral, dorsal, and posterior to the mandibular ramus and lateral to the tympano-periotic complex. This fat body inserts into the tympano-periotic complex at the lateral aperture between the tympanic and periotic bones and is in contact with the ossicles. There is also a second, smaller body of fat found within the tympanic bone, which contacts the ossicles as well. This is the first analysis of these fatty tissues' association with the auditory structures in a mysticete, providing anatomical evidence that fatty sound reception pathways may not be a unique feature of odontocete cetaceans.
\end{abstract}




\subsection{Introduction}

The transition to aquatic life resulted in several modifications to the auditory anatomy of cetaceans. Cetaceans lack external pinnae and the external auditory canal has been reduced to a very narrow channel. The middle and inner ear migrated laterally out from the skull, and are encased in the dense tympano-periotic complex (Hunter, 1787; Eschricht and Reinhardt, 1866; Kernan, 1919). Other characteristics of the auditory system are specific to each suborder. The gross auditory anatomy and hearing pathways in Odontoceti (toothed whales) have been relatively well-described. In odontocetes, the external auditory canal is considered vestigial (Reysenbach de Haan, 1957; Dudok Van Heel, 1962; Norris, 1968; McCormick et al., 1970). Bone conduction is thought to play a minor role because there is no osseous connection between the tympano-periotic complex and the rest of the skull in most odontocete species (Claudius, 1858, in Yamada, 1953; Ketten and Wartzok, 1990; Nummela et al., 2007). In addition, the air spaces around the tympano-periotic complex are thought to provide acoustic insulation from the rest of the skull, which may be important for directional hearing (Reysenbach de Haan, 1957).

A more likely mechanism for sound reception in odontocetes is via perimandibular "acoustic" fat bodies that are in direct contact with the ears, including both the tympanic and periotic bones (Norris, 1964; Ketten, 1994; Ketten, 1997; Ridgway, 1999; Cranford et al., 2010). While odontocetes receive sounds across various locations on the head (Bullock et al., 1968; Brill, 1988; Mohl et al., 1999; Mooney et al., 2008; Cranford et al., 2008a) these biochemically distinct fats are thought to act as a preferential pathway of sound from the environment to the ears (Norris, 1964; Bullock et al., 1968; Varanasi and Malins, 1971; Litchfield et al., 1975; Brill et al., 1988; Koopman et al., 2006; Zahorodny et al., 2009).

These odontocete "acoustic fats" are composed of multiple lobes, including the inner lobe filling the enlarged mandibular hiatus and the outer lobe covering the lateral and ventral portions of the mandible (Norris, 1968; Ketten, 1994; Ketten, 1997; Ridgway, 1999). In addition to these two fat lobes, which are located anterior to the tympano- 
periotic complex, there is also increasing evidence for a third fat channel located lateral to the tympano-periotic complex. In an electrophysiological study focused on striped dolphins (Stenella coeruleoalba), Bullock et al. (1968) found that the lateral area near the external auditory meatus opening was sensitive to low frequency sounds below $3 \mathrm{kHz}$. Renaud and Popper (1975) also found that the region near the external auditory meatus opening was more sensitive to lower frequency sounds (below $20 \mathrm{kHz}$ ) in a behavioral study on bottlenose dolphins (Tursiops truncatus). Furthermore, Ketten (1994) provided anatomical evidence for a distinct lateral fat channel by applying MRI techniques to multiple odontocete species. Most recently, Popov et al. (2008) used auditory brainstem response latencies to advance the hypothesis that there are two acoustic windows in the bottlenose dolphin. The acoustic window was calculated to be near the external auditory meatus opening at frequencies below $22 \mathrm{kHz}$, while sounds above $32 \mathrm{kHz}$ were received through the lower jaws.

The pathways of sound reception are unknown in Mysticeti (baleen whales) and there have been no reports of sound-conducting fats similar to those of odontocetes. The small opening to the external auditory meatus is visible on the surface, as in odontocetes. However, researchers disagree on whether the auditory canal is continuous from the opening of the external auditory meatus to the tympanic membrane and whether it is a functional part of the auditory system (Carte and Macalister, 1868; Yamada, 1953). At the end of the auditory canal is the "glove finger," an everted, extended, thickened tympanic membrane, the function of which remains unclear (Lillie, 1910; Fraser and Purves, 1960). This elongated glove finger is not found in odontocetes or any other mammals. Another major difference between odontocete and mysticete ears is the connection of the tympano-periotic complex with the skull. In mysticetes, the posterior flange of the periotic bone is wedged against the squamosal and the exoccipital bones (Yamada, 1948; Fig. 2.1). The anterior flange of the periotic is also firmly embedded in the squamosal bone, reducing the acoustic isolation of the tympano-periotic complex. Bone conduction has not been dismissed as a potential sound reception pathway in baleen whales (Ketten, 1992; Ketten, 2000). 


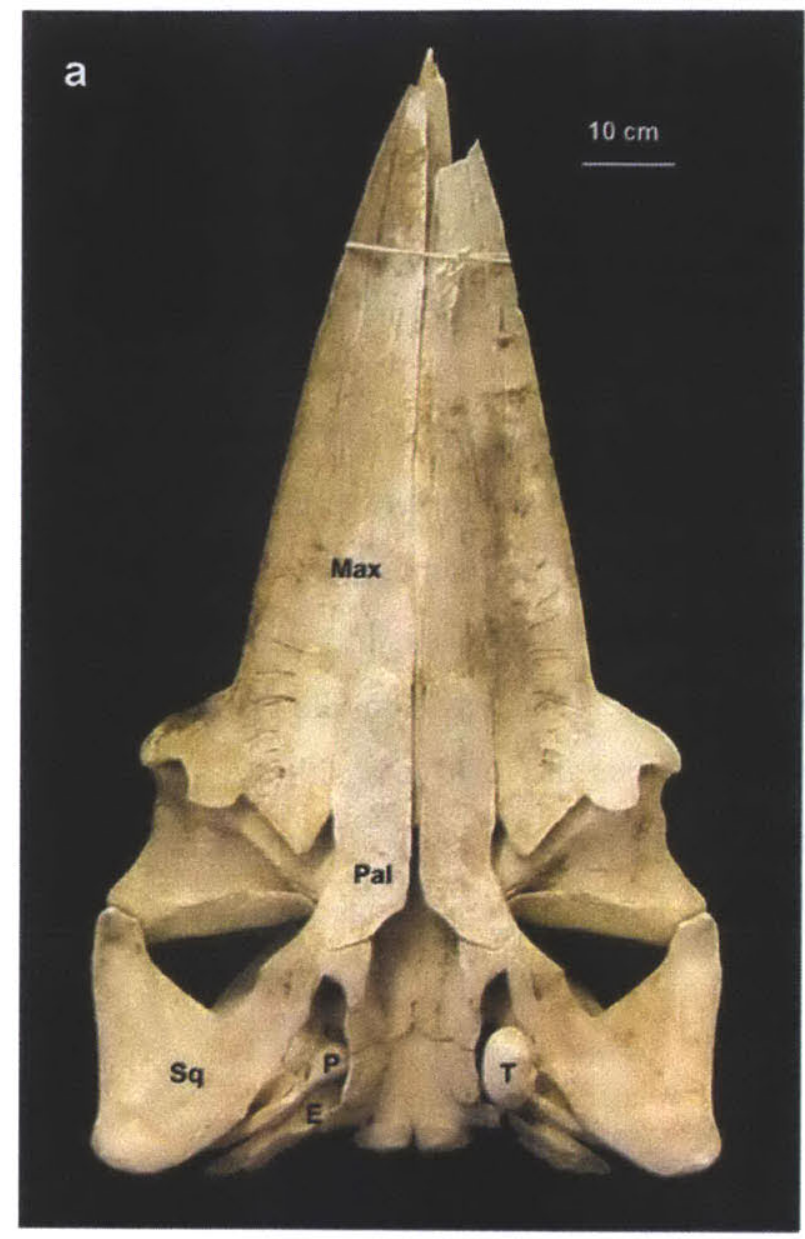

Figure 2.1. Photograph of a minke whale skull (B-acu21; not part of our study). (a) Ventral view of the skull, where the mandibles have been removed. The tympanic bone has been removed on the right side of the animal (left side of the photograph) to expose the periotic bone. (b) Enlarged view of the right ear showing the periotic bone, which is firmly embedded in the skull.

Abbreviations: $T$, tympanic; $P$, periotic; E, exoccipital; Sq, squamosal; Pal, palatine; Max, maxilla; PF, posterior flange of the periotic.

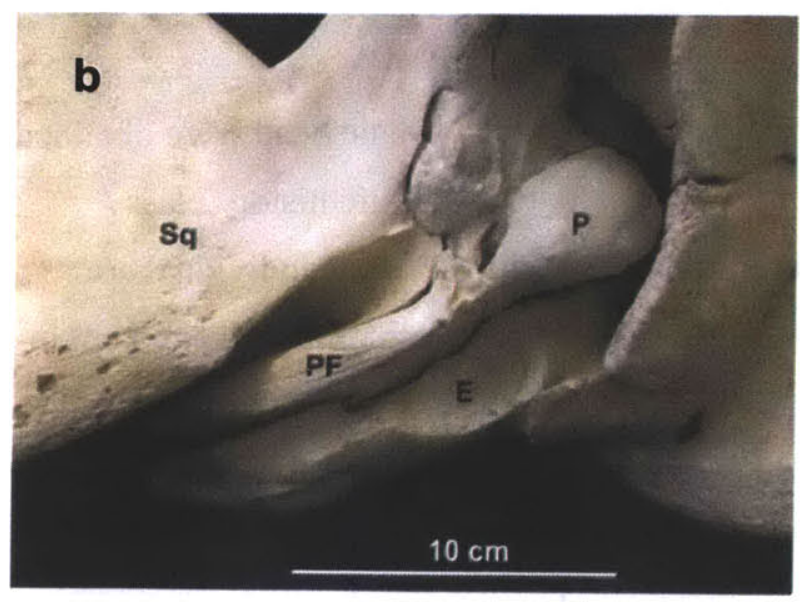


Advancing our understanding of sound reception mechanisms in mysticetes requires a thorough exploration of both the bone and soft tissue anatomy surrounding the ear. However, the study of soft tissues in mysticetes is particularly difficult due to the rarity of adequate specimens and the logistics of dissecting large animals, often on beaches. This study aimed to overcome these challenges in two ways. First, we focused on the minke whale (Balaenoptera acutorostrata), one of the smallest and most abundant mysticete species. Second, we used an integrative approach to studying the auditory anatomy through a combination of dissection, computerized tomography (CT), and magnetic resonance imaging (MRI). While distortion of tissues is inevitable during dissection, biomedical imaging techniques such as CT and MRI provide visualizations of internal structures in situ, preserving their geometries and relative positions. This is the first application of these medical imaging techniques for the study of a mysticete head and auditory system, providing an unprecedented view of the internal anatomy of these animals.

\subsection{Materials and Methods}

\subsubsection{Specimens}

Six complete minke whale heads and one partial minke whale head were obtained from strandings in the Northeast region of the United States. The life history class / category, length, sex, carcass condition, and stranding location of each individual are given in Table 2.1. All complete heads were either examined fresh or frozen and kept in a $-20^{\circ} \mathrm{C}$ freezer with no automatic thaw cycles to prevent freeze-thaw artifacts. Frozen heads were thawed prior to dissection. The partial head, B-acu17, was fixed in formalin. 
Table 2.1. Minke whales used in this study

\begin{tabular}{cccccc}
\hline Specimen ID & $\begin{array}{c}\text { Life history } \\
\text { category }\end{array}$ & Length & Sex & $\begin{array}{c}\text { Carcass } \\
\text { Condition* }\end{array}$ & Stranding location \\
\hline B-acu13 & Sub-adult & $389 \mathrm{~cm}$ & M & 3 & Wellfleet, MA \\
B-acu15 & Sub-adult & $426 \mathrm{~cm}$ & M & 2 & Sandwich, MA \\
B-acu17 & Sub-adult & $417 \mathrm{~cm}$ & F & 2 & Brooklyn, NY \\
B-acu18 & Sub-adult & $430 \mathrm{~cm}$ & F & 3 & Truro, MA \\
B-acu19 & Sub-adult & $465 \mathrm{~cm}$ & F & 3 & Orleans, MA \\
B-acu22 & Sub-adult & $530 \mathrm{~cm}$ & M & 3 & Vineyard Sound, MA \\
B-acu23 & Sub-adult & $523 \mathrm{~cm}$ & M & 3 & Wellfleet, MA \\
\hline
\end{tabular}

* 2: Fresh dead; 3: moderate decomposition.

\subsubsection{CT and MRI}

Heads were CT scanned at $3 \mathrm{~mm}$ slice thickness for the whole head and rescanned at $0.1 \mathrm{~mm}$ slice thickness through the ear region with a Siemens Volume Zoom scanner at the Woods Hole Oceanographic Institution's Computerized Scanning and Imaging lab. In two cases where the whole head did not fit into the CT gantry (B-acu18 and B-acu19), the mandible was removed from one side of the head. Two specimens (Bacu22 and B-acu23) were too large to scan even without the mandibles. Since a reduction in tissue bulk leads to improved image quality, one of the heads (B-acu19) was trimmed to the left ear region and re-scanned. The block of tissue included the left tympano-periotic complex and surrounding bones of the skull in addition to soft tissues extending laterally to the blubber and ventrally almost to the attachment of the mandibles. 
Tympano-periotic complexes were subsequently extracted from the heads by detaching the posterior flange of the periotic bone and then cutting through the squamosal bone to free the tympano-periotic complex. These isolated tympano-periotic complexes were scanned by $\mathrm{CT}$ at $0.5 \mathrm{~mm}$ slice thickness. In addition, the left tympano-periotic complex of B-acu 17 was re-scanned at the MRI unit at the Massachusetts Eye and Ear Infirmary in Boston, MA. While CT uses X-ray attenuation and is superior for distinguishing between air, soft tissue, and bone, MRI uses proton density and relaxation phenomena, making it well-suited for differentiating among soft, hydrated tissues (Bushberg et al., 2002).

\subsubsection{Three-dimensional Reconstructions}

The internal structures of the whole minke whale head and extracted ears were reconstructed using three-dimensional visualization softwar AMIRA® v.5.2.2. Individual tissues were segmented using both manual selection and automated segmentation tools within AMIRA, which is more reliable than using just automated thresholding techniques (Cranford et al., 2008b). The CT scans from B-acu 13 were used as the primary dataset since it was the smallest specimen, resulting in the best image quality. Data from CT scanning and dissections of all specimens were used to verify the tissue boundaries in B-acu13. A separate reconstruction was also done for the smaller section around the left ear of B-acul9.

\subsubsection{Dissection}

Photo-documented dissections took place at the Woods Hole Oceanographic Institution's marine mammal necropsy facility and were used to verify the tissue boundaries of the three-dimensional reconstructions. The auditory region was approached from the ventral side in all specimens except for B-acu15, which was 
dissected from the posterior of the head, and B-acu 17, which had already been dissected to expose the ear region when it was received.

From the ventral side, the mandibles were removed by cutting as close to the bone as possible. Investigation of the soft-tissue anatomy was followed by extraction of the tympano-periotic complex, which is a technically challenging procedure in mysticetes because the fragile connections between the periotic and tympanic bones are easily broken during attempts to dislodge the tympano-periotic complex from the skull. Once all soft tissues were removed from the area, the posterior flange was detached using an oscillating autopsy saw. The anterior flange of the periotic was freed using bone shears by incrementally chipping the thin sheet of squamosal bone lateral to the tympanic bone. Severing the soft tissue connections from inside the braincase helped to loosen the tympano-periotic complex as well.

\subsection{Results}

In all minke whales examined, there was a distinct, de-pigmented (white) line on the epidermis projecting posteriorly from the aperture of the external auditory meatus. This marker is rarely, if ever, mentioned in the literature but would be helpful in locating the minuscule external auditory meatus. The auditory canal appeared to be continuous from its external opening to the glove finger, though winding and narrow.

The CT images showed a large, well-formed fat body lateral, dorsal, and posterior to the mandibular ramus, ventral to the squamosal bone, and lateral to the tympanoperiotic complex. This fat body will be referred to as "ear fat" (Fig. 2.2). Preliminary results from lipid extractions on ear fat tissues suggest that some regions are made up of $>80 \%$ lipid by wet weight (Yamato et al., 2011). The CT images and dissections indicated that the ear fat bundle became more fibrous ventrally and is integrated with the fibrous joint with the mandible. The posterior portion of the ear fat is also more fibrous, affording an attachment to the posterior margin of the squamosal bone. 


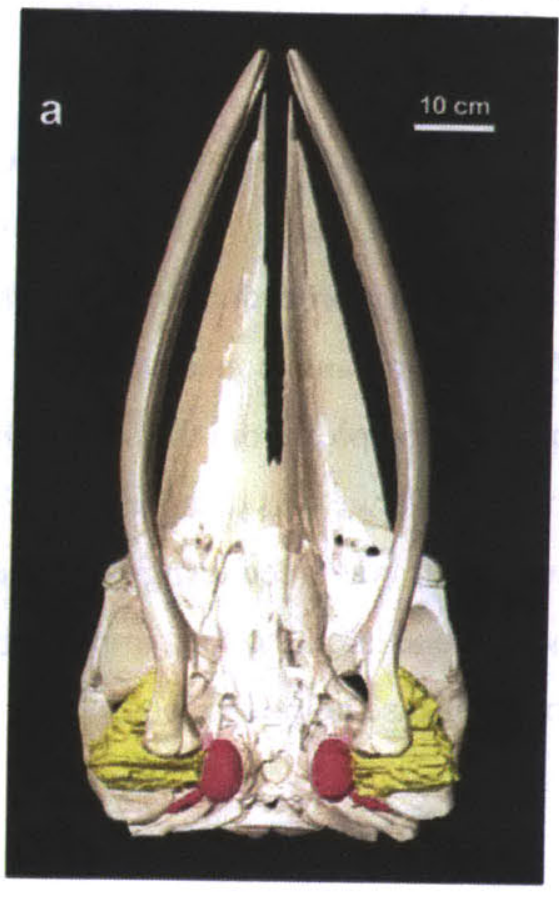

Fig. 2.2. Three-dimensional reconstructions showing the contact between the ear fats and the tympano-periotic complex (ears) in the minke whale. The mandibles are still attached. (a) Ventral view. (b) Posterior view. Yellow, ear fats; purple, tympanoperiotic complex; white, other bones.

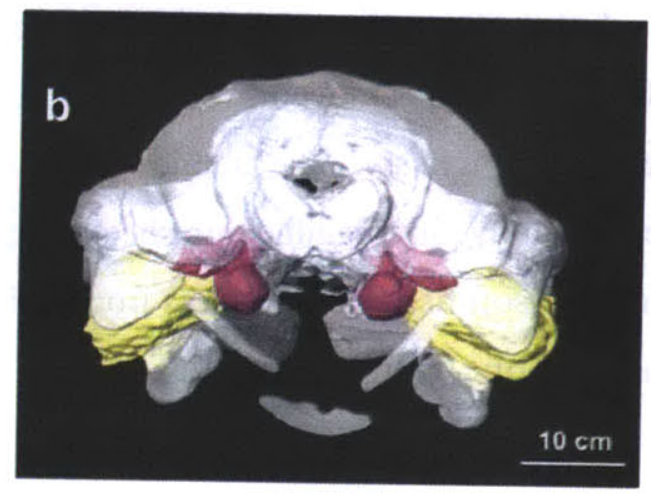

From the ventral perspective, the ear fat has a somewhat triangular shape with the three prominences contacting the blubber region (lateral), tympano-periotic complex (medial), and the mandible (anterior; Fig. 2.2). Thus, a portion of the ear fat extends from the blubber region to the tympano-periotic complex (Fig. 2.3). The anterior portion of the ear fat is well removed from the blubber layer and is adjacent to muscle. The ear fat attaches to the tympano-periotic complex at the lateral aperture between the tympanic and periotic bones, inserting into the space that Mead and Fordyce (2009) term the "triangular opening" (Figs. 2.2-2.5). Although direct contact with the glove finger could not be determined, the ear fat is pressed against an area of the tympano-periotic complex including the ventral portion of the glove finger. At the entry to the middle ear, the ear fat contacts the malleus (Fig. 2.4). 

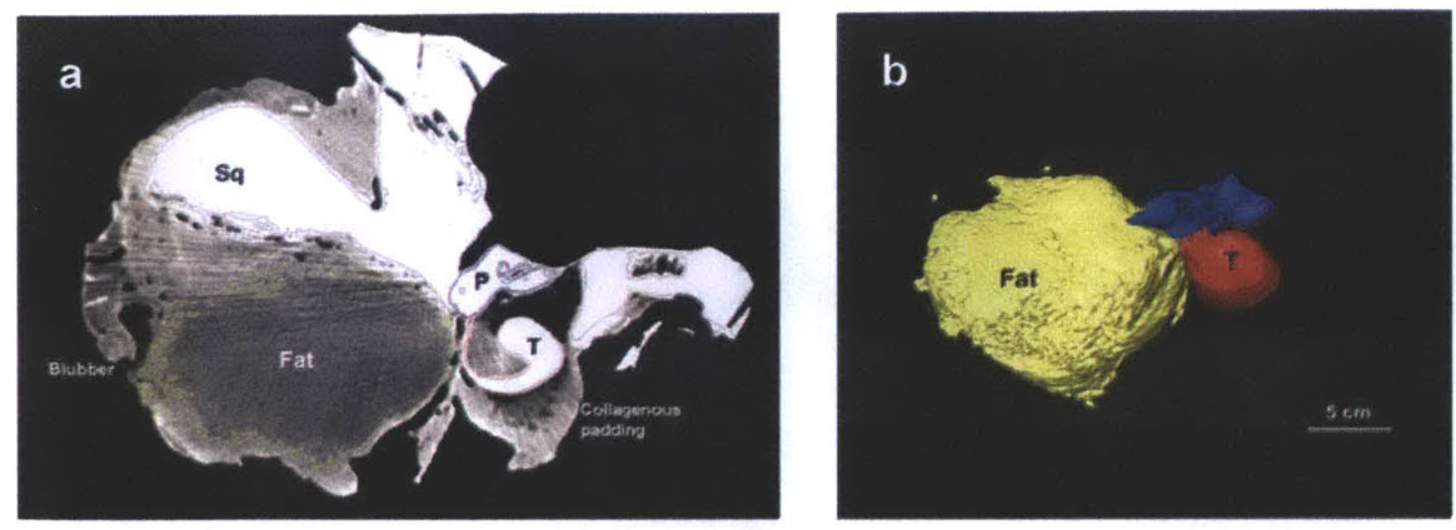

Figure 2.3. Posterior view of the partially dissected left ear region of Bacu19. (a) Axial CT image showing the ear fat extending from the blubber region to the tympanoperiotic complex (ears). Most of the blubber has been trimmed, but the remaining parts can be seen on the far left side of the image. The collagenous padding is covering the ventral portion of the tympanic bone. (b) Three-dimensional reconstruction. Yellow, ear fats; blue, periotic; red, tympanic. Abbreviations: T, tympanic; P, periotic; Sq, squamosal.

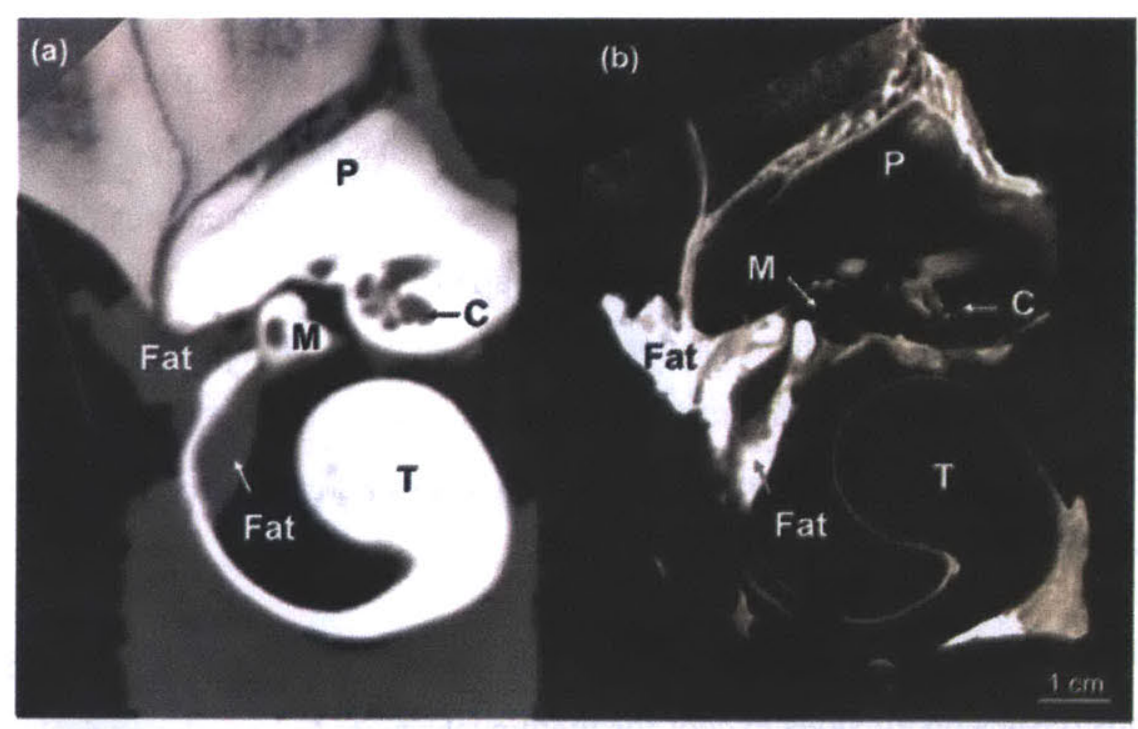

Figure 2.4. Images of the left tympano-periotic complex of B-acu17 showing the ear fat inserting into the ears at the lateral aperture between the tympanic and periotic bones (left side of the images) and then attaching to the malleus. The smaller fat body within the tympanic bone is also shown. (a) CT and (b) MRI. Abbreviations: T, tympanic; P, periotic; $\mathrm{M}$, malleus; $\mathrm{C}$, cochlea. 


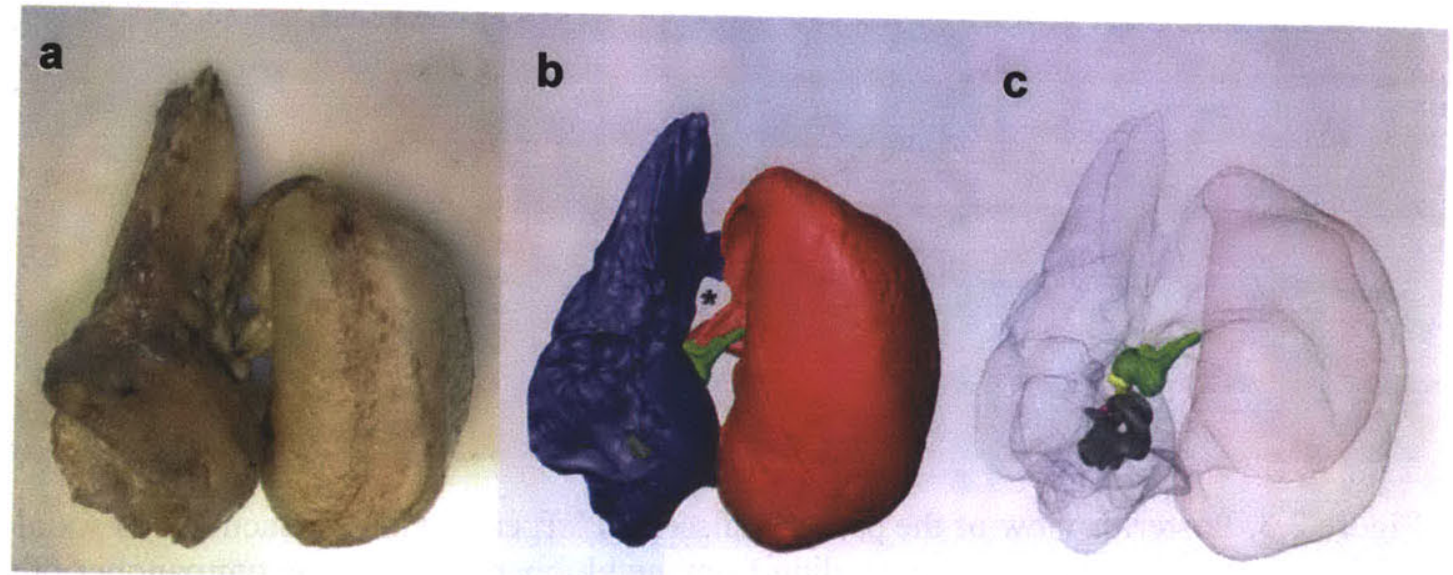

Figure 2.5. Medial view of the left tympanoperiotic complex. (a) Photograph from Bacu22. The posterior flange of the periotic has been removed to facilitate extraction. (b) Three-dimensional reconstruction for B-acu17 in approximately the same orientation as (a). The ear fat inserts into the triangular opening, which is indicated by an asterisk. (c) Same reconstruction as (b) with the tympanic and periotic bones made transparent. Blue, periotic; red, tympanic; green, malleus; yellow, incus; purple, stapes; gray, cochlea.

Within the middle ear space, the malleus also contacts a smaller fat pad attached to the inner wall of the tympanic bone, adjacent to the base of the glove finger (Fig. 2.4). The CT and MRI of the tympano-periotic complex show these structures clearly and they are readily visible on careful dissection. The malleus was attached to the inside of the glove finger by a strong ligamentous connection, consistent with previous reports (Lillie, 1910). While the smaller fat pad attaches to the base of the glove finger inside the tympano-periotic complex, neither of the fat bodies extend into the distal regions of the internal surface of the glove finger.

The tympanic bone was covered in a thick, dense, white padding composed of collagenous tissues on all sides except for the dorsal aspect (where the periotic is) and the lateral aspect, at the insertion of the ear fat into the tympano-periotic complex (Fig. 2.3). The innermost layer of the padding was somewhat fatty, loosely adhering to the ventral surface of the tympanic bone. The outer portion of the padding contained irregularly dispersed cavities. The thickest portion of the padding was approximately $5 \mathrm{~cm}$ deep. 


\subsection{Discussion}

Sound reception in terrestrial mammals involves an air-filled outer ear. In odontocetes, which receive sound under water, the air-filled ear canal has been replaced by multiple lobes of fatty tissues leading to the tympano-periotic complex (Norris, 1968). Two of the fat lobes are oriented anteriorly from the ears, including the inner fats filling the enlarged mandibular hiatus and the outer fats covering the lateral and ventral portions of the mandible (Ketten, 1994). These two anterior lobes are separated by the mandible, which has a thinned region termed the "pan bone" (Norris, 1968). While Norris (1968) states that this "thin bone is transparent to the sounds used by porpoises," the precise role of the pan bone in odontocete sound reception is still unclear (Ketten, 2000; Cranford et al., 2008a). In addition to the inner fat body and the outer fat body, a third fat lobe is located lateral to the tympano-periotic complex and is thought to be a better sound reception pathway for lower frequency sounds (Bullock et al., 1968; Renaud and Popper, 1975; Popov et al., 1990; Ketten, 1994; Ketten, 1997; Popov et al., 2008). All fatty lobes have well-defined connections with the tympano-periotic complex.

The mechanism for sound reception in mysticetes is currently unknown and no "acoustic fats" have been reported in mysticetes to date. However, our anatomical observations indicate that mysticetes also possess fat bodies associated with their ears. The contact point between the minke whale ear fat and the tympano-periotic complex is similar to the area of contact between odontocete acoustic fats and their tympano-periotic complex. While the odontocete acoustic fats contact a larger surface area of the tympano-periotic complex, the minke whale ear fats taper to insert into the "triangular opening" (Mead and Fordyce, 2009) of the tympano-periotic complex. Inside the tympano-periotic complex, the ear fats contact the ossicles. Laterally, the ear fat extends from the ossicles to the blubber region. Thus, the ear fats may provide a direct pathway for sound to reach the ossicles and the inner ear.

While odontocete acoustic fats are composed of both anteriorly-oriented and laterally-oriented fat lobes, an exclusively lateral sound reception pathway in baleen 
whales is appealing. Baleen whales do not have an enlarged mandibular hiatus to house fats with any acoustic function, or a thin "pan bone" region in the mandible.

Balaenopterid whales like the minke whale also lunge-feed, dropping their mandibles by almost 90 degrees. While the ear fats would certainly be distorted during feeding, an anteriorly oriented sound reception pathway along the mandibles would be even more displaced.

The location of the ear fats somewhat overlaps with the area of the temporomandibular joint, which is currently being addressed in a separate study. Analogous to the multi-purpose odontocete mandible, which is involved in both feeding and sound reception, it is possible that the mysticete ear fat is involved in other functions besides sound reception. In fact, the existence of some fatty tissue in this area of the head had been reported previously in the context of the temporo-mandibular joint (Hunter, 1787; Beauregard, 1882; Lambertsen et al., 1995). However, the relationship between this fatty tissue and the ears has never been explored. Interestingly; Yamada (1953) briefly noted that "similar tissue structures [as odontocetes] are seen in the impression in front of the sigmoid process" (which is between the triangular opening and the glove finger on the tympanic bone) in his study of blue (Balaenoptera musculus), sei (Balaenoptera borealis), and fin (Balaenoptera physalus) whales. However, he did not give a description of the tissue and it is not clear whether he is referring to the ear fat reported here. Furthermore, Yamada did not agree with a soft-tissue sound reception pathway in cetaceans and his work pre-dated Norris's theory on odontocete sound reception. Thus, ours is the first study to describe the fat bodies located lateral to the tympano-periotic complex as a potential sound reception pathway in mysticetes.

Similar to odontocetes, the minke whale ear canal is narrow, winding, and most likely a vestigial part of the auditory system. Although we propose the ear fats to be a primary sound reception pathway in the minke whale, it is also possible that additional mechanisms of sound reception may exist in baleen whales. For example, vibrations of the whole skull could cause differential motion between the periotic bone, which is firmly 
attached to the skull, and the ossicles. However, this bone conduction mechanism is less suited to produce sound localization cues compared to the proposed soft-tissue sound reception pathway. It is noteworthy that in some beaked whale species (Ziphiidae) and the sperm whale (Physeteridae), the tympano-periotic complex also maintains a firm, osseous connection with the skull (Yamada, 1953). Yet, the primary sound reception pathways are considered to be through soft tissues for these species (Ketten and Wartzok, 1990; Ketten, 2000). Interestingly, in a preliminary study, the area of ear fat attachment in the minke whale tympanic bone (thin portion near the triangular opening) was stimulated at $40 \mathrm{~nm}$ amplitude with frequencies of $20 \mathrm{~Hz}-50 \mathrm{kHz}$ using a piezoelectric stack to simulate incoming sound. This resulted in a movement of the stapes at the oval window, the input to the cochlea (Tubelli et al., 2012; A. Zosuls, personal communication).

An additional finding is that the majority of the tympanic bone is surrounded by a thick, collagenous padding except laterally, at the point of insertion of the ear fat, and dorsally, where the periotic bone is found. Odontocete tympanic bones are also partially covered by a fibrous padding, although it is much less developed than the padding in the minke whale. The same padding was described in a humpback whale (Megaptera novaeangliae) by Lillie (1915) as having an inner layer comprised of fatty tissue and yellow elastic tissue, and an outer layer comprised of spongy tissue with air cavities. Such coloration and distinct boundaries between tissue layers could not be seen in the minke whale specimen, but some cavities could be seen on the outer portion of the padding. It was unclear whether these cavities were filled with air. Yamada's (1948) description of the padding in the fin whale and the blue whale more closely match our observations. He describes the padding as a "white, thick, and hard layer of connective tissue" which is fibrous but is loosely joined to the surface of the tympanic bone because of a fatty inner layer. While this collagenous padding may be protecting the tympanic bone from external stresses, it may also impair sound transmission of signals from locations other than the ear fat especially if the small cavities are air-filled in vivo, as described by Lillie (1915). 
Preliminary investigations of the fin whale and the humpback whale indicate that they have similar ear fat anatomies as the minke whale. Therefore, we hypothesize that the ear fats act as an important sound reception pathway in at least the balaenopterid family. It would be interesting to examine the soft-tissue anatomy surrounding the ears of balaenid whales, such as the North Atlantic right whale (Eubalaena glacialis) and the bowhead whale (Balaena mysticetus), which are skim feeders and have very different temporo-mandibular anatomies compared to the lunge-feeding balaenopterids (Eschricht and Reinhardt, 1866; Lambertsen et al., 2005).

Although there are many unanswered questions regarding mysticete hearing, our study suggests that fatty sound reception pathways may also exist in mysticete cetaceans. The lateral orientation of the ear fats, combined with vocalization and anatomical data indicating that mysticetes are likely to hear at low frequencies (Ketten, 2000), suggest that the mysticete ear fats could be analogous to the lateral low-frequency sound reception pathway found in some odontocete species (Fig. 2.6). It is hypothesized that the mysticete ear fats and odontocete acoustic fats share a common evolutionary origin and developed into a more sophisticated, multi-lobed structure specialized for highfrequency hearing and echolocation in odontocetes. Although physiological validation studies are not yet feasible for most mysticete species, future work stemming from our anatomical study could potentially lead to a unified theory of underwater sound reception in all cetaceans. 

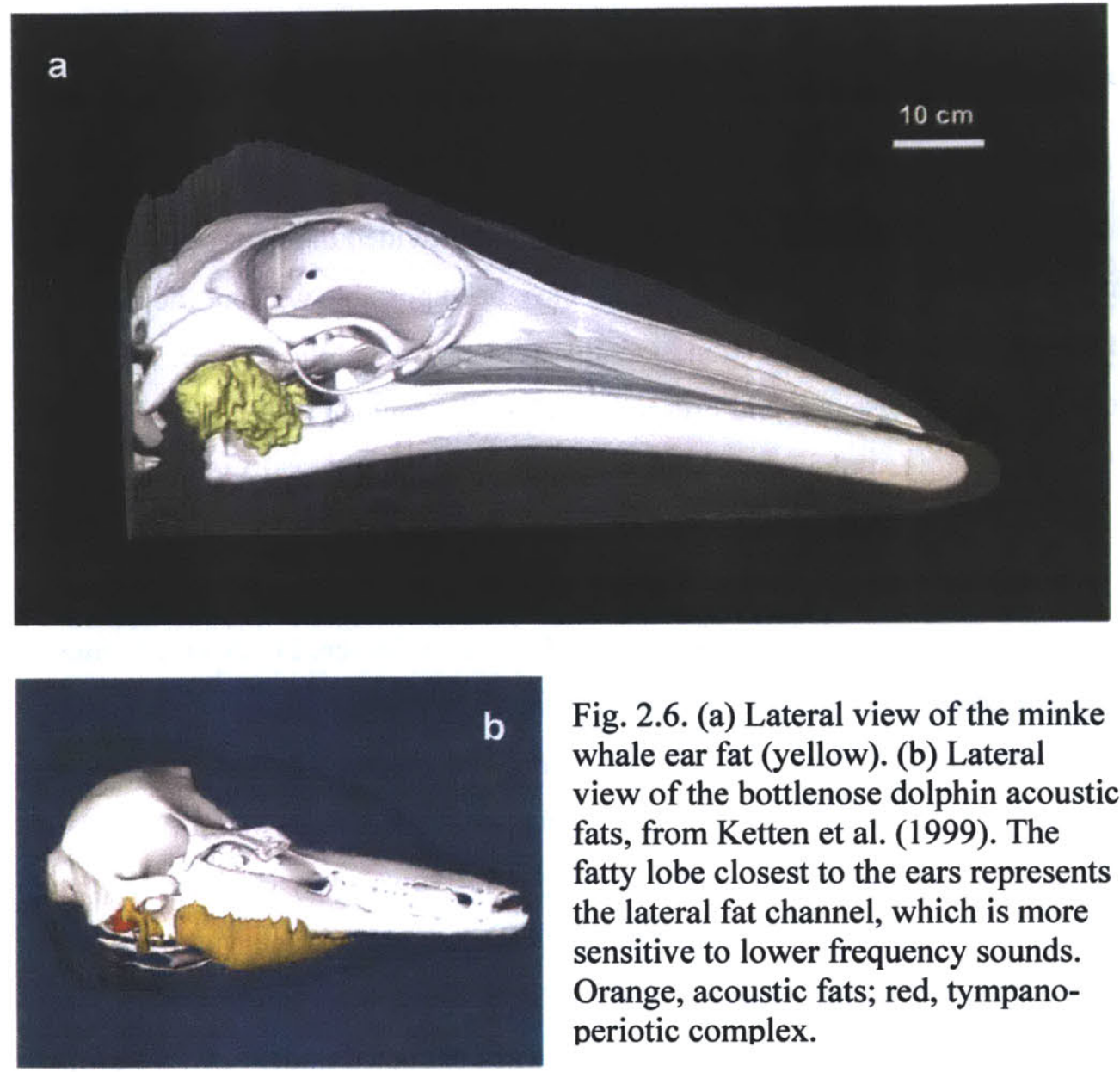

Fig. 2.6. (a) Lateral view of the minke whale ear fat (yellow). (b) Lateral view of the bottlenose dolphin acoustic fats, from Ketten et al. (1999). The fatty lobe closest to the ears represents the lateral fat channel, which is more sensitive to lower frequency sounds. Orange, acoustic fats; red, tympanoperiotic complex. 


\subsection{Acknowledgements}

The authors would like to thank the IFAW Marine Mammal Rescue and Research Group (formerly Cape Cod Stranding Network), which provided the majority of specimens for this study. This work would not have been possible without their staff's dedicated efforts in specimen collection. Dr. Joy Reidenberg and the Riverhead Foundation for Marine Research and Preservation kindly provided the partial head from New York as well as the minke whale skull in Figure 2.1. Dr. Michael Moore and Ms. Misty Niemeyer provided logistical expertise both in the field and the laboratory. Dr. Ann Pabst, Dr. Heather Koopman, Mr. Andrew Tubelli, Mr. Aleks Zosuls, Dr. Peter Tyack, Dr. Dennis Freeman, Dr. Gonzalo Feijoo, Dr. Frants Jensen, Dr. Aran Mooney, and one anonymous reviewer provided helpful critiques to this manuscript. This study was funded by the National Science Foundation Graduate Research Fellowship Program, WHOI Ocean Life Institute Fellowship, WHOI Summer Student Fellowship, WHOI Minority Fellowship, Princeton University Ecology and Evolutionary Biology Department Senior Thesis Fund, the Joint Industry Program, the Marine Mammal Program of the Office of Naval Research, and the Naval Operations Energy and Environmental Readiness Division. This research was conducted under NMFS Permit number 493-1848-00. 


\subsection{References}

Beauregard H. 1882. L'articulation temporomaxillaire chez les Cetaces. Journal de l'Anatomie et de la Physiologie 18:16-26.

Brill RL, Sevenich ML, Sullivan TJ, Sustman JD, Witt RE. 1988. Behavioral Evidence for hearing through the lower jaw by an echolocating dolphin (Tursiops truncatus). Marine Mammal Science 4:223-230.

Bullock T H, Grinnell AD, Ikezono E, Kameda K, Katsuki Y, Nomoto M, Sato O, Suga N, Yanigasawa K. 1968. Electrophysiological studies of central auditory mechanisms in cetaceans. Zeitschrift fur vergleichende Physiologie 59:117-156.

Bushberg JT, Seibert AJ, Leidholdt EMJ, Boone JM. 2002. The essential physics of medical imaging, Second Edition ed. Philadelphia: Lippincott Williams \& Wilkins.

Carte A, Macalister A. 1868. On the Anatomy of Balaenoptera rostrata. Phil. Trans. 158:201-261.

Cranford TW, Krysl P, Amundin M. 2010. A New Acoustic Portal into the Odontocete Ear and Vibrational Analysis of the Tympanoperiotic Complex. PLoS ONE 5:e11927.

Cranford TW, Krysl P, Hildebrand JA. 2008a. Acoustic pathways revealed: Simulated sound transmission and reception in Cuvier's beaked whale (Ziphius cavirostris). Bioinspiration \& Biomimetics 3.

Cranford TW, McKenna MF, Soldevilla MS, Wiggins SM, Goldbogen JA, Shadwick RE, Krysl P, Leger JAS, Hildebrand JA. 2008b. Anatomic geometry of sound transmission and reception in Cuvier's beaked whale (Ziphius cavirostris). Anat Rec 291:353-378.

Dudok Van Heel WH. 1962. Sound and cetacea. Netherlands Journal of Sea Research 1:407-507.

Eschricht DF, Reinhardt, J. 1866. On the Greenland right-whale: (Balaena mysticetus. Linn.): with especial reference to its geographical distribution and migrations in times past and present, and to its external and internal characteristics. Ray Society Publication.

Fraser FC, Purves PE. 1960. Anatomy and Function of the Cetacean Ear. Proceedings of the Royal Society of London. Series B, Biological Sciences 152:62-77.

Hunter J. 1787. Observations on the Structure and Oeconomy of Whales. Philosophical Transactions of the Royal Society of London 77:371-450. 
Kernan JD. 1919. Bone conduction of sound in cetacean and its relation to increased bone conduction in human beings. The Laryngoscope 29:510-521.

Ketten DR. 1992. The marine mammal ear: specializations for aquatic audition and echolocation. In: Webster D, Fay Richard R., and Popper Arthur N., editor. The Evolutionary Biology of Hearing. New York: Springer-Verlag. p 717-750.

Ketten DR. 1994. Functional Analyses of Whale Ears: Adaptations for Underwater Hearing. I.E.E.E. Proceedings in Underwater Acoustics 1:264-270.

Ketten DR. 1997. Structure and function in whale ears. Bioacoustics 8:103-136.

Ketten DR. 2000. Cetacean Ears. In: Au WWL, Popper AN, Fay RR, editors. Hearing by Whales and Dolphins. New York: Springer-Verlag. p 43-108.

Ketten DR, Merigo C, Chittick E, Krum H, Melvin EF. 1999. Acoustic Fatheads: Parallel evolution of underwater sound reception mechanisms in dolphins, turtles, and sea birds. Invited paper, joint meeting, Acoustical Society of America/European Acoustics Association, Berlin. J. Acoust. Soc. Am. 105:1110.

Ketten DR, Wartzok D. 1990. Three-dimensional reconstructions of the dolphin ear. In: Thomas J, Kastelein R, editors. Sensory Abilities of Cetaceans: Field and Laboratroy Evidence. New York: Plenum Press. p 81-105.

Koopman HN, Budge SM, Ketten DR, Iverson S. 2006. Topographic distribution of lipids inside the mandibular fat bodies of odontocetes: Remarkable complexity and consistency. IEEE Journal of Oceanic Engineering 31:95-106.

Lambertsen R, Ulrich N, Straley J. 1995. Frontomandibular Stay of Balaenopteridae: A Mechanism for Momentum Recapture during Feeding. Journal of Mammalogy 76:877899.

Lambertsen RH, Rasmussen KJ, Lancaster WC, Hintz RJ. 2005. Functional morphology of the mouth of the bowhead whale and its implications for conservation. Journal of Mammalogy 86:342-352.

Lillie DG. 1910. Observations on the Anatomy and General Biology of some Members of the Larger Cetacea. Proceedings of the Zoological Society of London 80:769-792.

Lillie DG. 1915. Cetacea. Brit. Antarc. ("Terra Nova") Exped. 1910. Brit. Mus. (Nat. Hist.) Rep. Zool. 3:85-124.

Litchfield C, Greenberg AJ, Caldwell DK, Caldwell MC, Sipos JC, Ackman RG. 1975. Comparative Lipid Patterns in Acoustical and Nonacoustical Fatty Tissues of Dolphins, 
Porpoises and Toothed Whales. Comparative Biochemistry and Physiology BBiochemistry \& Molecular Biology 50: 591-597.

McCormick JG, Wever EG, Palin J, Ridgway SH. 1970. Sound Conduction in the Dolphin Ear. J. Acoust. Soc. Am. 48:1418-1428.

Mead JG, Fordyce RE. 2009. The Therian Skull: A Lexicon with Emphasis on the Odontocetes. Smithson Contrib Zool, no 627. Washington DC: Smithsonian Institution Scholarly Press.

Mohl B, Au WWL, Pawloski J, Nachtigall PE. 1999. Dolphin hearing: Relative sensitivity as a function of point of application of a contact sound source in the jaw and head region. J. Acoust. Soc. Am. 105:3421-3424.

Mooney TA, Nachtigall PE, Castellote M, Taylor KA, Pacini AF, Esteban JA. 2008. Hearing pathways and directional sensitivity of the beluga whale, Delphinapterus leucas. J. Exp. Mar. Biol. Ecol. 362:108-116.

Norris KS. 1964. Some problems of echolocation in cetaceans. In: Tavolga WN, editor. Marine bioacoustics. New York: Pergamon Press. p 317-336.

Norris KS. 1968. The evolution of acoustic mechanisms in odontocete cetaceans. In: Drake ET, editor. Evolution and Environment. New Haven: Yale University Press. p 298-323.

Nummela S, Thewissen JGM, Bajpai S, Hussain T, Kumar K. 2007. Sound transmission in archaic and modern whales: Anatomical adaptations for underwater hearing. Anat Rec 290:716-733.

Popov V, Supin A. 1990. Localization of the acoustic window at the dolphin's head In: Thomas JA, Kastelein RA, editors. Sensory Abilities of Cetaceans. New York: Plenum. p 417-426.

Popov VV, Supin AY, Vladimir OK, Mikhail BT, Mikhail GP. 2008. Evidence for double acoustic windows in the dolphin, Tursiops truncatus. J. Acoust. Soc. Am. 123:552-560.

Renaud DL, Popper AN. 1975. Sound localization by the bottlenose porpoise Tursiops truncatus. J. Exp. Biol. 63:569-585.

Reysenbach De Haan FW. 1957. Hearing in whales. Acta oto-laryngologica. Supplementum 134:1-114. 
Ridgway SH. 1999. An illustraton of Norris' acoustic window. Marine Mammal Science 15:926-930.

Tubelli AA, Zosuls A, Ketten D, Mountain DC. 2012. Prediction of a mysticete audiogram via finite element analysis of the middle ear. In: Popper AN, Hawkins A, editors. Effects of Noise on Aquatic Life. New York: Springer Science+Business Media, LLC.

Varanasi U, Malins DC. 1971. Unique lipids of the porpoise (Tursiops gilli): Differences in triacyl glycerols and wax esters of acoustic (mandibular canal and melon) and blubber tissues. Biochimica et Biophysica Acta (BBA) - Lipids and Lipid Metabolism 231:415418.

Yamada M. 1948. Auditory Organ of the Whalebone Whales. Sci. Rep. Whales Res. Inst. 2:21-30.

Yamada M. 1953. Contribution to the Anatomy of the Organ of Hearing of Whales. Sci. Rep. Whales Res. Inst. 8:1-79

Yamato M, Ketten D, Koopman H, Cramer S, Arruda J, Moore K. 2011. Morphology and lipid biochemistry of fat bodies in minke and fin whale heads: comparison with odontocete acoustic fats. In: Sixth Triennial Conference on Secondary Adaptations of Tetrapods to Life in Water. San Diego, CA. p 79.

Zahorodny ZP, Koopman HN, Budge SM. 2009. Distribution and development of the highly specialized lipids in the sound reception systems of dolphins. Journal of Comparative Physiology B-Biochemical Systemic and Environmental Physiology 179:783-798. 
Chapter 3: Morphology and lipid biochemistry of fats associated with cetacean ears 


\begin{abstract}
Cetaceans possess highly derived auditory systems adapted for underwater hearing. Odontocetes, or toothed whales, are thought to receive sound through specialized fat bodies associated with their lower jaws (Norris, 1964; Bullock et al., 1968; Norris and Harvey, 1974; Brill et al., 1988). These "acoustic fats" have very unusual chemical compositions, comprised of endogenously synthesized short, branched chain fatty acids and fatty alcohols within triacylglycerols and wax esters (Varanasi and Malins, 1970a). These acoustic fats and hearing mechanisms in odontocetes are relatively well studied. In contrast, virtually nothing is known about hearing in mysticetes, or baleen whales. Yamato et al. (2012) reported the discovery of a large, well-formed fat body which extends from the blubber region to the ears of the minke whale (Balaenoptera acutorostrata). These "ear fats" attach to the tympano-periotic complex and contact the ossicles. Preliminary investigations of the fin whale (Balaenoptera physalus) also revealed the presence of ear fats (Yamato et al., 2012). This study compares the morphology and biochemical composition of these newly described fat bodies in minke and fin whales with the acoustic fats of several odontocete species, including the bottlenosed dolphin (Tursiops truncatus), harbor porpoise (Phocoena phocoena), beluga whale (Delphinapterus leucas), and pygmy sperm whale (Kogia breviceps). The differences between the odontocete acoustic fats and mysticete ear fats were immediately apparent: ear fats do not have a multi-lobed structure, do not fill the mandibular canals, and are made up of typical mammalian lipids. However, acoustic fats and ear fats shared several potentially important characteristics, such as retaining their lipids even during starvation, containing fewer dietary signals, and being composed of fats, which have reduced sound speeds compared to surrounding non-fatty tissues (Duck, 1990). Furthermore, the acoustic fats of odontocetes are incredibly diverse in both morphology and lipid composition. Thus, fatty tissues may not be restricted to a certain type of lipid composition or morphological form to have an acoustic function. It is hypothesized that both odontocete and mysticete cetaceans evolved to use fatty tissues for underwater sound reception, with the ear fats representing a less biochemically sophisticated form of "acoustic" fat.
\end{abstract}




\subsection{Introduction}

Cetacean ears are very different from terrestrial mammalian ears in several ways. Cetaceans have lost the external pinna and the ear canal has been reduced to a narrow, sometimes plugged channel. The bones containing the middle and inner ear structures form the tympano-periotic complex and are external to the skull (Hunter, 1787; Eschricht and Reinhardt, 1866; Kernan, 1919). The increased separation between the skull and ears may reduce bone conduction, helping with directional hearing under water (Claudius, 1858 , in Yamada, 1953).

The mechanism of sound reception in cetaceans has been debated for centuries, and continues to be debated today. However, Norris (1964) made a major contribution by proposing the "jaw hearing" hypothesis for odontocetes. Odontocetes possess unusual lower jaw bones, which have an enlarged mandibular hiatus filled with fats. These fats also cover the outer portions of the mandible and contact the ears. Norris hypothesized that these derived mandibles and fat bodies may be involved in sound reception. It had been noted earlier that physical properties of sound in water are similar to those in body tissues (Reysenbach de Haan, 1957), so that the ear canal is not well-suited for underwater sound reception. However, Norris suggested that the fat bodies associated with the mandibles act as a preferential pathway for sound to get from the aquatic environment to the ears (Norris, 1964; Norris, 1968). While the detailed mechanisms are still unclear, Norris's theory has been subsequently validated by behavioral, physiological, and acoustical studies (e.g., Bullock et al., 1968; Brill et al., 1988; Norris and Harvey, 1974). In addition to the anteriorly oriented fat lobes described by Norris (1964), there is also anatomical and physiological evidence for another fat lobe located lateral to the ears in some odontocete species, which may be a better sound reception pathway for lower frequency sounds (Bullock et al., 1968; Renaud and Popper, 1975; Popov and Supin, 1990; Ketten, 2000; Popov et al., 2008).

These "acoustic fats" involved with odontocete sound reception are an example of a structural fatty tissue, as opposed to a storage tissue. Whereas the volume and lipid 
composition of storage fat, like human abdominal fat marine mammal blubber, generally changes with body condition and diet, structural fats, such as those found in the feet, joints, and eye sockets, are metabolically inert and do not expand during obesity or shrink during fasting (Pond, 1998). These structural fats also contain fewer dietary signals than storage tissues. The fatty melon, which is part of the sound emission pathway, is another structural "acoustic fat" in odontocetes. Cranford et al. (1996) noted that even starving dolphins retain a completely robust melon, and Koopman et al. (2003) has shown that the lipid content and fatty acid composition of the melon is stable across body conditions, while the blubber lipids show significant differences between robust and emaciated individuals.

Odontocete acoustic fats are particularly unique in that they are comprised of endogenously synthesized lipids that are not typically found in mammalian adipose tissues. Although typical mammalian fat is primarily composed of triacylglycerols, with individual fatty acids having chain lengths of $14-22$ carbon atoms (Pond, 1998), odontocete acoustic fats also contain wax esters and high levels of short, branched chain fatty acids and fatty alcohols with 5-16 carbons (Varanasi and Malins, 1970a; Varanasi and Malins, 1970b; Varanasi and Malins, 1971; Morris, 1986; Litchfield and Greenberg, 1974; Litchfield et al., 1975). These lipids are arranged in a specific pattern, in which the wax esters and shorter, branched fatty acids are found in the highest quantities in the inner core (Litchfield et al., 1973; Wedmid et al., 1973; Morris, 1975; Varanasi et al., 1975; Blomberg and Lindholm, 1976; Koopman et al., 2006). Because sound travels more slowly through wax esters and shorter, branched fatty acids (Guow and Vlugter, 1976; Hustad et al., 1971), it has been hypothesized that the topographical arrangement of these lipids serves to focus sound as it bends towards regions of minimum sound speed in the outgoing echolocation beam for the melon and the incoming pathway through the perimandibular fats to the ears. Measurements of sound speed through different regions of the melon have supported this notion that the acoustic fats function as a "waveguide" or "sound channel" (Norris and Harvey, 1974; Blomberg and Lindholm, 1976; Goold and 
Clarke, 2000), although recent studies indicate that there may be subtle variations in these patterns (Goold and Clarke, 2000; Zahorodny et al., 2009).

It is important to note that many odontocete species also deposit short, branched fatty acids and wax esters in the blubber in varying quantities (Varanasi and Malins, 1971; Litchfield et al., 1975; Litchfield et al., 1976; Koopman et al., 2003; Koopman, 2007). For example, sperm whale and beaked whale (kogiids, physterids, and ziphiids) blubber is made up of primarily wax esters, whereas the melon and jaw fats contain high levels ( $>50 \%$ ) of triacylglycerols (Litchfield et al., 1975; Litchfield et al., 1976; Koopman et al., 2006; Koopman, 2007). Studies comparing the lipids of blubber and acoustic fats of odontocetes have shown that the fatty acids found in the acoustic fats contain higher levels of endogenous lipids and consistently have lower average chain lengths than those found in the blubber (Ackman et al., 1971; Varanasi and Malins, 1971; Litchfield et al., 1975; Litchfield et al., 1976; Koopman et al., 2003).

Although it is widely accepted that specialized fat bodies are involved in odontocete sound reception, sound reception pathways in mysticete cetaceans (baleen whales) remain unknown. Mysticetes possess very different cranial morphologies compared to odontocetes and the types of sounds used by mysticetes and odontocetes differ greatly. However, recent investigations found well-formed fat bodies associated with the tympano-periotic complex of the minke whale (Balaenoptera acutorostrata; Yamato et al., 2012). These fat bodies were referred to as "ear fats" rather than "acoustic fats", because their function has not yet been demonstrated.

The purpose of this study is to compare the morphology and lipid composition of these newly described ear fats in minke and fin whales with the acoustic fats of odontocetes. Previous studies have indicated that there are major interspecific structural differences in cetacean ears (Ketten, 1994; Ketten, 1997). Therefore, we examined the morphology of mysticete ear fats and odontocete perimandibular acoustic fats using CT data. (CT has been used to examine the morphological diversity of the odontocete melon acoustic fats by Cranford et al. (1996) and McKenna et al. (2011)). Lipid composition 
data for odontocetes was obtained from published values (Koopman et al., 2006; Zahorodny et al., 2009). The odontocete species included in the analysis were the bottlenosed dolphin (Tursiops truncatus; family Delphinidae), harbor porpoise (Phocoena phocoena; family Phocoenidae), beluga whale (Delphinapterus leucas; family Monodontidae - morphology only), and pygmy sperm whale (Kogia breviceps; family Kogiidae). These four species are found in four different families of odontocetes and were employed to place the mysticete ear fats in a broader comparative context.

\subsection{Materials and Methods}

\subsubsection{Morphology}

The morphological data for mysticete ear fats was obtained from Yamato et al. (2012), which combined CT, MRI, and dissections of minke whales to create threedimensional reconstructions of the ear fats. Although the fin whale heads and ear fats were too large to fit within the available scanner, dissections showed that fin whales also have an ear fat morphology similar to minke whales (Yamato et al., 2012).

To investigate the morphology of the odontocete acoustic fats, CT data was obtained from the Woods Hole Oceanographic Institution's Computerized Scanning and Imaging database. The length, sex, body condition, carcass condition, and stranding locations of these specimens are summarized in Table 3.1. Three-dimensional reconstructions were created using the software program AMIRA® v.5.2.2 (Yamato et al., 2009). Individual tissues were segmented using both manual selection and automated segmentation tools within AMIRA, which is more reliable than using only automated thresholding techniques (Cranford et al., 2008). 
Table 3.1. Specimens used in this study

\begin{tabular}{|c|c|c|c|c|c|}
\hline $\begin{array}{l}\text { Specimen } \\
\text { ID }\end{array}$ & Length & Sex & $\begin{array}{c}\text { Body } \\
\text { condition }\end{array}$ & $\begin{array}{l}\text { Carcass } \\
\text { Condition* }\end{array}$ & $\begin{array}{l}\text { Stranding } \\
\text { location }\end{array}$ \\
\hline $\begin{array}{l}\text { Beluga } \\
\text { D-leu08 }\end{array}$ & $264 \mathrm{~cm}$ & $M$ & - & 2 & $\begin{array}{c}\text { South } \\
\text { Portland, ME }\end{array}$ \\
\hline $\begin{array}{c}\text { Pygmy } \\
\text { sperm whale } \\
\text { K-bre09 }\end{array}$ & $235 \mathrm{~cm}$ & $F$ & Thin & 2 & $\begin{array}{l}\text { Oregon Inlet } \\
\text { Channel, NC }\end{array}$ \\
\hline $\begin{array}{l}\text { Harbor } \\
\text { Porpoise } \\
\text { P-pho94 }\end{array}$ & - & $F$ & - & 2 & - \\
\hline $\begin{array}{l}\text { Bottlenose } \\
\text { T-tru59 }\end{array}$ & $191 \mathrm{~cm}$ & $F$ & - & 2 & Bahamas \\
\hline $\begin{array}{c}\text { Minke } \\
\text { B-acu18 }\end{array}$ & $430 \mathrm{~cm}$ & $F$ & Emaciated & 3 & Truro, MA \\
\hline $\begin{array}{c}\text { Minke } \\
\text { B-acu19 }\end{array}$ & $465 \mathrm{~cm}$ & $F$ & Robust & 3 & Orleans, MA \\
\hline $\begin{array}{c}\text { Minke } \\
\text { B-acu22 }\end{array}$ & $530 \mathrm{~cm}$ & $M$ & Robust & 3 & $\begin{array}{l}\text { Vineyard } \\
\text { Sound, MA }\end{array}$ \\
\hline $\begin{array}{c}\text { Fin } \\
\text { B-phy11 }\end{array}$ & $\begin{array}{c}1221 \\
\mathrm{~cm}\end{array}$ & $M$ & Thin & 3 & Wellfleet, MA \\
\hline
\end{tabular}

*2: Fresh dead; 3: moderate decomposition.

\subsubsection{Lipid biochemistry}

The ear fats of three minke whales and one fin whale were sampled in this study. All specimens were obtained from strandings in Cape Cod, Massachusetts. The length, sex, body condition, carcass condition, and stranding locations of the specimens are summarized in Table 3.1. All individuals were sub-adults and exhibited signs of moderate, but not advanced, decomposition. Body condition was categorized as "emaciated", "thin", or "robust" by experienced stranding network personnel based on standard external observations, such as concavities in the area of the epaxial muscle and 
prominent indentations at the nape, consistent with emaciation. Ear fats were extracted from the right side of each animal. In B-acu18 and B-acu22, fat bodies were also extracted on the left side. The extracted fat bodies were sectioned transversely and then subsampled in a grid to provide representation of all regions (Figures 3.1 and 3.2).

Subsamples were approximately $2 \mathrm{~cm} \times 2 \mathrm{~cm} \times 2 \mathrm{~cm}$. There were a total of 119 subsamples of ear fat.

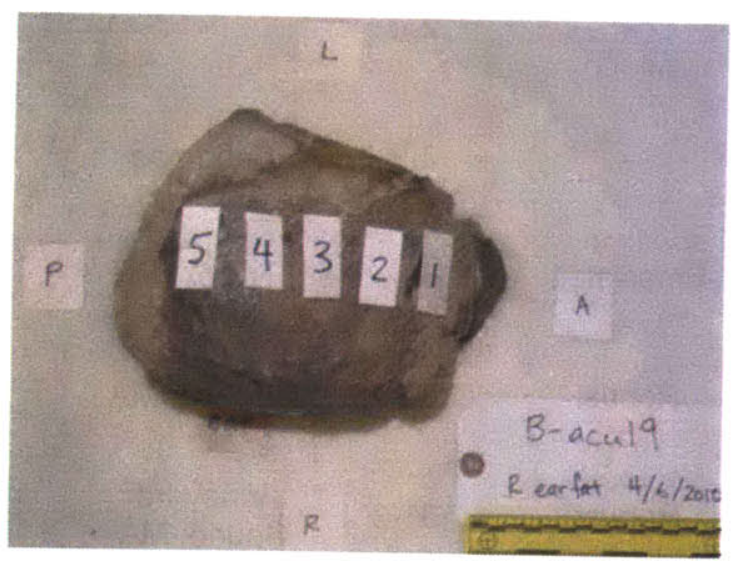

Figure 3.1. Sampling scheme of B-acu19R (minke whale). $\mathrm{A}=$ anterior, $\mathrm{P}=$ posterior, $\mathrm{L}=$ left, $\mathrm{R}=$ right.

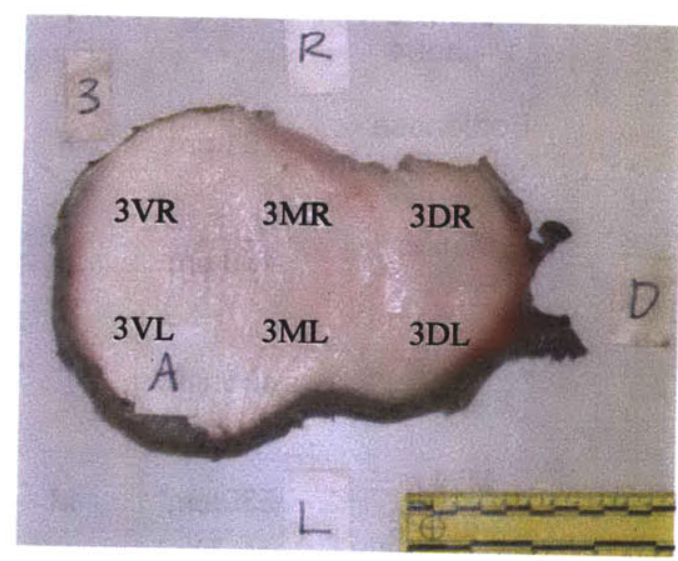

Figure 3.2. Slice 3 from Figure 3.1 (anterior view) labeled with sample locations. $\mathrm{V}=$ ventral, $\mathrm{M}=$ middle, $\mathrm{D}=$ dorsal.

In addition to the ear fat samples, blubber was sampled from the region of the pectoral fin for each animal. For B-acu22, blubber was taken from multiple locations (lateral, ventral, dorsal, and at the external auditory meatus) to assess the effect of sample location on lipid content and identity. Because lipid content and composition of blubber has been shown to vary with depth from the epidermis (Ackman et al., 1965; Lockyer et al., 1984; Olsen and Nielsen, 2003; Ruchonnet et al., 2006, Koopman, 2007), each piece of blubber was subsequently subsampled from the surface, the middle, and the deepest layer except for B-acu19, in which the blubber sample was too small and did not span from the epidermis to the underlying musculature. 
Lipids were extracted from each sample following a modified Folch procedure (Folch et al., 1957; Koopman et al., 1996; Koopman et al., 2003; Koopman et al., 2006; Koopman et al., 2007). Approximately $0.5 \mathrm{~g}$ of each sample was weighed and extracted with a $2: 1$ chloroform : methanol solution with $0.01 \%$ BHT to obtain lipid content. For lipid class analysis, samples were resuspended in hexane, spotted onto silica rods, and developed in 94/6/1 hexane/ethyl acetate/formic acid. Each lipid class was quantified and analyzed separately via Thin Layer Chromatography with Flame Ionization Detection (TLC/FID) using an Iatroscan Mark VI. For fatty acid analysis, total lipids were converted to FA butyl esters using $\mathrm{BF}_{3}$ in butanol (10\% Supelco), and analyzed on a Varian 3800 GC fitted with a Zebron ZB-FFAP nitroterephthalic acid modified polyethylene glycol $30 \mathrm{~m}$ x $0.25 \mathrm{~mm}$ column (Phenomenex Torrance, CA) equipped with a flame ionization detector. Butyl esters were used instead of the more commonly used methyl esters because short chain fatty acids incorporated into methyl esters are lighter and more volatile (Shantha and Napolitano, 1992; Koopman et al., 1996; Budge et al., 2006). Further details of the methods are described in Koopman et al. (2006) and Koopman (2007).

Fatty acid profiles for all samples were examined using the program Primer 6 (Plymouth Routines In Multivariate Ecological Research, Primer-E, Ltd., Ivybridge, UK). While many statistical analyses require random, independent samples and parametric data, Primer requires fewer assumptions. Furthermore, the number of variables entered into the Primer models is not restricted by the number of samples in the dataset (Lane, 2009). This makes it ideal for use with fatty acid data, which are inherently non-independent. In Primer, resemblance matrices were created using the Bray-Curtis Method (Clarke and Gorley, 2006). This was followed by a non-metric, multidimensional scaling analysis (MDS), which represents each sample on a two-dimensional map according to the similarity matrix. Samples that are more similar to each other are placed closer together on the map than samples that are dissimilar from each other. The algorithm is an iterative process and the confidence level of the output is represented by the "stress value". A low stress value indicates that the output is reliable, while a high stress value indicates that the 
relationships between the samples may not be represented faithfully (Clarke and Gorley, 2006). Clarke and Warwick (2001) defines a "high" stress value as greater than 0.2 , with values of over 0.3 approaching a two-dimensional map with arbitrarily placed points. Outputs with stress values of less than 0.1 are defined as "good ordination with no real prospect of a misleading interpretation" (Clarke and Warwick, 2001).

Individual fatty acids found in quantities averaging $>5 \%$ for any individual / tissue type were categorized as "endogenous" or "dietary" lipids following the classification of Iverson et al. (2004). "Endogenous" lipids can only originate from biosynthesis, such as fatty acids with chain lengths of less than 14 carbons, which are oxidized immediately following ingestion. "Dietary" lipids originate either entirely or primarily from direct dietary intake, and include lipids such as 20:1n-9 and 22:1n-11, which have a specific source in calanoid copepods and organisms feeding on calanoid copepods (Falk-Petersen et al., 2000). Fatty acids that may originate from the diet but also have a large contribution from biosynthesis were not included in either category. An example of the latter case is $16: 0$, the primary product of de novo synthesis in marine predators according to Budge et al. (2006).

The lipid composition for odontocete species was taken from published values given in Koopman et al. (2006) and Zahorodny et al. (2009). In cases where the lipid quantities were given for both inner and outer fat bodies, the two values were averaged to generate one representative quantity value. When there were data for an ontogenetic series (the bottlenose dolphin), data for the mature individuals were used for consistency with other odontocete species. 


\subsection{Results}

\subsubsection{Morphology of the ear fats vs. odontocete acoustic fats}

The minke whale ear fats did not extend as far anteriorly along the mandible compared to the acoustic fats of the bottlenose dolphin (Figures 3.3 and 3.4). The acoustic fats of the bottlenose dolphin had well-developed anterior lobes, including the "mandibular" lobe inside of the mandibular hiatus and "ventro-lateral" lobe on the exterior surface of the mandible (Ketten, 2000). However, the minke whale ear fat was primarily lateral to the tympano-periotic complex. Mysticetes like the minke whale also do not have an enlarged mandibular hiatus, and the ear fats did not extend into the mandibular canal (Figure 3.3, red arrows). The lateral view indicates that the ear fats are in a similar location of the head as the lateral fat lobe of the acoustic fat in the bottlenose dolphin (Figure 3.4, red circle).

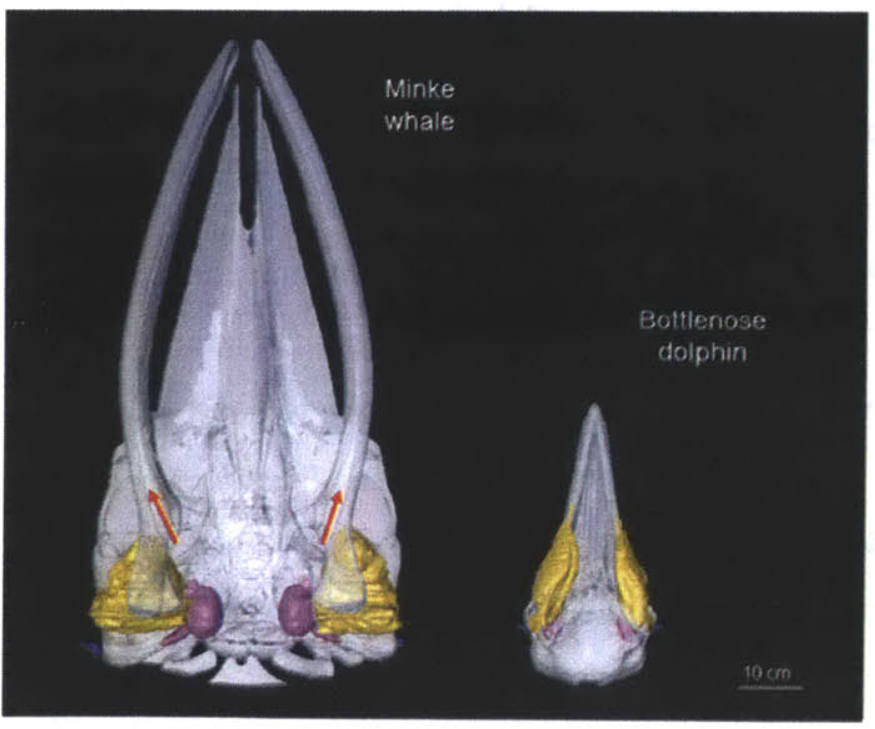

Figure 3.3. Ventral views of the bottlenose dolphin acoustic fats compared to the minke whale ear fats. Yellow, fat; purple, ears; gray, other bones; blue, ear canal. The red arrows indicate the mandibular canal of the minke whale, which is not filled by fat. 


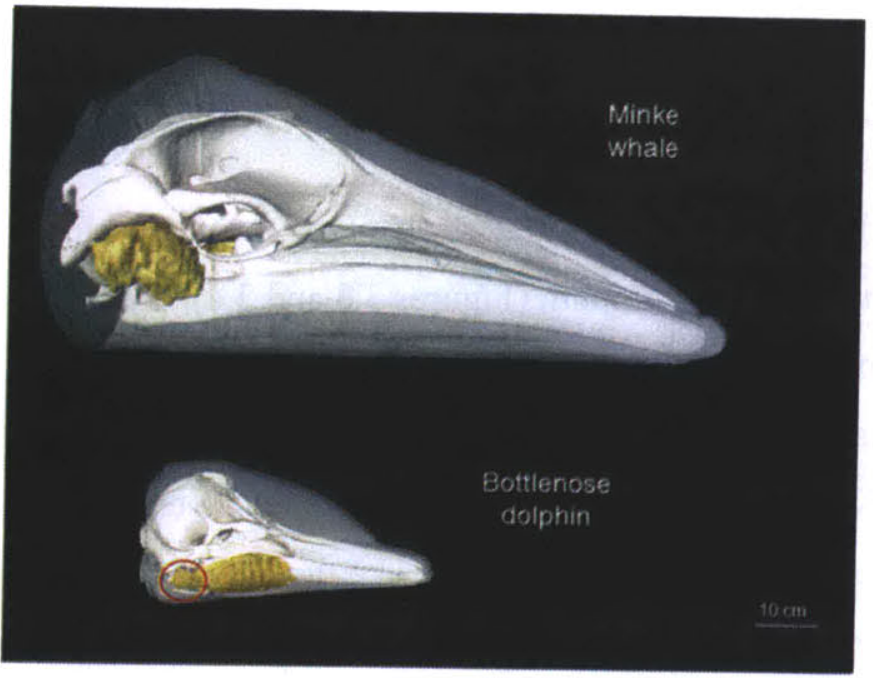

Figure 3.4. Lateral views of the bottlenose dolphin acoustic fat and minke whale ear fat. The red circle indicates the lateral fat lobe which has been proposed as an additional acoustic window for lower frequencies (Bullock et al., 1968; Renaud and Popper, 1975; Popov and Supin, 1990; Ketten, 1994, 1997; Popov et al., 2008) in the bottlenose dolphin.

The odontocete reconstructions were based on one individual from each species and the exact shapes of the acoustic fats need to be confirmed through additional investigations, including dissections and evaluations of tissue quality, which is not always consistent with the initial assessments of carcass condition. However, the preliminary three-dimensional reconstructions of the harbor porpoise, beluga whale, and the pygmy sperm whale showed that there are substantial differences in acoustic fat morphology among odontocete species (Figures 3.5 and 3.6). The harbor porpoise acoustic fats appeared to cover a greater proportion of the mandibles than in the bottlenose dolphin. In the beluga whale, the posterior, lateral fat lobe was not as evident as in the other odontocete species. The pygmy sperm whale acoustic fats appeared very different from the other three odontocete species, with large balls of fat located halfway between the ears and the anterior end of the mandible (Figures 3.5 and 3.6). 


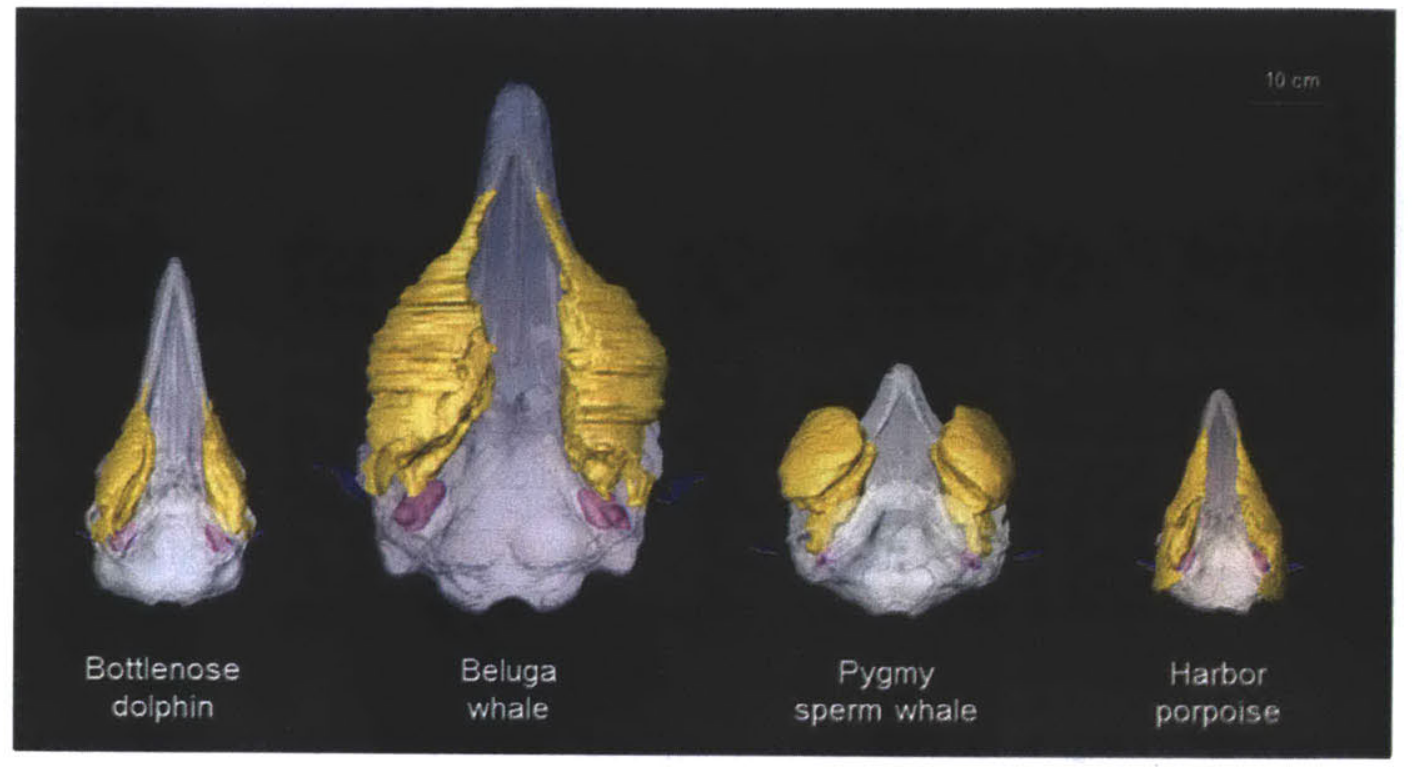

Figure 3.5. Ventral views of odontocete acoustic fats. The color scheme is the same as in Figure 3.3.

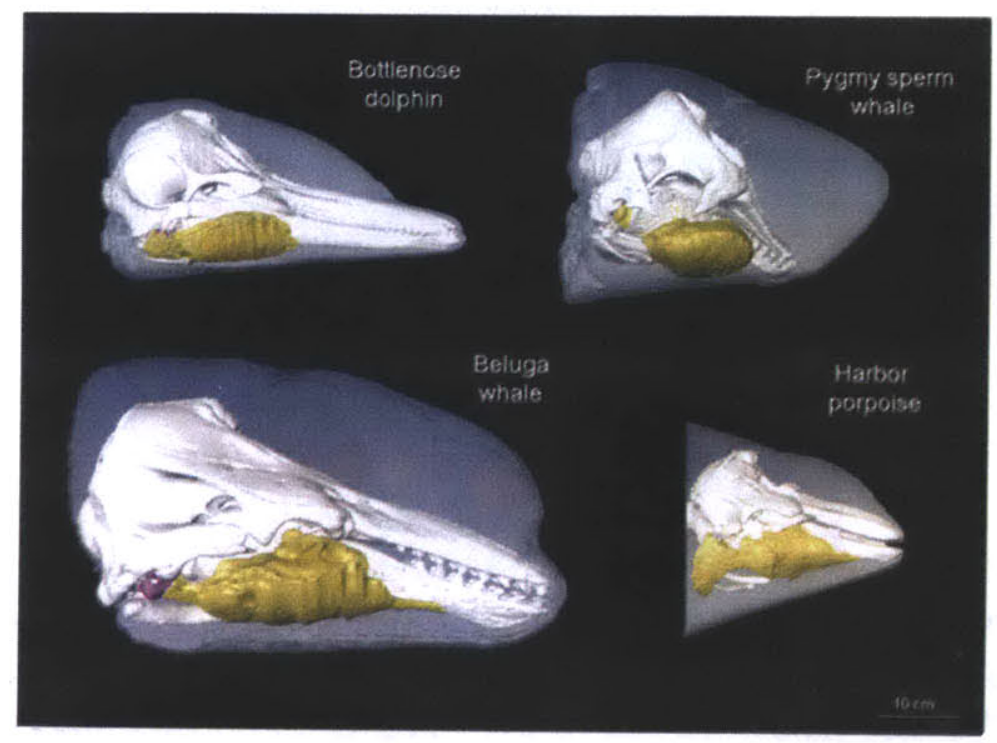

Figure 3.6. Lateral views of the odontocete acoustic fats. The color scheme is the same as in Figure 3.3. 


\subsubsection{Lipid composition of ear fats}

\subsubsection{Lipid content}

There was a large spatial variability in the lipid content of ear fats, ranging from less than $10 \%$ lipid by wet weight to greater than $90 \%$ lipid. The mean lipid content value for all samples was $61 \mathrm{wt} \%$ (SD 24). All samples with lipid content values of less than $10 \%$ were from ventral locations. The CT images show that the ventral and posterior areas of the ear fat may be more fibrous, consistent with a transition of the tissue to the fibrous joint with the mandible (Figure 3.7). However, consistent patterns in lipid content heterogeneity could not be confirmed.

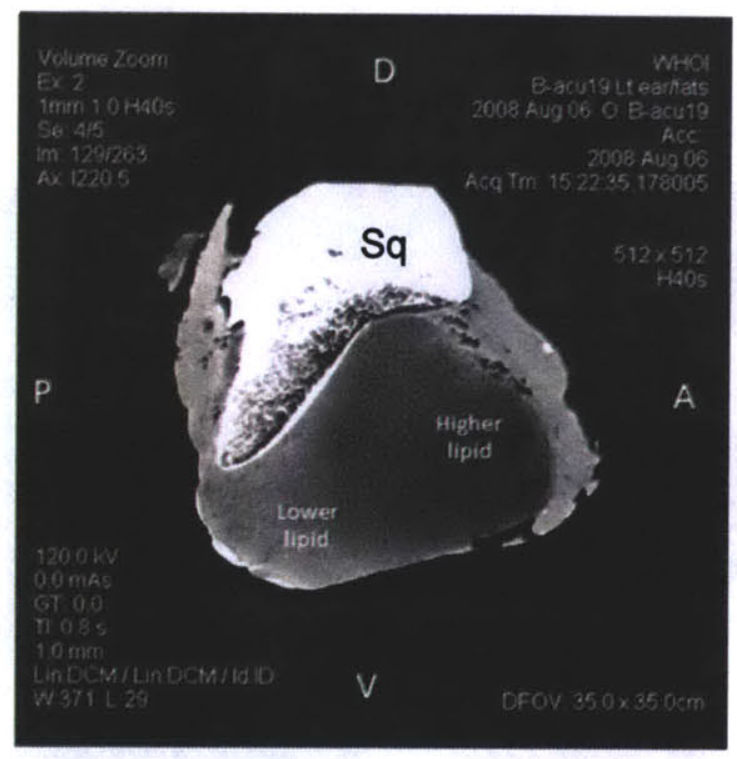

Figure 3.7. Sagittal CT section through the minke whale (B-acu19) left ear fat, lateral to the tympano-periotic complex. $\mathrm{D}=$ dorsal, $\mathrm{V}=$ ventral, $\mathrm{P}=$ posterior, $\mathrm{A}=$ anterior, $\mathrm{Sq}=$ squamosal bone. Regions of the ear fat which appear to have higher lipid content (anterior and more dorsal sections) and lower lipid content (posterior and ventral sections) are labeled. 
The lipid content of blubber was strongly influenced by stratification and body condition (Table 3.2). In all individuals, lipid content increased from the inner layer of blubber to the outer layer of blubber (closest to skin), which was consistent with previous studies (Ackman et al., 1965; Lockyer et al., 1984). Blubber from animals described as "robust" had the highest lipid content values, while thin or emaciated animals had blubber with low lipid content. Although the lipid content was strongly influenced by stratification, the location on the body from which the blubber was sampled had little influence on lipid content (Figures 3.8 and 3.9).

As noted above, there was high variability in the lipid content values of both ear fats and blubber. However, the lipid content values of ear fats were much more consistent across individuals compared to blubber (Figure 3.10). The blubber of the emaciated individual (B-acu18) was depleted in lipid, but the lipid content of its ear fat was comparable to that of robust individuals.

Table 3.2: Stratification of lipid content in mysticete blubber

\begin{tabular}{|c|c|c|c|}
\hline Individual & Body Condition & Blubber sample location & \% Lipid \\
\hline B-acu18 & emaciated & $\begin{array}{l}\text { Inner } \\
\text { Middle } \\
\text { Outer }\end{array}$ & $\begin{array}{r}8.9 \\
11.2 \\
27.6\end{array}$ \\
\hline B-acu19 & robust & Unknown & 73.6 \\
\hline B-acu22 & robust & $\begin{array}{l}\text { Inner } \\
\text { Middle } \\
\text { Outer }\end{array}$ & $\begin{array}{l}55.5 \\
77.3 \\
86.4\end{array}$ \\
\hline B-phy11 & thin & $\begin{array}{l}\text { Inner } \\
\text { Middle } \\
\text { Outer }\end{array}$ & $\begin{array}{l}24.3 \\
40.2 \\
46.2\end{array}$ \\
\hline
\end{tabular}




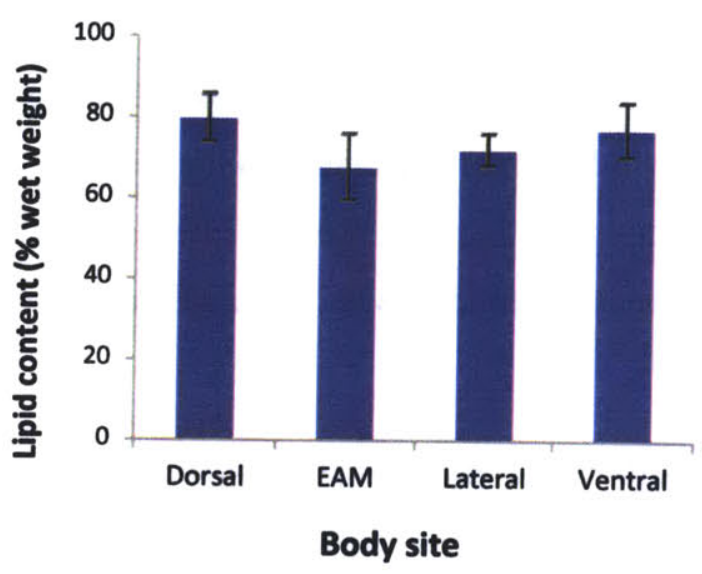

Fig. 3.8. The lipid content of blubber from B-acu22 in relation to body site. Error bars indicate the standard error of the mean.

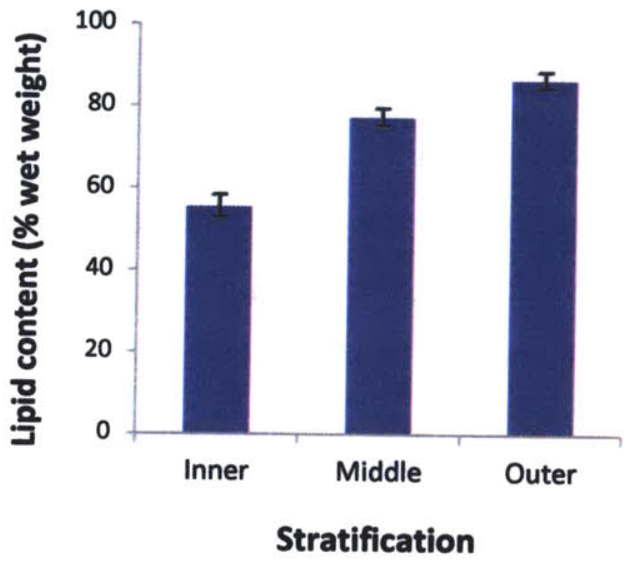

Fig. 3.9. The lipid content of blubber from B-acu22 in relation to blubber stratification. Error bars indicate the standard error of the mean.

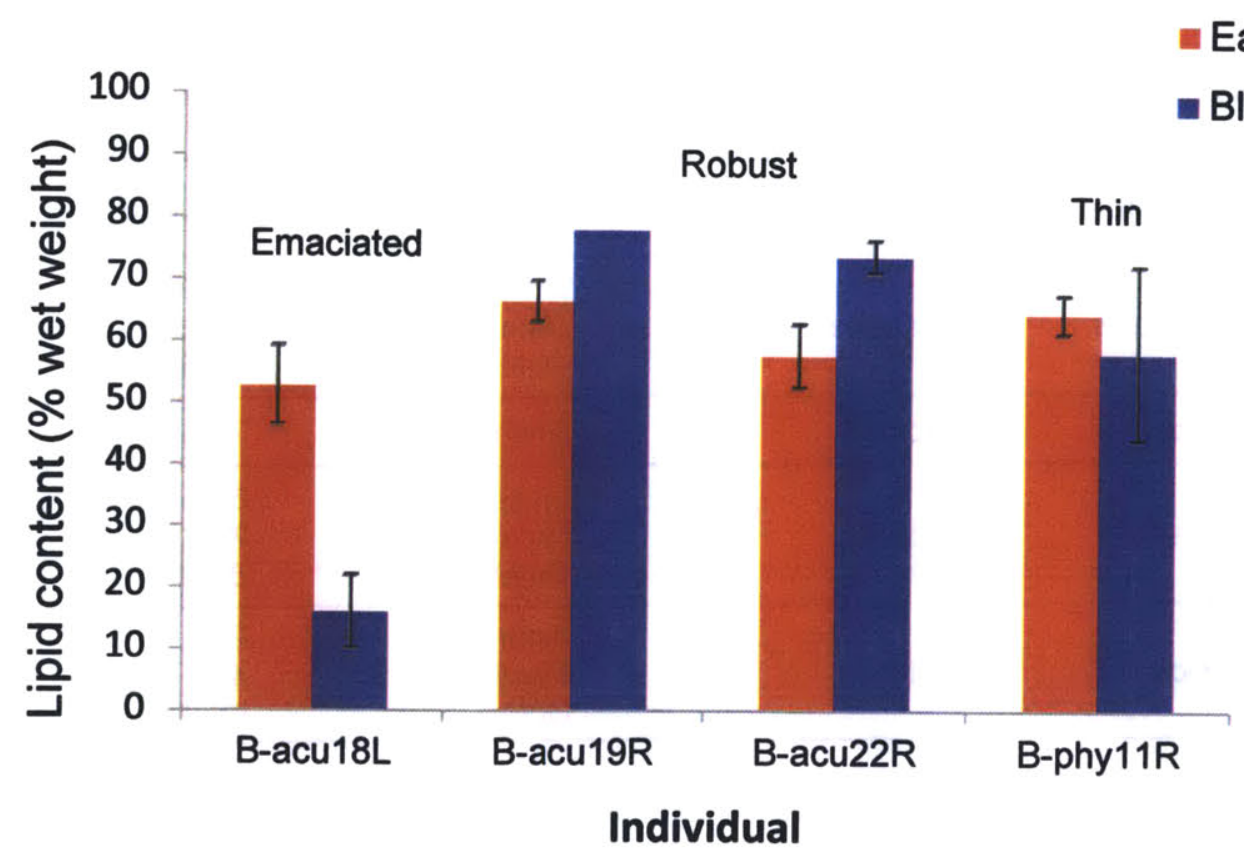

Figure 3.10. Lipid content in ear fat samples compared with lipid content in blubber samples for four individuals. Error bars indicate the standard error of the mean. 


\subsubsection{Lipid classes}

The majority of lipids in both ear fats and blubber consisted of triacylglycerols (TAG), which is typical for mammalian adipose tissues. For all ear fat samples combined, the average TAG content was $95.4 \mathrm{wt} \%$ (SD 8.7). For all blubber samples combined, the average TAG content was $99.1 \mathrm{wt} \%$ (SD 0.75).

Ear fat samples contained $0-30 \%$ non-TAG lipids, with one sample containing $56.2 \%$ non-TAG lipids. In contrast, blubber lipids were almost exclusively made up of TAG, with up to $2.5 \%$ non-TAG lipids in a limited number of samples. Lipid class composition was tissue- and specimen-dependent. On average, the fin whale ear fat samples were comprised of $>99 \%$ TAG with approximately $1 \%$ or less of phospholipid and cholesterol for two samples. The blubber was also > 99\% TAG with less than $1 \%$ phospholipid for one sample. For the minke whales, B-acu19 contained almost exclusively TAG in both ear fat and blubber samples. The ear fat samples of B-acu18 were made up of approximately $98 \% \mathrm{TAG}$, and $2 \%$ of cholesterol, free fatty acid, phospholipid, and what appears to be sterol ester. There was $<1 \%$ cholesterol and phospholipid in the blubber of B-acu18, and no sterol esters or free fatty acids.

The ear fat samples of B-acu22 contained the highest amount of non-TAG lipids. On average, B-acu22 ear fat samples contained approximately $84 \%$ TAG, $1 \%$ sterol ester, $6 \%$ free fatty acid, $2 \%$ cholesterol, and $6 \%$ phospholipid. In contrast, none of the twelve blubber samples for B-acu22 contained non-TAG lipids except for the innermost blubber sample from the area of the external auditory meatus, adjacent to the ear fat. This sample contained approximately $1 \%$ free fatty acid and $1 \%$ phospholipid.

\subsubsection{Fatty acid composition}

Both ear fats and blubber of minke and fin whales were primarily composed of medium to long chain fatty acids ranging from 14-22 carbons in length. A commonly used notation for identifying fatty acids is $\mathrm{A}: \mathrm{Bn}-\mathrm{X}$, where $\mathrm{A}$ indicates the number of 
carbon atoms in the chain, $\mathrm{B}$ is the number of double bonds, and $\mathrm{X}$ is the position of the first double bond relative to the terminal methyl $\left(\mathrm{CH}_{3}\right)$ group. An italicized $i$ before the A:Bn-X notation indicates a branched fatty acid with a methyl branch at the second carbon (see Budge et al., 2006).

Branched chain fatty acids such as $i-14: 0$ and $i-15: 0$, and medium length fatty acids such as 12:0, 13:0, and 15:0 were detectable in the mysticete tissues, but at quantities of less than 1\%. 5:0 and 10:0 were found at quantities of less than $0.05 \%$. There were noticeable differences between the fatty acid signatures of the three minke whales compared to the fin whale. The most obvious difference was that the tissues of minke whales contained considerable amounts of $20: 1 \mathrm{n}-9$ and $22: 1 \mathrm{n}-11$ that were not abundant in the fin whale (see Table 3.3).

The MDS analysis in Primer clearly separated the fin whale samples from the three minke whales samples (Figure 3.11). The low stress value of 0.09 indicates that this two-dimensional representation of similarity is reliable (Clarke and Warwick, 2001). Figure 3.11 also shows some separation between the ear fat and blubber samples for both species. Furthermore, ear fat samples from all three minke whales seem to be more similar to each other compared to the blubber, which exhibits variability among samples and individuals. This is consistent with the finding that blubber samples contained higher levels of dietary fatty acids compared to ear fat samples in all individuals, showing that the blubber fatty acid signature may be more affected by differences in diet (Table 3.3 and Figure 3.12). The only strictly "endogenous" fatty acid in our samples was $18: 1 \mathrm{n}-11$, which was found in low and variable quantities. 


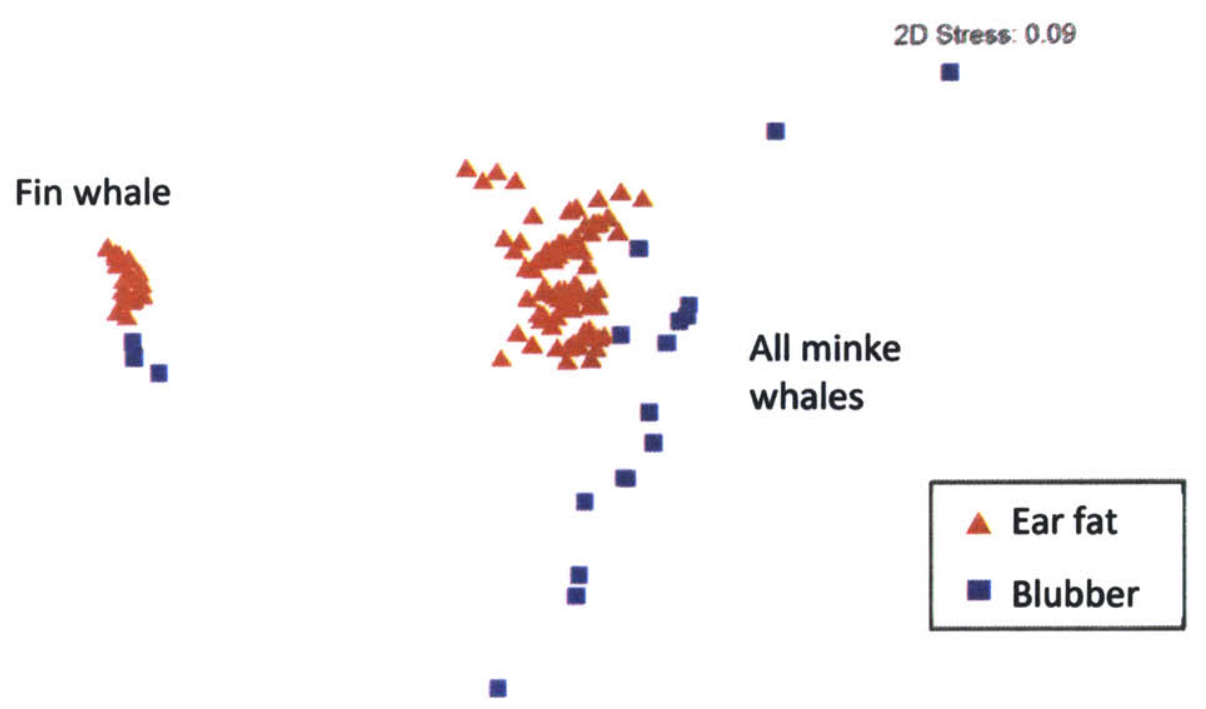

Fig. 3.11. MDS plot of all fatty acid data based on a Bray-Curtis resemblance matrix. Samples that are more similar to each other are placed closer together on the map. The confidence level of the output is represented by the stress value. Stress values of less than 0.1 are defined as "good ordination with no real prospect of a misleading interpretation" according to Clark and Warwick (2001).

Table 3.3. The major fatty acids present in the minke and fin whale fats

\begin{tabular}{|l|rr|rr|rr|rr|}
\hline & \multicolumn{2}{|c|}{ B-acu18 } & \multicolumn{2}{|c|}{ B-acu19 } & \multicolumn{2}{c|}{ B-acu22 } & \multicolumn{2}{c|}{ B-phy11 } \\
\hline \multicolumn{1}{|c|}{ Fatty } & & & & & & & & \\
Acid & Ear fat & Blubber & Ear fat & Blubber & Ear fat & Blubber & Ear fat & Blubber \\
\hline $14: 0$ & 4.7 & 3.9 & 4.9 & 4.7 & 5.6 & 5.5 & 5.0 & 4.9 \\
$16: 0$ & 11.6 & 6.7 & 12.1 & 9.5 & 13.0 & 10.1 & 18.0 & 16.0 \\
$16: 1 n-7$ & 9.6 & 5.1 & 13.7 & 13.3 & 12.0 & 8.0 & 8.6 & 7.5 \\
$18: 1 n-11$ & 4.7 & 5.5 & 4.0 & 4.1 & 4.0 & 3.0 & 1.4 & 1.4 \\
$18: 1 n-9$ & 20.2 & 18.9 & 17.7 & 16.2 & 19.1 & 14.6 & 26.8 & 24.7 \\
$18: 1 n-7$ & 4.6 & 3.7 & 5.0 & 4.5 & 4.1 & 3.2 & 6.3 & 5.6 \\
$20: 1 n-11$ & 4.5 & 7.4 & 3.6 & 3.7 & 3.8 & 3.9 & 1.4 & 1.7 \\
$20: 1 n-9$ & 12.4 & 16.8 & 11.2 & 12.0 & 10.1 & 12.3 & 3.9 & 4.5 \\
$22: 1 n-11$ & 8.5 & 10.2 & 7.1 & 7.7 & 7.4 & 9.9 & 2.0 & 2.2 \\
$22: 6 n-3$ & 1.6 & 1.8 & 1.9 & 3.5 & 2.7 & 6.3 & 3.4 & 6.8 \\
\hline
\end{tabular}

Numbers indicate quantities in wt\%, averaged from all samples of the tissue. 18:1n-11 was classified as an "endogenous" fatty acid and fatty acids indicated in blue italics were classified as "dietary" lipids, following Iverson et al. (2004). All other fatty acids have large contributions from both biosynthesis and diet. 


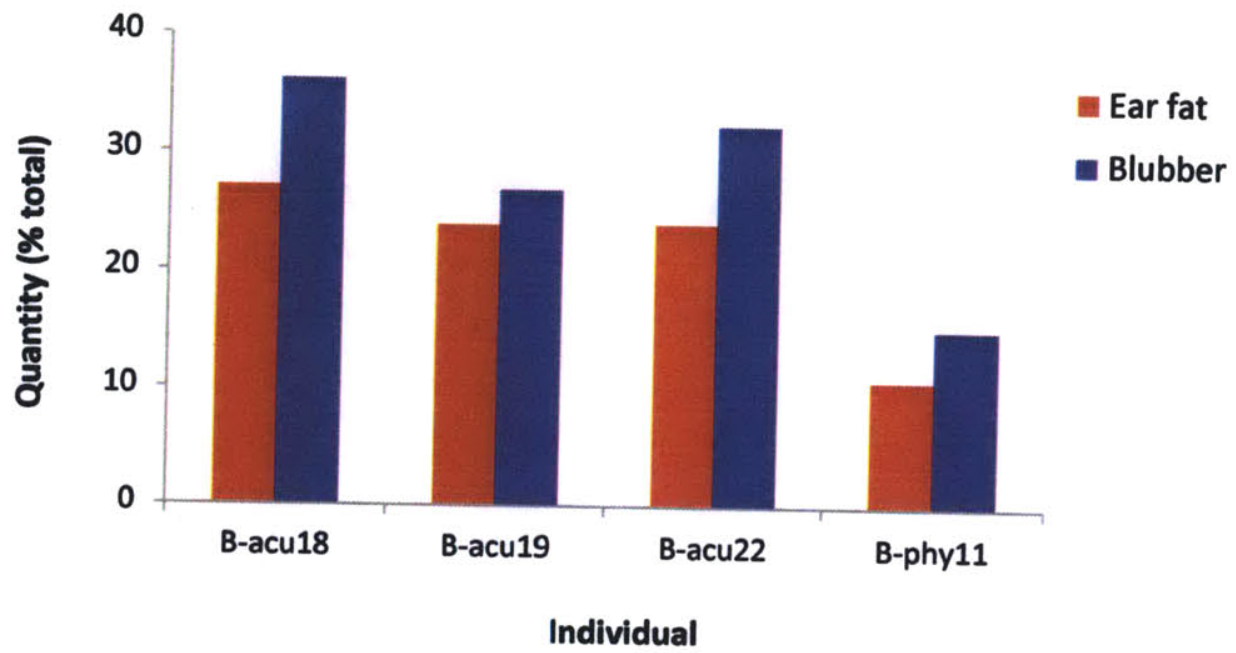

Figure 3.12. Total dietary fatty acids, as defined in Table 3.3., as a percent total of all fatty acids.

The fatty acid signature of blubber from minke whale B-acu22 exhibited a stronger dependence on stratification than body location, which was contrary to Ruchonnet et al. (2006)'s findings from the blubber of one fin whale. There were no discernible differences in fatty acid signatures between the four different body sites, including blubber adjacent to the external auditory meatus (Figure 3.13). 


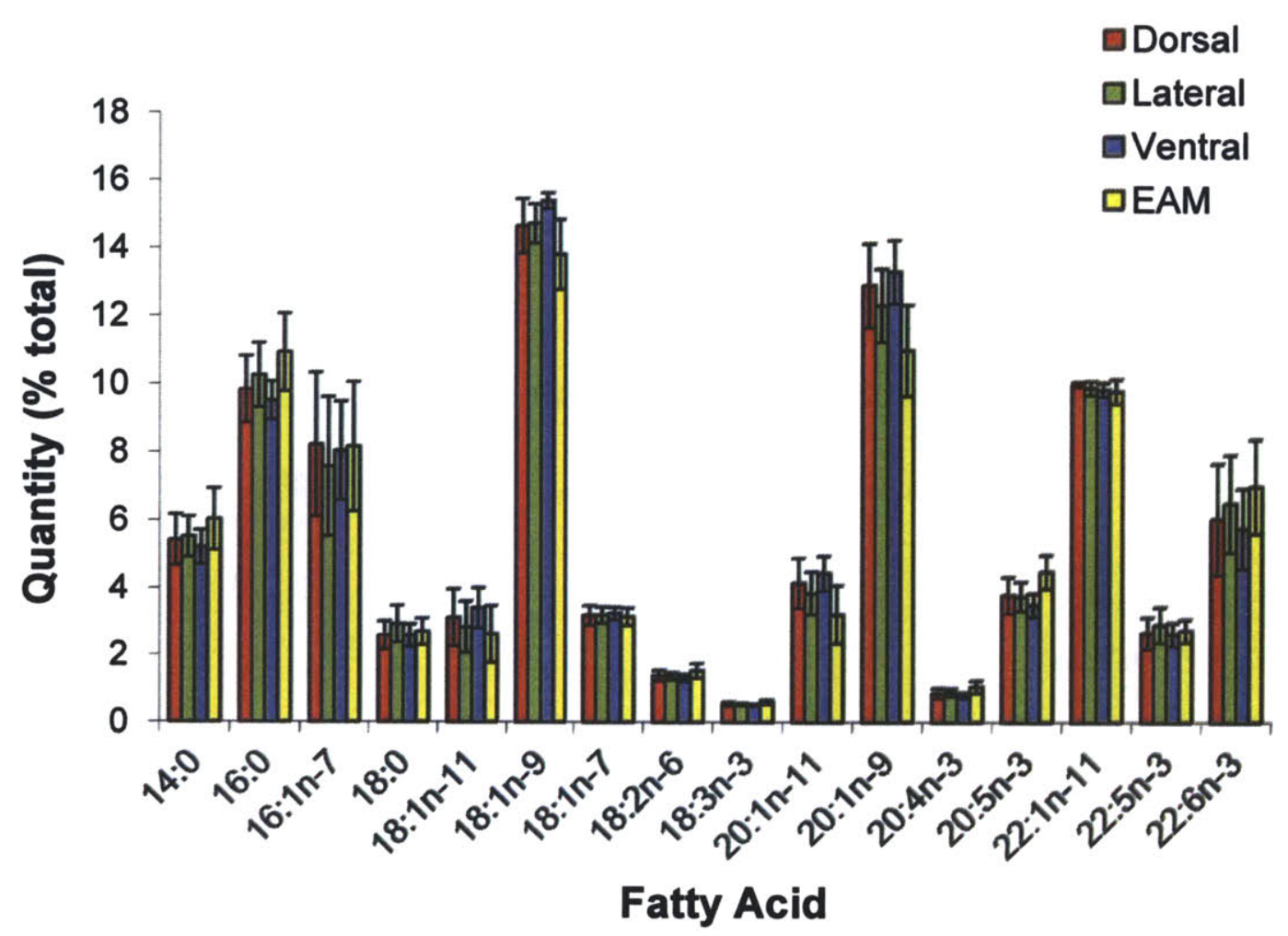

Figure 3.13. The fatty acid signatures of blubber from B-acu22, shown by body site. Error bars represent the standard error of the mean.

\subsubsection{Comparison of ear fat lipid composition with odontocete acoustic fats}

The lipid content of the minke and fin whale ear fats was slightly lower than the published values for the bottlenose dolphin, harbor porpoise, and the pygmy sperm whale (Table 3.4). However, the ear fats of mysticetes still contained greater than $50 \%$ lipid. No appreciable amounts of wax ester or short, branched fatty acids were found in the mysticete ear fats. Yet, the biochemical composition of odontocetes was also diverse. For example, harbor porpoise acoustic fats contain very little wax esters, while the acoustic fats of the pygmy sperm whale is composed of $40 \%$ wax ester. On the other hand, the pygmy sperm whale acoustic fats do not contain significant amounts of 
isovaleric acid (one of the short, branched fatty acids), whereas the bottlenose dolphin acoustic fats are made of more than $50 \%$ isovaleric acid. Regardless of the identities of the fatty acids, there are elevated levels of endogenously synthesized lipids in all odontocete acoustic fats examined to date (Koopman et al., 2006).

Table 3.4. Mysticete ear fats vs. odontocete acoustic fats

\begin{tabular}{cccccc} 
& Minke & Fin whale & Bottlenose & $\begin{array}{c}\text { Harbor } \\
\text { porpoise }\end{array}$ & $\begin{array}{c}\text { Pygmy sperm } \\
\text { whale }\end{array}$ \\
\hline $\begin{array}{c}\text { \% Lipid } \\
\begin{array}{c}\text { \% Wax } \\
\text { Ester }\end{array}\end{array}$ & 59 & 65 & 71 & 77 & 83 \\
$1-5: 0$ & $<1$ & $<1$ & 20 & 4 & 40 \\
& $<1$ & 54 & 28 & $<1$
\end{tabular}

Selected data from the minke and fin whale ear fats (this study) compared with published values for several odontocete species (Koopman et al., 2006; Zahorodny et al., 2009). Numbers indicate quantities in wt\%, averaged from all samples of the tissue.

\subsection{Discussion}

\subsubsection{Morphology of the ear fats vs. odontocete acoustic fats}

Both the ear fats and the odontocete acoustic fats had well-defined connections to the tympano-periotic complex and extend from the blubber region to the ears (Figures 3.3 and 3.5). There were several consistent differences between the morphology of the minke whale ear fats and the acoustic fats of the four different odontocete species examined here. First, the minke whale ear fats did not extend as far anteriorly along the mandibles compared to any of the odontocete acoustic fats, and were primarily located lateral to the ears. Furthermore, the minke whale ear fats did not fill the mandibular foramen, whereas all odontocetes have fat-filled, enlarged mandibular hiatuses. However, 
there was also a substantial diversity in acoustic fat morphology among different odontocete species. Although the odontocete reconstructions in this study were based on one individual each and need to be confirmed through additional investigations, it clearly illustrated this morphological diversity.

The functional implications of such variations are an emerging area of research. For example, Mooney et al. (2008) found that the beluga whale is more sensitive to sound inputs at the tip of the mandibles compared to the bottlenose dolphin (Mohl et al., 1999). This difference could be caused by the beluga whale's acoustic fats extending much farther anteriorly towards the tip of the mandible compared to the bottlenose dolphin (Figure 3.5). Similarly, the primarily lateral orientation of the minke whale ear fats may result in enhanced sensitivity of each ear to sounds originating from the side of the animal, or decreased sensitivity to sounds from directly in front of the animal. The bottlenose dolphin is known to have a forward-directed receiving beam for high frequencies, attributed to the perimandibular acoustic fats (Au and Moore, 1984; Aroyan, 2001).

\subsubsection{Lipid composition of ear fats}

\subsubsection{Lipid content}

Although the lipid content of blubber fluctuated with body condition, the overall lipid content of ear fats remained consistent. Even in the emaciated individual (B-acu18), whose blubber lipids were greatly depleted compared to robust individuals, the ear fats contained greater than $50 \%$ lipid (Figure 3.10). While the conservation of lipid in the tissue does not necessarily point to an acoustic function, it is consistent with the ear fat being more than just an additional site for lipid storage. Cranford et al. (1996) stated that starving animals maintain melons with a robust appearance, and Koopman et al. (2003) showed that the lipid content and composition of the fatty melon (another acoustically 
important tissue in odontocetes) does not change during starvation. The authors argued that these findings support the hypothesis that the melon lipids are conserved for a specific function, which was proposed to be acoustic in this case.

The mean value of $61 \mathrm{wt} \%$ lipid for the ear fats is within the normal range for adipose tissues of wild animals (Pond, 1998). An interesting feature of adipose tissues is that sound speeds through fats are slower than through other types of soft tissues at body temperatures in mammals, excluding the lungs (Duck, 1990). At $37^{\circ} \mathrm{C}$, sound speeds through typical mammalian fats are in the range of $1412 \mathrm{~m} / \mathrm{s}-1471 \mathrm{~m} / \mathrm{s}$. In contrast, sound speeds through muscles at $37^{\circ} \mathrm{C}$ are between $1567 \mathrm{~m} / \mathrm{s}-1631 \mathrm{~m} / \mathrm{s}$ and calculated sound speed through collagen (a major component of fibrous tissues) is $1570 \mathrm{~m} / \mathrm{s}$. Sound speeds through most bones are greater than $2000 \mathrm{~m} / \mathrm{s}$ (Duck, 1990). Thus, the ear fats, which are composed of typically mammalian lipids, are likely to have lower sound speeds than the surrounding tissues.

Gradients in sound speeds and their functional implications have been explored for odontocete acoustic tissues, including the melon and the peri-mandibular fats (Litchfield et al., 1973; Blomberg and Lindholm, 1976; Wedmid et al., 1973, Varanasi et al., 1975; Scano et al., 2005; Koopman et al., 2006; Zahorodny et al., 2009). For example, Koopman et al. (2006) found that the distribution of lipids within perimandibular fats of odontocetes show consistent patterns, where the shortest and branched chain compounds were concentrated in the middle of the inner fat body and around the tympano-periotic complex. The highest relative wax ester concentrations also occurred in the regions closest to the tympano-periotic complex. It has been shown that sound velocity in lipids is a function of their carbon chain length and that sound travels faster through triacylglycerols than through wax esters (Guow and Vlugter, 1967; Hustad et al., 1971; Flewellen and Morris, 1978). Therefore, Koopman et al. (2006) hypothesized that the topographical arrangement of lipids within peri-mandibular fat bodies of odontocetes are arranged so that sound is directed to the ears as it bends towards the inner low velocity center of the mandibular fat body, which has a higher concentration of wax 
esters and short, branched chain lipids. The minke and fin whale ear fats may similarly act as a waveguide towards the ears on a grosser scale, by having a lower sound speed than the surrounding, non-fatty tissue.

The waveguide properties of the ear fats may be enhanced if the regions closest to the ears have elevated lipid content values and therefore even lower sound speeds (Duck, 1990). The CT images (Figure 3.7), visual inspection (Figure 3.2), and some of the lipid content data suggested that the dorsal, middle, and anterior regions of the ear fat, closest to the ears, had higher fat content. However, the data were inconclusive perhaps because of limitations in the sampling scheme.

Another unique feature of fatty tissues is that unlike other soft tissues, sound speed through fat decreases with increasing temperature (Bamber and Hill, 1979; Duck, 1990; Figure 3.14). This temperature - sound speed relationship is well-documented in lipids, including those extracted from odontocete melons (Hustad et al., 1971; Blomberg and Jensen, 1976; Flewellen and Morris, 1977; Bamber and Hill, 1979; Litchfield et al., 1979; Duck, 1990; Goold and Clarke, 2000). Thus, thermoregulation of acoustic fats would be another way to create sound speed gradients through these tissues without relying on fine-scale topographical arrangements of unique lipids (Blomberg and Jensen, 1976; Flewellen and Morris, 1977; Goold and Clarke, 2000). In fact, functional imaging studies on captive bottlenose dolphins suggest that odontocetes may be able to thermoregulate their acoustic fats through increased blood flow to both the melon and peri-mandibular fats (Houser et al., 2004). Cetaceans inhabiting colder waters may naturally have a sound speed gradient through their acoustic fats, with warmer, slower sound speed fats at the core, near the ears, and cooler, faster sound speed fats at the interface with the environment. 


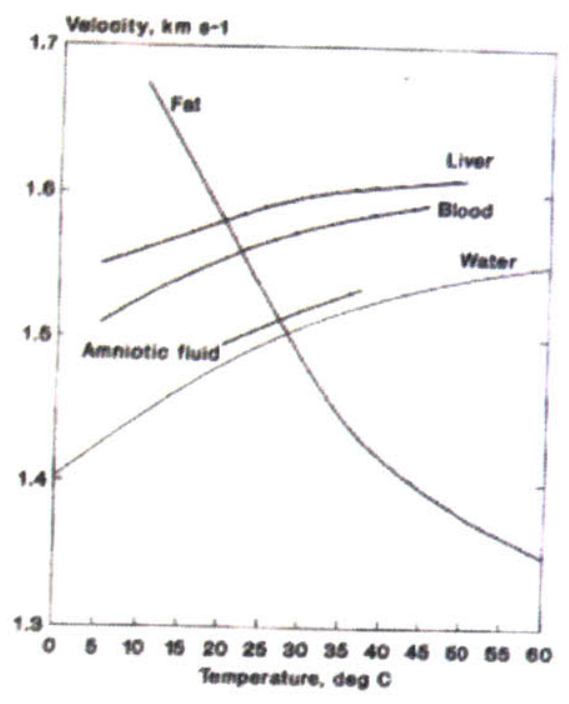

Figure 3.14. Sound speed through various materials as a function of temperature, from Duck (1990). Non-fatty soft tissues, including muscle (not illustrated in figure), have positive temperature coefficients of acoustic velocity, while fatty tissues have a negative temperature coefficient (Bamber and Hill, 1979; Duck, 1990).

\subsubsection{Lipid classes}

Mammalian adipose tissues are primarily composed of triacylglycerols (TAG), but the acoustic fats of some odontocete species are rich in wax esters (Varanasi and Malins, 1970a; Varanasi and Malins, 1970b; Varanasi and Malins, 1971; Litchfield et al., 1975; Morris, 1986; Litchfield and Greenberg, 1974; Litchfield et al., 1975). We did not see any wax esters in the ear fats of minke and fin whales. We did see some non-TAG lipids in some of the ear fat samples, which were not present in our blubber samples. These non-TAG lipids included sterol esters, free fatty acids, cholesterol, and phospholipids. However, Lockyer et al. (1984) reported the presence of these non-TAG lipids in fin whale blubber. Furthermore, she noted that the quantity of free fatty acids (up to $34 \mathrm{wt} \%$ in her samples) may have been elevated because of autolysis from the relatively long post-mortem time. Therefore, the elevated levels of non-TAG lipids in ear fat may be because of more advanced autolysis in these tissues compared to blubber. This is plausible in some cases, because the internal tissues of whales, such as the ear fat, maintain body temperature for a much longer time postmortem than the external tissues 
like blubber from the insulating effect of the outer tissues. Thus, there is no conclusive evidence that there are different lipid classes in ear fat compared to blubber at this time.

\subsubsection{Fatty acid composition}

The acoustic fats of odontocetes are characterized by endogenously synthesized, short, branched fatty acids found within wax esters and TAG (Varanasi and Malins, 1970a; Varanasi and Malins, 1970b; Varanasi and Malins, 1971; Litchfield et al., 1975; Morris, 1986; Litchfield and Greenberg, 1974; Litchfield et al., 1975). Although we did not detect these unique fatty acids at appreciable quantities, the minke and fin whale ear fats did have lower levels of dietary fatty acids compared to the blubber (Figure 3.12). This was a consistent pattern across all four individuals. Interestingly, the MDS analysis showed that all ear fat samples from the three minke whales were more similar to each other compared to the blubber (Figure 3.11). Thus, the fatty acid composition of blubber is more variable across individuals and is more influenced by the diet, while the fatty acid composition of ear fat appears to be conserved for a given species.

The major dietary lipids in Table 3.3 have longer carbon chain lengths than the fatty acids that can have a large endogenous contribution. Therefore, there are higher levels of long chain fatty acids in blubber compared to the ear fat. Odontocete acoustic fats, including the melon and peri-mandibular fats, are known to contain fatty acids and alcohols with a lower average chain length than in the blubber of the same animal (Ackman et al., 1971; Varanasi and Malins, 1971; Litchfield et al., 1975; Litchfield et al., 1976). This contributes to the reduced sound speeds found in acoustic fats because sound speeds through shorter fatty acids are slower than through longer fatty acids (Guow and Vlugter, 1967; Hustad et al., 1971). The elevated levels of relatively shorter (14-18 carbons) fatty acids in the minke and fin whale ear fats may further decrease the sound speeds through these tissues, enhancing the waveguide effect that was discussed above.

Future studies should aim to determine the degree of conservation in ear fat fatty acid signatures relative to dietary shifts by increasing sample sizes across several species. 
In our study, both the ear fat and blubber of the minke whales contained higher levels of 20:1n-9 and 22:1n-11 compared to the fin whales. Falk-Petersen et al. (2000) reports that the higher molecular weight monounsaturates $20: 1 n-9$ and 22:1n-11 have a specific source in calanoid copepods. Therefore, minke whales in this study may have had diets richer in copepods or in fishes that feed on copepods (such as herring) compared to the fin whale. According to Lockyer et al. (1984), North Atlantic fin whales feed predominantly on euphausiids which in turn feed on phytoplankton, meaning calanoid copepods would be excluded from their diets. Yet, there are reports of fin whales caught off of Nova Scotia, Spain, and Gulf of St. Lawrence in the summer months with high levels of 20:1n-9 and 22:1n-11 in their blubber (Ackman et al., 1965; Lockyer et al., 1984). The fatty acid signatures of ear fat for such individuals are unknown.

\subsubsection{Comparison with odontocete acoustic fats}

The composition of odontocete acoustic fats is highly variable across species, illustrated in Table 3.4. Therefore, it is not the case that there is one definitive "acoustic lipid" or a set mixture of lipids which give fats an acoustic function (Litchfield et al., 1975). Yet, there are some unifying features that can be found in odontocete acoustic fats, based on the above discussions: (1) they are composed of lipids not typically found in mammalian tissues; (2) the spatial heterogeneity of lipids likely enhances the waveguide effect; (3) their lipid content and fatty acid signatures are stable across body conditions; (4) they contain fewer dietary signals, and the fatty acids and alcohols are composed of shorter-chained lipids than in blubber; (5) sound speeds are lower compared to normal fats and surrounding tissues.

In the case of mysticete ear fats, (1) does not seem to apply; to our knowledge, odontocete cetaceans are the only mammals which have acquired the ability to synthesize and store short, branched-chain fatty acids and wax esters in appreciable quantities. The results also do not support (2), at least in terms of the arrangement of fatty acids within 
the ear fats. However, the ear fats do maintain their lipids even during starvation, and their fatty acid signatures seems to be conserved for individuals of the same species, consistent with (3). This suggests that the ear fats, like the odontocete acoustic fats, are a structural fat body, conserved for a particular function rather than just providing an additional site for lipid storage.

The ear fats also contain fewer dietary signals compared to blubber, although the differences are not as large as the differences between the acoustic fats and blubber of odontocetes. Since the strictly dietary fatty acids also have longer chain lengths than other fatty acids, the ear fats also have slightly higher levels of shorter fatty acids than blubber (4). Finally, both the acoustic fats and the ear fats are low sound speed, fatty tissues leading from the environment directly to the tympano-periotic complex. Thus, minke and fin whale ear fats share several characteristics with odontocete acoustic fats and could potentially represent a less biochemically sophisticated form of fatty tissue involved in the sound reception pathway.

\subsection{Conclusions}

For the past several decades, fatty sound reception in cetaceans was thought to be a phenomenon unique to odontocetes. However, a recent study by Yamato et al. (2012) found large, well-formed fat bodies intimately associated with the ears in the minke whale, contributing anatomical evidence that fatty sound reception pathways may be a possibility for some mysticete species as well. This study compared the morphology and the biochemical composition of these newly described "ear fats" to the acoustic fats of various odontocete species.

Unlike odontocetes, minke and fin whales do not have conspicuously large mandibular canals and these canals are not filled with fat. The mysticetes also do not have peri-mandibular fat bodies. Instead of having a multi-lobed structure, the ear fats 
are single-lobed and are located primarily lateral to the tympano-periotic complex. Both the acoustic fats and the ear fats extend from the blubber region to the ears, having welldefined attachments to the tympano-periotic complex.

The ear fats do not contain the conspicuous, unique lipids found in odontocete acoustic fats. However, it has been recognized that there is a large variability in the biochemical composition of odontocete acoustic fats, and that no single type of lipid turns a fat body into "acoustic" fat (Litchfield et al., 1975). Mysticetes may have developed a fatty sound reception pathway using typically mammalian lipids, lacking the ability to synthesize wax esters and short, branched chain fatty acids. In this study, we have shown that like acoustic fats, the mysticete ear fats maintain their lipids even during starvation, when the blubber lipids are greatly depleted. The fatty acid signatures of ear fats also seem to be conserved for individuals of the same species, whereas the blubber fatty acid composition was more influenced by diet. Thus, the ear fats seem to be more than an additional site for lipid storage.

Although the precise reason for having wax esters and short, branched fatty acids in odontocete acoustic fats is unknown, they all reduce sound speeds through the acoustic fat compared to normal fats and surrounding tissues of the head (Guow and Vlugter, 1967; Hustad et al., 1971; Bamber and Hill, 1979; Duck, 1990). Because sound bends towards regions of minimum sound speed, incorporating a particularly low sound speed tissue in their sound reception pathway may help to focus sound towards the ears of odontocetes, which depend on hearing their returning echolocation clicks for foraging and survival. The mysticete ear fats, having a lower sound speed than the surrounding, non-fatty tissues (Bamber and Hill, 1979; Duck, 1990), may also help to channel sound towards the ears.

Odontocetes and mysticetes both face the challenge of listening entirely under water, where external pinnae and ear canals are ineffective for collecting and amplifying sound. It is proposed that both sub-orders of cetaceans have incorporated fatty tissues into their auditory systems for aquatic sound reception. The different lineages of 
odontocetes may have subsequently acquired the ability to synthesize and deposit even more effective lipids in their acoustic tissues. While these unexpected types of lipids and conspicuous mandibular and acoustic fat morphologies have led us to believe that fatty sound reception pathways are a uniquely odontocete phenomenon, results from this study suggest that the mysticete ear fats share some potentially important characteristics with odontocete acoustic fats and may be a functionally important component of the auditory system. 


\subsection{Acknowledgements}

This work would not have been possible without Dr. Heather Koopman's generous donation of her time, lab space, equipment, and extensive knowledge on a subject completely foreign to me three years ago. Thank you so much for your patience and mentorship. Members of her lab group were also incredibly supportive and helpful during my time at UNCW in various ways - thank you to Andrew Westgate, Hillary Lane, Sandy Camilleri, Caitlin McKinstry, Sara McClelland, and Zach Siders.

The time spent at UNCW would not have been the same without Dr. Ann Pabst, who adopted me into her lab group and introduced me to Flaming Amy's burritos. She as well as Bill McLellan, Steve Thornton, and Butch Rommel, Laura Bagge, and the rest of the lab gave me valuable feedback on my thesis while making me feel at home in Wilmington. Justin Eichinger and Kristen Jabanoski literally provided a home for me in Wilmington, and were great housemates. Thank you also to the UNCW Biology and Marine Biology Department as well as the administrative staff for allowing me access to your buildings and resources at odd hours of the day. Dan Noonan of UCNW and Clayton Hainsworth of MIT facilitated videoconferences with Dr. Koopman once I left UNCW.

Funding to pursue this work came from the National Science Foundation Graduate Research Fellowship, WHOI Coastal Ocean Institute Award, WHOI Ocean Life Institute Fellowship, MIT Student Assistance Fund, and the WHOI Academic Programs Office. 


\subsection{References}

Ackman RG, Eaton CA, Jangaard PM. 1965. Lipids of Fin Whale (Balaenoptera Physalus) from North Atlantic Waters .1. Fatty Acid Composition of Whole Blubber and Blubber Sections. Canadian Journal of Biochemistry 43:1513-1520.

Ackman RG, Eaton CA, Litchfield C. 1971. Composition of Wax Esters, Triglycerides and Diacyl Glyceryl Ethers in Jaw and Blubber Fats of Amazon River Dolphin (IniaGeoffrensis). Lipids 6:69-77.

Au WWL, Moore PWB. 1984. Receiving beam patterns and directivity indices of the Atlantic bottlenose dolphin Tursiops truncatus. The Journal of the Acoustical Society of America 75:255-262.

Bamber JC, Hill CR. 1979. Ultrasonic attenuation and propagation speed in mammalian tissues as a function of temperature. Ultrasound in medicine \& biology 5:149-157.

Blomberg J, Jensen BN. 1976. Ultrasonic studies on the head oil of the North Atlantic pilot whale (Globicephala melaena melaena). JASA 60:755-758.

Blomberg J, Lindholm L-E. 1976. Variations in lipid composition and sound velocity in melon from the North Atlantic pilot whale,Globicephala melaena melaena. Lipids 11:153-156.

Brill RL, Sevenich ML, Sullivan TJ, Sustman JD, Witt RE. 1988. Behavioral Evidence for hearing through the lower jaw by an echolocating dolphin (Tursiops truncatus). Marine Mammal Science 4:223-230.

Budge SM, Iverson SJ, Koopman HN. 2006. Studying trophic ecology in marine ecosystems using fatty acids: A primer on analysis and interpretation. Marine Mammal Science 22:759-801.

Bullock T H, Grinnell AD, Ikezono E, Kameda K, Katsuki Y, Nomoto M, Sato O, Suga N, Yanigasawa K. 1968. Electrophysiological studies of central auditory mechanisms in cetaceans. Zeitschrift für vergleichende Physiologie 59:117-156.

Clarke KR, Gorley RN. 2006. PRIMER v6: User Manual / Tutorial. Plymouth, UK: PRIMER-E.

Clarke KR, Warwick RM. 2001. Changes in marine communities: an approach to statistical analysis and interpretation, 2 ed. Plymouth, UK: PRIMER-E. 
Cranford TW, Amundin M, Norris KS. 1996. Functional morphology and homology in the odontocete nasal complex: Implications for sound generation. Journal of Morphology 228:223-285.

Cranford TW, McKenna MF, Soldevilla MS, Wiggins SM, Goldbogen JA, Shadwick RE, Krysl P, Leger JAS, Hildebrand JA. 2008. Anatomic geometry of sound transmission and reception in Cuvier's beaked whale (Ziphius cavirostris). Anat Rec 291:353-378.

Duck FA. 1990. Physical Properties of Tissue. A Comprehensive Reference Book. San Diego: Academic Press.

Eschricht DF, Reinhardt, J. 1866. On the Greenland right-whale: (Balaena mysticetus. Linn.): with especial reference to its geographical distribution and migrations in times past and present, and to its external and internal characteristics. Ray Society Publication.

Falk-Petersen S, Hagen W, Kattner G, Clarke A, Sargent J. 2000. Lipids, trophic relationships, and biodiversity in Arctic and Antarctic krill. Canadian Journal of Fisheries and Aquatic Sciences 57:178-191.

Flewellen CG, Morris RJ. 1978. Sound velocity measurements on samples from the spermaceti organ of the sperm whale (Physeter catodon). Deep Sea Research 25:269-277.

Folch J, Lees M, Stanley GHS. 1957. A simple method for the isolation and purification of total lipids from animal tissues. J. Biol. Chem. 226:497-509.

Goold JC, Clarke MR. 2000. Sound velocity in the head of the dwarf sperm whale, Kogia sima, with anatomical and functional discussion. Journal of the Marine Biological Association of the United Kingdom 80:535-542.

Gouw IRTH, Vlugter IRJC. 1967. Physical Properties of Triglycerides III: Ultrasonic Sound Velocity. Fette, Seifen, Anstrichmittel 69:159-164.

Houser DS, Finneran J, Carder D, Van Bonn W, Smith C, Hoh C, Mattrey R, Ridgway S. 2004. Structural and functional imaging of bottlenose dolphin (Tursiops truncatus) cranial anatomy. In. p 3657-3665.

Hunter J. 1787. Observations on the Structure and Oeconomy of Whales. Philosophical Transactions of the Royal Society of London 77:371-450.

Hustad GO, Richardson T, Winder WC, Dean MP. 1971. Acoustic properties of some lipids. Chemistry and physics of lipids 7:61.

Iverson SJ, Field C, Bowen WD, Blanchard W. 2004. Quantitative fatty acid signature analysis: A new method of estimating predator diets. Ecological Monographs 74:211-235. 
Kernan JD. 1919. Bone conduction of sound in cetacean and its relation to increased bone conduction in human beings. The Laryngoscope 29:510-521.

Ketten DR. 1994. Functional Analyses of Whale Ears: Adaptations for Underwater Hearing. I.E.E.E. Proceedings in Underwater Acoustics 1:264-270.

Ketten DR. 1997. Structure and function in whale ears. Bioacoustics 8:103-136.

Ketten DR. 2000. Cetacean Ears. In: Au WWL, Popper AN, Fay RR, editors. Hearing by Whales and Dolphins. New York: Springer-Verlag. p 43-108.

Koopman HN. 1996. Stratification and age-related differences in blubber fatty acids of the male harbour porpoise (Phocoena phocoena). Journal of comparative physiology. B, Biochemical, systemic, and environmental physiology 165:628.

Koopman HN. 2007. Phylogenetic, ecological, and ontogenetic factors influencing the biochemical structure of the blubber of odontocetes. Marine Biology 151:277-291.

Koopman HN, Budge SM, Ketten DR, Iverson S. 2006. Topographic distribution of lipids inside the mandibular fat bodies of odontocetes: Remarkable complexity and consistency. IEEE Journal of Oceanic Engineering 31:95-106.

Koopman HN, Iverson SJ, Read AJ. 2003. High concentrations of isovaleric acid in the fats of odontocetes: variation and patterns of accumulation in blubber vs. stability in the melon. Journal of Comparative Physiology B-Biochemical Systemic and Environmental Physiology 173:247-261.

Lane HA. 2009. Variation in the nutritional value of Atlantic Herring (Clupea Harengus) from the Bay of Fundy, Canada. Master's thesis, University of North Carolina, Wilmington Department of Biology and Marine Biology. 104p.

Litchfield C, Greenberg AJ. 1974. Comparative lipid patterns in the melon fats of dolphins, porpoises and toothed whales. Comp. Biochem. Physiol. 47B:401-407.

Litchfield C, Greenberg AJ, Caldwell DK, Caldwell MC, Sipos JC, Ackman RG. 1975. Comparative lipid patterns in acoustical and nonacoustical fatty tissues of dolphins, porpoises and toothed whales. Comparative Biochemistry and Physiology Part B: Comparative Biochemistry 50:591-597.

Litchfield C, Greenberg AJ, Mead JG. 1976. The distinctive character of Ziphiidae head and blubber fats. Cetology 23:1-10. 
Litchfield C, Karol R, Greenberg AJ. 1973. Compositional topography of melon lipids in the Atlantic bottlenosed dolphin Tursiops truncatus: Implications for echo-location. Marine Biology 23:165-169.

Litchfield C, Greenberg AJ, Caldwell DK, Caldwell MC, Sipos JC, Ackman RG. 1975. Comparative lipid patterns in acoustical and nonacoustical fatty tissues of dolphins, porpoises and toothed whales. Comparative Biochemistry and Physiology Part B: Comparative Biochemistry 50:591-597.

Lockyer CH, McConnell LC, Waters TD. 1984. The Biochemical-Composition of Fin Whale Blubber. Canadian Journal of Zoology-Revue Canadienne De Zoologie 62:25532562.

Mohl B, Au WWL, Pawloski J, Nachtigall PE. 1999. Dolphin hearing: Relative sensitivity as a function of point of application of a contact sound source in the jaw and head region. J. Acoust. Soc. Am. 105:3421-3424.

Mooney TA, Nachtigall PE, Castellote M, Taylor KA, Pacini AF, Esteban JA. 2008. Hearing pathways and directional sensitivity of the beluga whale, Delphinapterus leucas. Journal of Experimental Marine Biology and Ecology 362:108-116.

Morris RJ. 1975. Further studies into the lipid structure of the spermaceti organ of the sperm whale (Physeter catodon). Deep Sea Research and Oceanographic Abstracts 22:483-489.

Morris RJ. 1986. The acoustic faculty of dolphins. In: Kroodsma DE, Miller EH, Ouellet $\mathrm{H}$, editors. Acoustic Communication in Birds. New York: Academic Press. p 183-212.

Norris KS. 1964. Some problems of echolocation in cetaceans. In: Tavolga WN, editor. Marine bioacoustics. New York: Pergamon Press. p 317-336.

Norris KS. 1968. The evolution of acoustic mechanisms in odontocete cetaceans. In: Drake ET, editor. Evolution and Environment. New Haven: Yale University Press. p 298-323.

Norris KS, Harvey GW. 1974. Sound transmission in the porpoise head. The Journal of the Acoustical Society of America 56:659-664.

Olsen E, Grahl-Nielsen O. 2003. Blubber fatty acids of minke whales: Stratification, population identification and relation to diet. Marine Biology 142:13-24.

Pond CM. 1998. The fats of life. Cambridge: Cambridge University Press. 
Popov V, Supin A. 1990. Localization of the acoustic window at the dolphin's head In: Thomas JA, Kastelein RA, editors. Sensory Abilities of Cetaceans. New York: Plenum. p 417-426.

Popov VV, Supin AY, Vladimir OK, Mikhail BT, Mikhail GP. 2008. Evidence for double acoustic windows in the dolphin, Tursiops truncatus. J. Acoust. Soc. Am. 123:552-560.

Renaud DL, Popper AN. 1975. Sound localization by the bottlenose porpoise Tursiops truncatus. J. exp. Biol. 63:569-585.

Reysenbach De Haan FW. 1957. Hearing in whales. Acta oto-laryngologica. Supplementum 134:1-114.

Ruchonnet D, Boutoute M, Guinet C, Mayzaud P. 2006. Fatty acid composition of Mediterranean fin whale Balaenoptera physalus blubber with respect to body heterogeneity and trophic interaction. Marine Ecology-Progress Series 311:165-174.

Scano P, Maxia C, Maggiani F, Crnjar R, Lai A, Sirigu P. 2005. A histological and NMR study of the melon of the striped dolphin (Stenella coeruleoalba). Chemistry and Physics of Lipids 134:21-28.

Shantha NC, Napolitano GE. 1992. Gas chromatography of fatty acids. J Chrom 624:3751.

Varanasi US, Malins DC. 1970a. Unusual wax esters from the mandibular canal of the porpoise (Tursiops gilli). Biochemistry 9:3629-3631.

Varanasi US, Malins DC. 1970b. Ester and ether-linked lipids in the mandibular canal of a porpoise (Phocoena phocoena). Occurrence of isovaleric acid in glycerolipids.

Biochemistry 9:4576-4579.

Varanasi U, Feldman HR, Malins DC. 1975. Molecular basis for formation of lipid sound lens in echolocating cetaceans. Nature 255:340-343.

Varanasi U, Malins DC. 1971. Unique lipids of the porpoise (Tursiops gilli): Differences in triacyl glycerols and wax esters of acoustic (mandibular canal and melon) and blubber tissues. Biochimica et Biophysica Acta (BBA) - Lipids and Lipid Metabolism 231:415418.

Wedmid Y, Litchfield C, Ackman RG, Sipos JC, Eaton CA, Mitchell ED. 1973. Heterogeneity of lipid composition within the cephalic melon tissue of the pilot whale (Globicephala melaena). Biochimica et biophysica acta 326:439-447. 
Yamada M. 1953. Contribution to the Anatomy of the Organ of Hearing of Whales. Sci. Rep. Whales Res. Inst. 8:1-79

Yamato M, Ketten DR, Arruda J, Cramer S, Moore K. 2012. The Auditory Anatomy of the Minke Whale (Balaenoptera acutorostrata): A Potential Fatty Sound Reception Pathway in a Baleen Whale. The Anatomical Record: Advances in Integrative Anatomy and Evolutionary Biology 295:991-998.

Yamato M, Mooney TA, Ketten DR, Cramer S, Arruda J. 2009 Auditory anatomy and sound reception in the beluga whale (Delphinapterus leucas) compared to the Bottlenose Dolphin (Tursiops truncatus). In: 18th Biennial Conference on the Biology of Marine Mammals. Quebec City, Canada.

Zahorodny ZP, Koopman HN, Budge SM. 2009. Distribution and development of the highly specialized lipids in the sound reception systems of dolphins. J Compar Physiol B: Biochem Syst Environ Physiol 179:783-798. 
Chapter 4: Modeling sound propagation through the minke whale head using the Finite Element Method (FEM) 


\section{Abstract}

Although little is known about hearing mechanisms in mysticetes (baleen whales), experimental studies of sound reception pathways have not been accomplished because of major logistical challenges. An alternative method for exploring the behavior of sound through the various structures of a whale head is the Finite Element Method (FEM). In this study, a model of a minke whale head was created based on CT data presented in Chapter 2, combined with material property values from measurements and published data. By isolating various components of the minke whale head while altering sound source frequencies and locations, we investigated the role of the skull, air spaces, tympano-periotic complex, and ear fats in shaping the sound pressure field within the head. We found that the major patterns in the resulting pressure fields were driven by the air spaces at lower frequencies and by bony structures at higher frequencies. The ear fats, which have similar material properties as sea water compared to bone and air, contributed more subtle effects to the total pressure field. The presence of the ear fats slightly increased the total pressure magnitude near the ears. When the density and sound speed of the ear fats were decreased, sound pressures adjacent to the ears were increased. Conversely, when the density and sound speed of the ear fats were increased to match the properties of muscle, sound pressures adjacent to the ears were decreased. Thus, the presence of a low density, low sound speed tissue adjacent to the ears seems to be beneficial in focusing sound towards the ears. Fatty tissues are known to have lower densities and sound speeds than other types of soft tissue (Duck, 1990), which may explain why they are an important component of the auditory system in odontocetes, and perhaps in mysticete cetaceans as well. 


\subsection{Introduction}

Despite widespread interest in the effects of anthropogenic noise on mysticetes, or baleen whales, their hearing mechanisms and sound reception pathways are not well understood. Chapter 2 of this thesis was an anatomical investigation of the minke whale (Balaenoptera acutorostrata) auditory system, which described a large, well-formed body of fat extending from the blubber region to the ears and contacting the ossicles (Yamato et al., 2012). Interestingly, fatty tissues are known to play an important role in the sound reception system of odontocetes, or toothed whales (Norris, 1964; Bullock et al., 1968; Brill et al., 1988; Mohl et al., 1999). Although the minke whale "ear fats" lack the highly unusual lipids present in odontocete acoustic fats, the results from Chapter 3 indicated that the ear fats, like odontocete acoustic fats, seem to be a structural tissue that is conserved for a particular function rather than just providing an additional site for lipid storage. Based on these two chapters, it was hypothesized that the ear fat could be an important part of the sound reception pathway in some baleen whales. However, it is unlikely that the ear fats act in isolation because the whale head also contains bone and air, features which have dramatically different acoustic properties compared to sea water. The goal of this chapter was to understand the ear fats in the context of the head by modeling sound propagation using a numerical technique called the Finite Element Method (FEM).

In FEM, a model is constructed by defining a set of mathematical equations in a continuous domain. For example, to model sound propagation in tissue, the mathematical model is the wave equation together with a set of boundary conditions. The domain, which in this case corresponds to the space occupied by the tissue, is discretized into small connected "elements" creating what is called the finite element mesh. In three dimensional problems, the elements are usually tetrahedra or hexahedra. Automated techniques are used to create this mesh, which may contain millions of elements. The elements define the basic interpolation properties of the mathematical fields associated with the equations that are being solved, such as pressure and particle 
displacement. More detailed descriptions of the method and examples of its implementation can be found in numerous works, including Dietzen (2008) and Krysl et al. (2008).

The mathematical groundwork for the finite element method was realized in the 1970s (Strang and Fix, 1973; Babuska and Azis, 1973) and recent advances in computing power have allowed the method to be applied to diverse problems, including understanding hearing mechanisms in mammals. Many of these studies have focused on the mechanical motion of the human middle ear with reference to clinical applications (examples include Eiber, 1999; Koike et al., 2002; Lee et al., 2006). However, FEM can also be used to simulate how sound propagates in any medium, including animal tissues such as bone, muscle and fats. Thus, it is a useful tool for approximating the behavior of sound through a whale head, which is difficult to study experimentally.

The concept of using numerical techniques for simulating sound propagation through odontocete tissues was explored earlier by Aroyan et al. (1992). This study used a slightly different technique called the Finite Difference Method to model acoustic beam formation in a two-dimensional model of a common dolphin (Delphinus delphis) created from a parasagittal CT image traced onto a digitizing tablet. The model included the skull, fatty melon, and air sacs immersed in sea water, which were all modeled as inhomogeneous fluids with a sound source placed in the area of the monkey lip / dorsal bursae compex (Cranford et al., 1996). Despite its simplicity, the model simulations resulted in a forward-focused beam pattern consistent with experimentally measured beam angles.

Several years later, Aroyan (2001) created a three-dimensional version of his model to study sound reception in a common dolphin. By comparing outputs from models with and without soft tissues included, the study showed that the soft tissues (including the peri-mandibular acoustic fats) play an important role in focusing sound towards the ears. Furthermore, the study showed that higher frequencies generated more 
forward-oriented receiving beams, supporting the notion that the anterior fat channels may be specialized for ultrasonic sonar signal conduction (Aroyan, 2001).

Cranford et al. (2008) used FEM to study sound emission and reception in a Cuvier's beaked whale (Ziphius cavirostris). This model was more sophisticated than Aroyan's, incorporating elastic structures in addition to fluid structures. While fluid structures, such as water, only support longitudinal waves, elastic structures, such as bone, can support shear waves as well. (Longitudinal waves cause compressions in the direction of the wave motion, whereas shear waves result in deformations perpendicular to the direction of the wave motion.) One consequence of incorporating bone as an elastic structure was the finding of a "flexural wave" in the thinned, pan bone region of the mandible. The authors suggested that the incoming sound induces small-amplitude waves that flex the pan bone, which may explain how sound crosses from the outer fat bodies to the inner fat bodies. Another finding was that sound arrived at the ears primarily through an unconventional "gular pathway" in the simulated head, entering the head ventrally, traveling in between the mandibles, and through the inner acoustic fat bodies. While the authors acknowledge that these results must be considered with some skepticism, the study provided novel hypotheses to test if opportunities for experimental studies arise in the future.

Combined, the above studies established the utility of numerical techniques in studying sound emission and reception in odontocetes. Here, we build on these previous works by applying the FEM technique to study sound reception in a mysticete, the minke whale. By isolating various components of the minke whale head while altering sound source frequencies and locations, we investigated the role of the skull, air spaces, tympano-periotic complex, and ear fats in shaping the sound pressure field within the head. 


\subsection{Methods}

\subsubsection{Model development}

Three-dimensional FEM simulations of wave propagation involving complex shapes require: 1) proper representation of the geometry; 2) accurate material property inputs; 3 ) appropriate FEM program. The geometry of the minke whale head was obtained from CT data from a small, juvenile minke whale head, whose tissue boundaries were confirmed through dissections and scans of additional individuals (Yamato et al., 2012). Because of the complex geometry of the minke whale head and auditory structures, several simplifications were necessary to create a computationally manageable model. First, the three-dimensional reconstructions were smoothed to facilitate mesh generation. This was accomplished in AMIRA® v.5.2.2 using several automated segmentation tools combined with manual editing. The very fine structural details that may be lost from smoothing are insignificant in the whole-head FEM of the minke whale particularly for the low frequency sounds relevant to sound reception in baleen whales. In a first approximation structural details of fluid-like tissues (fats, muscle, etc) less than $\lambda / 10$ have a negligible effect in sound propagation models, so the level of detail that matters for sounds of $1000 \mathrm{~Hz}$ and $15 \mathrm{kHz}$ in water-like media are about $15 \mathrm{~cm}$ and $1 \mathrm{~cm}$, respectively.

Structures that were included in the model were the tympano-periotic complex (ears), the rest of the skull, air within the middle ear cavity, ear fats, and the surrounding sea water. Since normal soft tissues, such as muscle, have relatively similar material properties as water (Duck, 1990; Pickard and Emery, 1990; Table 4.1), the rest of the soft tissues were lumped with the surrounding sea water to facilitate mesh generation and computation. Additional simulations were run to address potential effects of this simplification (see below). 
All structures are modeled as acoustic fluids. This is a reasonable approximation for soft tissues, which have small shear moduli and high shear wave absorption coefficients (Frizzell et al., 1976; Aroyan et al., 1992; Aroyan, 2001). However, bone would be better modeled as an elastic structure (Ashman et al., 1987; Duck, 1990) and the effect of incorporating elasticity should be addressed in future studies.

\subsubsection{Material properties}

The material property inputs required for modeling sound propagation in fluidlike structures (water, air, fats, and other soft tissues) are density and either bulk modulus or longitudinal wave speed. These parameters are for structures assumed to be isotropic; computational challenges limit the incorporation of anisotropy in large, sophisticated FEM models. Density of the ear fats were measured from minke and fin whale specimens used in Chapter 3. Samples were weighed using a Mettler Toledo balance and volumes were obtained from the displacement method in addition to CT scanning the samples. These densities were compared to the values from typical mammalian fats, the densities of acoustic fats of odontocetes, and CT number expressed in Hounsfield Units. Solid density standards used for quantitative computerized tomography (CampbellMalone, 2007) were also weighed and scanned in the same way as the ear fat samples in order to determine the relationship between density and CT number. These relationships were compared with previous studies that have described specific linear relationships between CT number and tissue densities for marine mammals (Aroyan, 2001; Soldevilla et al., 2005). Such correlations have been used to derive material property values from CT data in previous studies that modeled sound propagation through odontocete heads (Aroyan, 2001; Krysl et al., 2006).

Other material properties of tissues change dramatically post-mortem, although there are some conflicting reports (Fitzgerald et al., 1957; McKenna et al., 2007). Therefore, realistic values were obtained from the literature (Table 4.1), under the assumption that properly measured material property values from relevant tissues of other 
mammals are better than values forcibly obtained from measurements on non-fresh tissue. The robustness of the model outputs were also assessed through sensitivity analyses varying material property inputs by up to $40 \%$.

Table 4.1. Material property values used in the basic, unaltered model.

\begin{tabular}{|l|c|c|}
\hline \multicolumn{1}{|c|}{ Tissue type } & $\begin{array}{c}\text { Mass density } \\
\rho\left(\mathrm{kg} / \mathrm{m}^{3}\right)\end{array}$ & $\begin{array}{c}\text { Sound speed } \\
c(\mathrm{~m} / \mathrm{s})\end{array}$ \\
\hline Bone & $1610^{\mathrm{a}}$ & $3060^{\mathrm{b}}$ \\
\hline T-P complex & $2510^{\mathrm{c}}$ & $5060^{\mathrm{d}}$ \\
\hline Soft tissue & $1040^{\mathrm{e}}$ & $1600^{\mathrm{g}}$ \\
\hline Ear fats & $970^{\mathrm{f}}$ & $1430^{\mathrm{g}}$ \\
\hline Air & $0.91^{\mathrm{h}}$ & $355^{\mathrm{I}}$ \\
\hline Sea water & $1030^{\mathrm{J}}$ & 1500 \\
\hline
\end{tabular}

Values were taken from:

a - Duck (1990), value for a human cranium

b - Within the range of human skull, Duck (1990)

c - Lees et al. (1996), average of values given for the tympanic and periotic bones.

$\mathrm{d}$ - Within the range of human, bovine, and canine teeth, which are the densest of bones listed in Duck (1990). Lees et al. (1996) lists the fin whale tympanic and periotic bones as having sound speeds of $4540 \mathrm{~m} / \mathrm{s}$ and $4550 \mathrm{~m} / \mathrm{s}$, respectively; $4550 \mathrm{~m} / \mathrm{s}$ was also used in additional simulations.

e - Duck (1990), value for human skeletal muscle.

$\mathrm{f}$ - The average density of the ear fat samples was $966 \mathrm{~kg} / \mathrm{m}^{3}$ (this study).

$\mathrm{g}$ - Duck (1990) gives the values for the in-vivo sound speed in pig muscle and fat as $1579 \mathrm{~m} / \mathrm{s}$ and $1426 \mathrm{~m} / \mathrm{s}$, respectively.

$\mathrm{h}$ - Calculated using the ideal gas law, assuming an ambient pressure of $100 \mathrm{kPa}$, a $50 \%$ air $/ 50 \%$ water vapor mixture, and $37^{\circ} \mathrm{C}$ for temperature.

$\mathrm{i}$ - Hewitt (1998): "The speed of sound in dry air at $0^{\circ} \mathrm{C}$ is about 330 meters per second... Water vapor in the air increases this speed slightly... For each degree rise in temperature above $0^{\circ} \mathrm{C}$, the speed of sound in air increases by 0.6 meters per second." Assuming air temperature of $37^{\circ} \mathrm{C}, 330+(37 \times 0.6)=352.2 \mathrm{~m} / \mathrm{s}$ is the sound speed for dry, warm air. For warm, moist air, this value should be slightly higher.

j - Pickard and Emery (1990) lists the approximate mean density for the world ocean as $1027 \mathrm{~kg} / \mathrm{m}^{3}$. 


\subsubsection{FEM program}

The programming system that was used for this analysis was written by Dr. Gonzalo Feijoo. This state-of-the-art system has several advantages over other FEM software, including commercially available ones. First, it contains a module to construct three-dimensional unstructured meshes directly from segmentated images (Figure 4.1). These unstructured meshes can conform to interfaces, improving the accuracy of the simulations. In contrast, programs that use Cartesian meshes, where the threedimensional space is divided into predetermined cubes or hexahedra, are limited in that interfaces are poorly discretized; this results in larger relative errors in the field variables. Another module, the Solver (the main calculation engine), operates with these unstructured meshes. Our final unstructured mesh of the minke whale head contained $15,148,782$ elements with edge lengths of approximately $3-5 \mathrm{~mm}$.

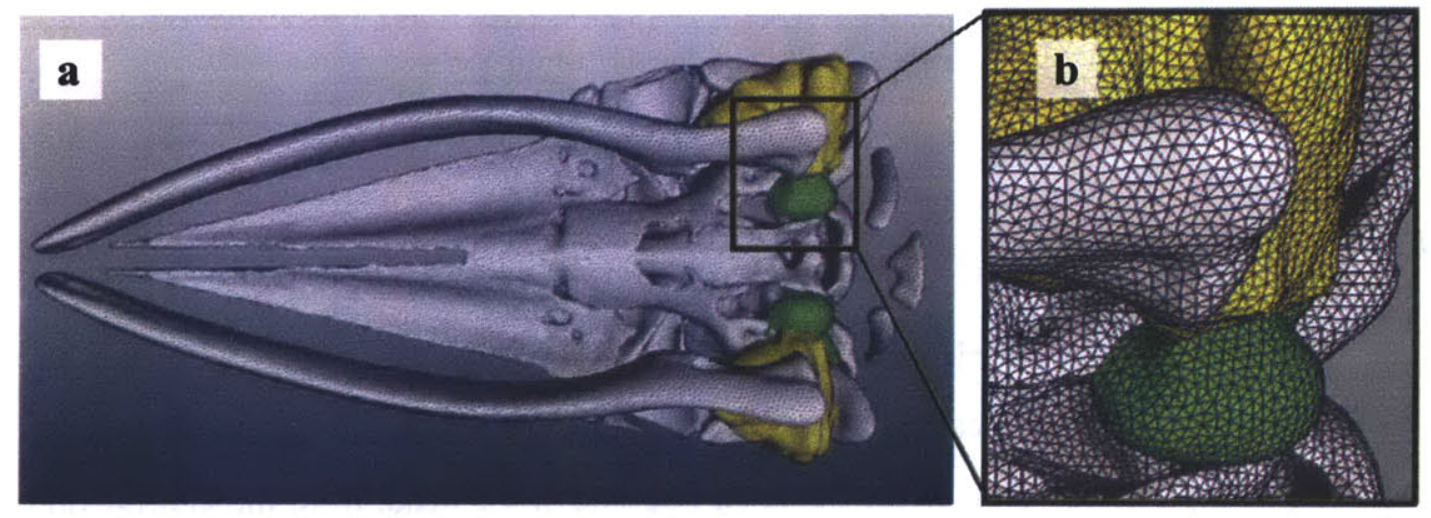

Figure 4.1. a) FEM mesh of minke whale head showing only the skull (grey), ears (green), and ear fat (yellow) for visualization (ventral view). b) Enlarged section of left ear region, showing details and the quality of the tetrahedral mesh.

Another capability of the Solver is the ability to properly deal with the propagation condition at the limits of the computational domain using a technique called the Perfectly Matching Layer (PML), which minimizes reflection artifacts from the outer 
boundary of the model. The program has been benchmarked against analytical solutions and laboratory experiments, showing excellent agreement with these results (Figure 4.2).

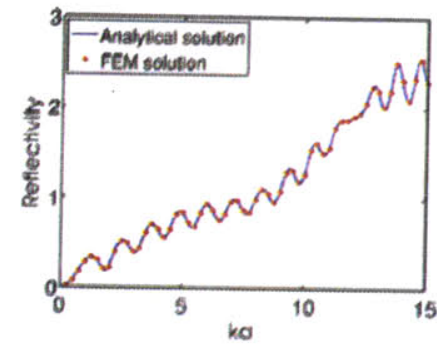

(a)

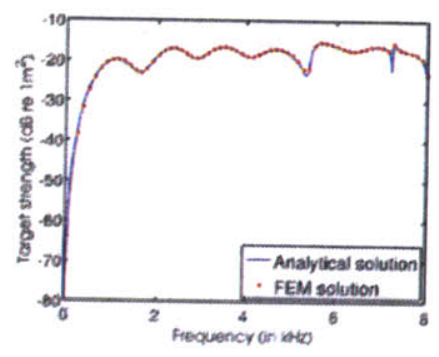

(b)

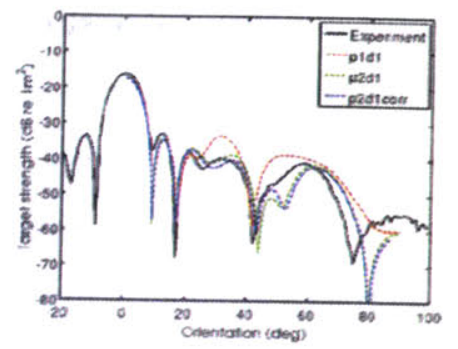

(c)

Figure 4.2. Benchmarking the finite element code against analytical solutions and laboratory measurements. (a) Back-scattering from a sphere with 0.8 contrast in sound speed relative to the medium. (b) Scattering from a solid elastic sphere. (c) Comparison between measurements (black line) and finite element computations (colored lines) of backscattering at $70 \mathrm{kHz}$ from an $8 \mathrm{~cm}$ diameter, $0.19 \mathrm{~cm}$ thick aluminum disk.

\subsubsection{Simulations}

The model was ensonified with a plane wave sound source ranging from $300 \mathrm{~Hz}-$ $10 \mathrm{kHz}$ (Figure 4.3). The location of the sound source was altered for each simulation and was either placed in front of the head, on one side of the head, from the ventral side, or the dorsal side. In addition to the complete, unaltered model, several variations of the model were run to isolate the effect of individual structures and their material properties on the resulting pressure fields. These variations included: a) removal of air spaces (replacing the material property values with those of the surrounding water); b) removal of bony structures, including the skull and the tympano-periotic complex; c) alteration of the material properties of the tympano-periotic complex; d) removal of the ear fat; e) alteration of the material properties of ear fat; $f$ ) immersion of the structures in soft tissue rather than water. Simulation outputs were visualized as the magnitude of the total 
pressure field (sum of the incident field and scattered pressure field) in a customized workspace in ParaView, an open source, multi-platform data analysis and visualization application.

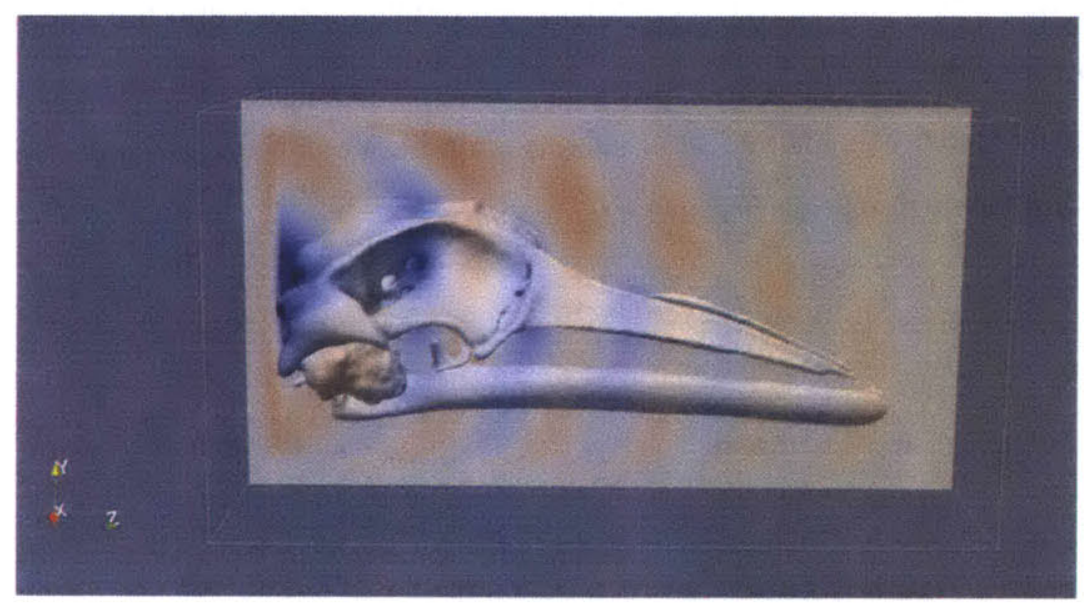

Figure 4.3. A simulation with a $5 \mathrm{kHz}$ plane wave sound source from the front of the animal (right side of page) using the basic, unaltered model. The right lateral view of the whale head's surface, as well as a sagittal slice through the entire domain and PML, is visualized. Red indicates high total pressure magnitude and blue indicates low total pressure magnitude.

\subsection{Results}

\subsubsection{Density of ear fat samples}

The volume measurements from displacement and CT were consistent with each other. However, the CT measurements were much more precise. The density of ear fat samples ranged from $781 \mathrm{~kg} / \mathrm{m}^{3}$ to $1062 \mathrm{~kg} / \mathrm{m}^{3}$ for all samples and from $928 \mathrm{~kg} / \mathrm{m}^{3}$ to $1020 \mathrm{~kg} / \mathrm{m}^{3}$ in the subset of samples for which volume was determined by CT. The mean density value for all samples, including the fibrous regions, was $966 \mathrm{~kg} / \mathrm{m}^{3}(\mathrm{SD}=44)$. 
There was a correlation between calculated density values and the lipid content (\% lipid of total wet weight), which was measured in Chapter 3; the higher the lipid content, the lower the density (Figures 4.4 and 4.5 ). This relationship was particularly clear when looking at only the samples that were CT scanned (Figure 4.5). As expected, there was also a correlation between calculated density values and the average CT number through each sample's volume; the higher the density, the higher the CT number (Figure 4.6). There was also a linear relationship between the CT number of the solid standards and their densities (Figure 4.7).
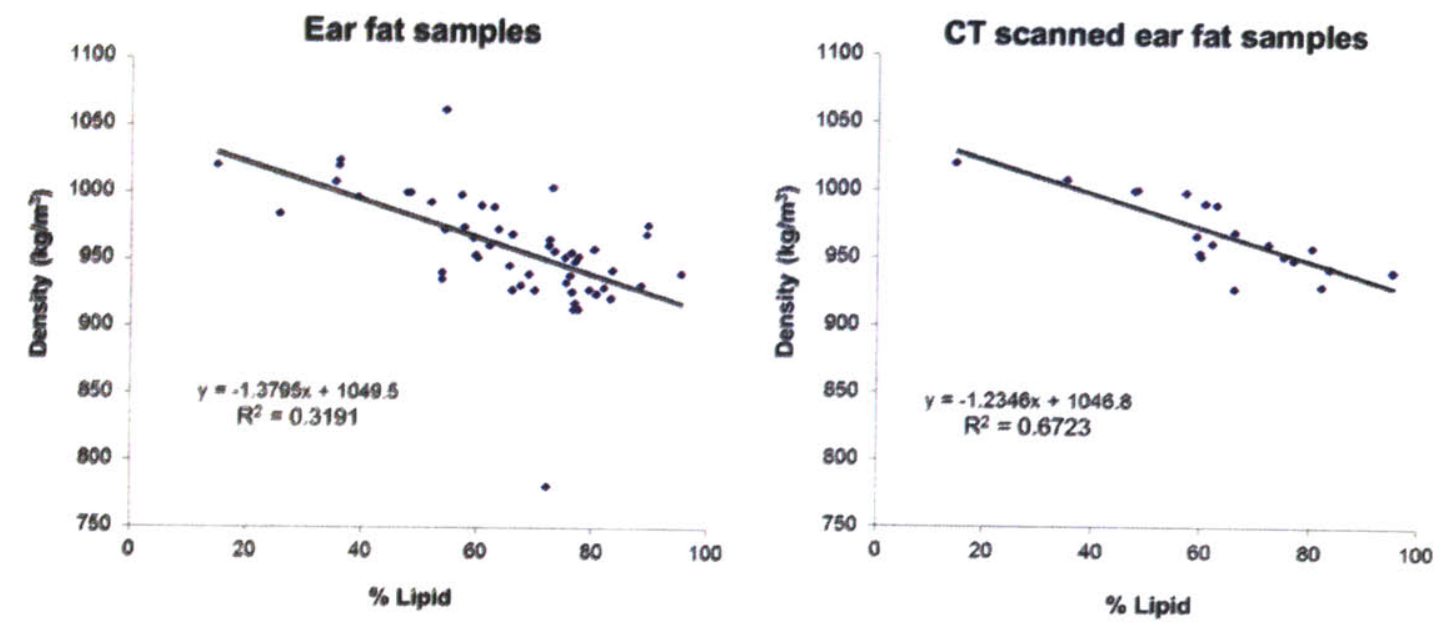

Figure 4.4. Plot of lipid content vs. density for ear fat samples.

Figure 4.5. Plot of lipid content vs. density for ear fat samples, where volumes for density calculations were obtained from CT data. 


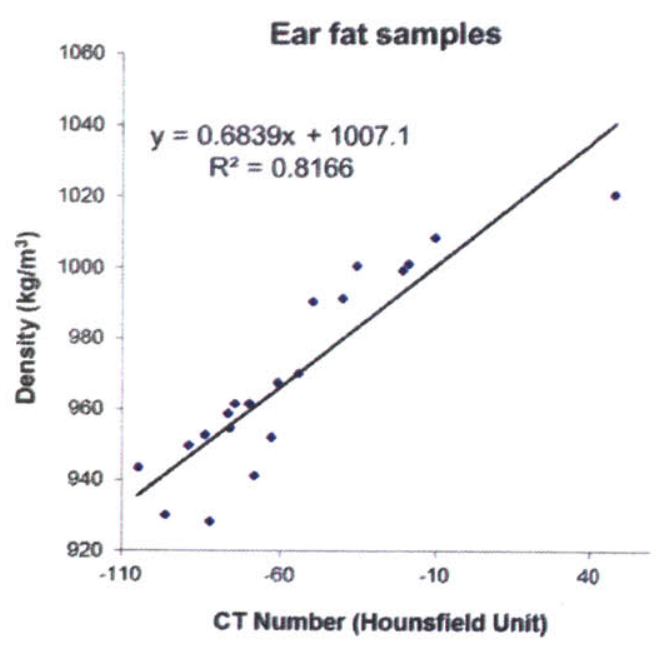

Figure 4.6. Plot of CT number vs. density for CT scanned ear fat samples.

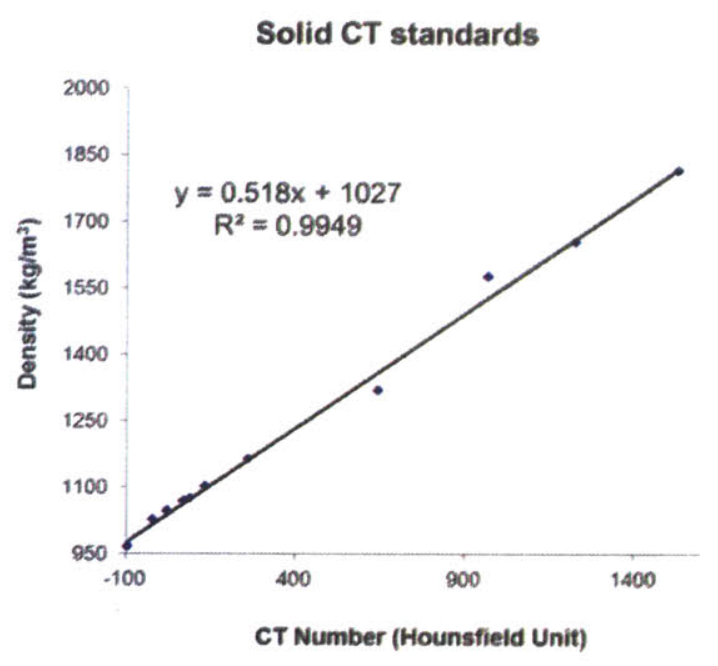

Figure 4.7. Plot of CT number vs. density for solid CT standards.

\subsubsection{The basic model and effect of sound source location}

Figures 4.8 - 4.10 show results of simulations using the basic model, which had material property inputs listed in Table 4.1. In the first set of simulations (Figures 4.84.9), the sound source was placed in front of the head, which is the top of the page in this case. The magnitude of the total pressure field for sound source frequencies of $300 \mathrm{~Hz}, 1$ $\mathrm{kHz}, 2 \mathrm{kHz}, 5 \mathrm{kHz}$, and $10 \mathrm{kHz}$ is shown in Figures 4.8 and 4.9. Figure 4.8 is a visualization of the surface of the whale head seen from the ventral aspect. The surrounding sea water was included in the simulations but is not pictured. Blue indicates a low magnitude of pressure and red indicates a high magnitude of pressure. All figures are on the same standardized color scale.

To provide a better visualization of the total pressure field by the ears, a coronal slice was taken through the whole volume including the sea water (Figure 4.9). These results indicated that there was an area of very low pressure magnitude at the ears, likely 
caused by the small air space within the middle ear. This effect dominated the pressure field at the lower frequencies of $300 \mathrm{~Hz}-2 \mathrm{kHz}$. At higher frequencies, a region of very high pressure magnitude developed adjacent to the low pressure area by the ears.

Structures in the ear could harness such difference in pressures to drive pressure-induced motions in the cochlea.

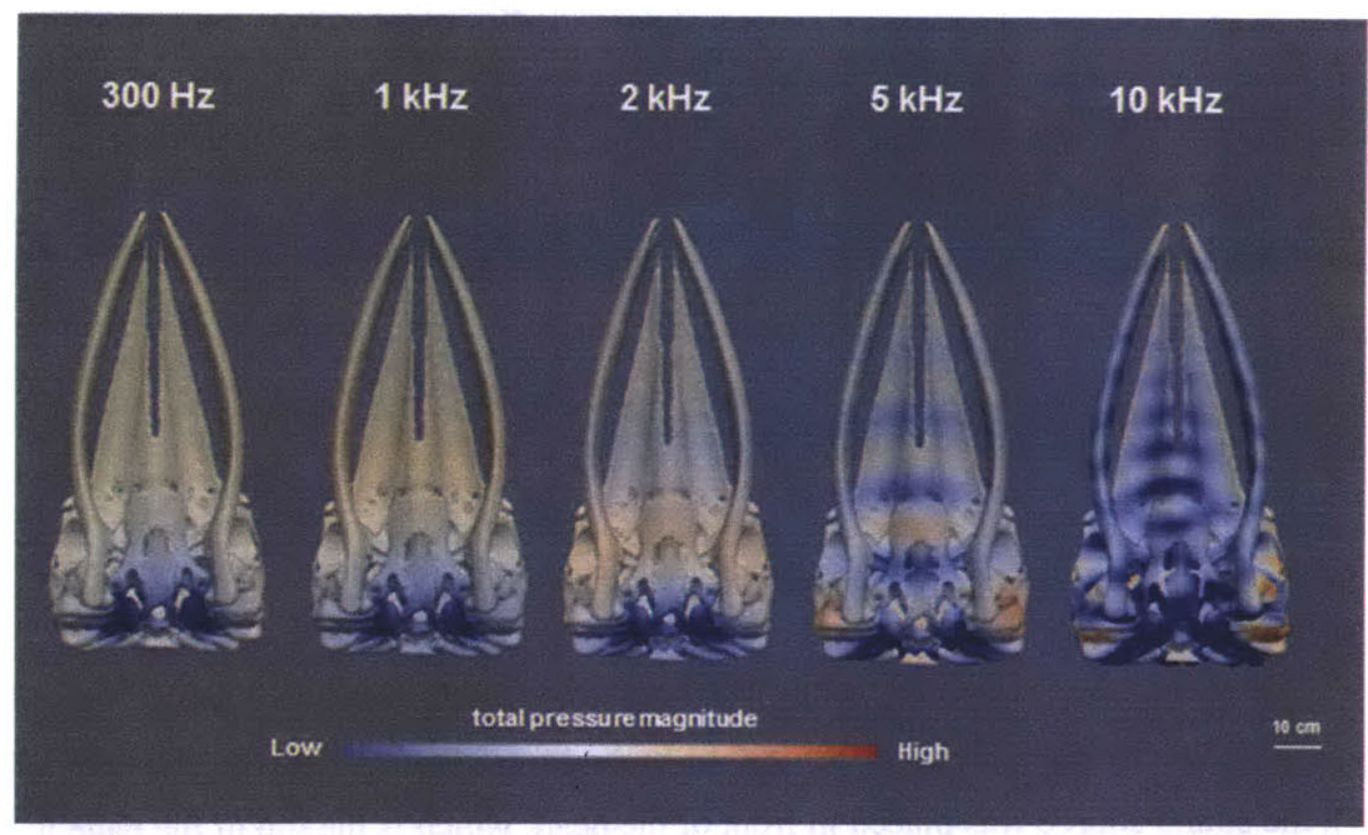

Figure 4.8. Ventral surface views of the total pressure magnitude for the basic, unaltered model ensonified with a plane wave sound source in front of the animal (top of the page). Sea water was present in the model, but not included in the visualization. Red indicates high total pressure magnitude and blue indicates low total pressure magnitude. 


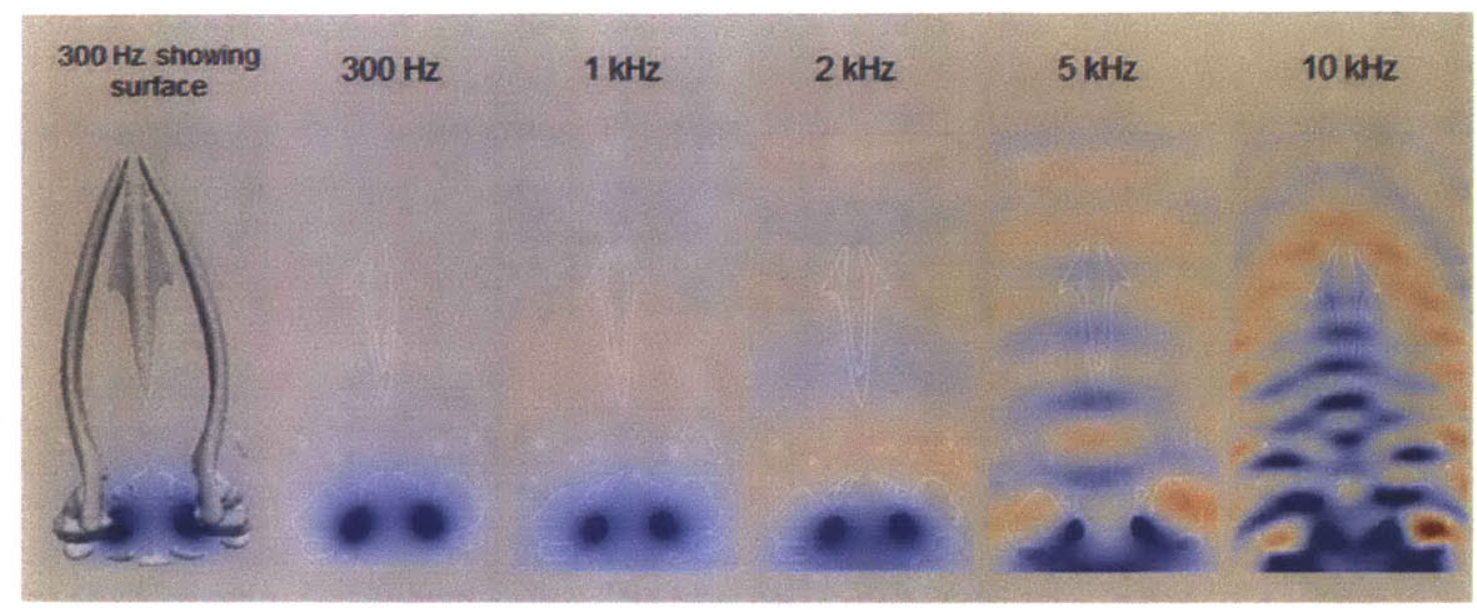

Figure 4.9. Ventral views of the total pressure magnitude for the basic, unaltered model ensonified with a plane wave sound source in front of the animal (top of the page). The leftmost panel shows the surface of the whale head with a coronal slice through the tympano-periotic complex and ear fats. In the subsequent panels, the surface view has been removed to show the total pressure field for the domain in the equivalent position.

Next, the basic model described above was used for simulations in which the sound source was moved to the right of the head (left side of the page), to the dorsal side, and to the ventral side of the head. The results (Figure 4.10) indicated that the sound source location did not greatly affect the resulting pressure fields at frequencies below 2 kHz. However, the sound source location had a large effect at higher frequencies. For example, the simulation with the 5 and $10 \mathrm{kHz}$ sound source from the right showed that the right ear (left side of the page) would experience much greater pressure fluctuations than the left ear. Sound sources placed ventral to the head resulted in much higher magnitudes of pressure compared to sound sources placed dorsally. The slightly asymmetric patterns seen in the dorsal and ventral models were likely because of the head being placed somewhat off-center within the volume. Overall, sound sources placed in front of the head and on the ventral side of the head were most effective at creating areas of high pressure magnitude at both ears. 


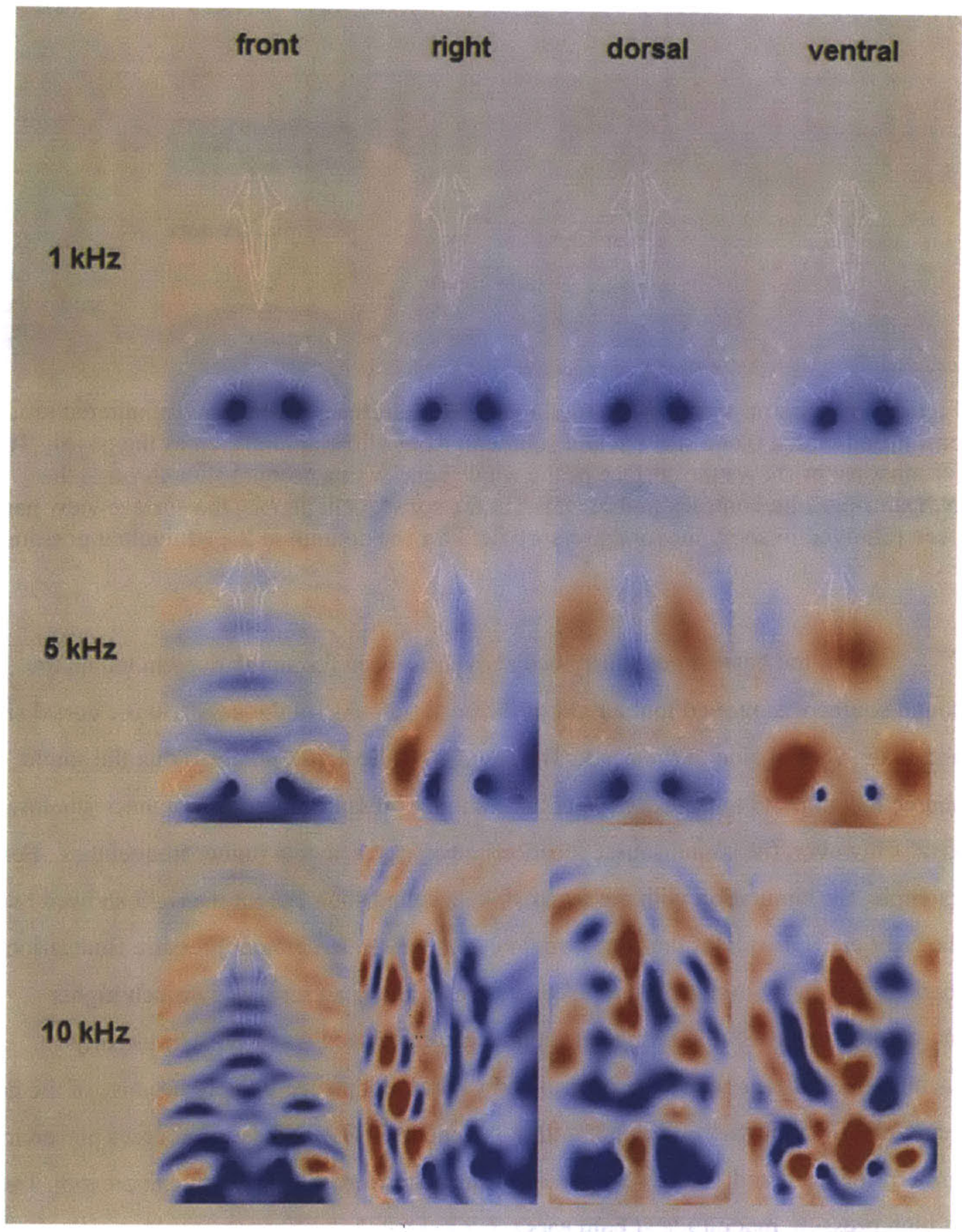

Figure 4.10. Coronal slices through the domain at equivalent positions as Figure 4.9 (ventral view). The sound source locations and frequencies were altered in each simulation. Red indicates high total pressure magnitude and blue indicates low total pressure magnitude. 


\subsubsection{The effect of air spaces}

Figure 4.11 shows simulations from models that did not include air in the middle ear space. As expected, there was a major difference in the resulting pressure field for lower frequencies compared to the unaltered models. Without air, the low-pressure region near the ears was greatly reduced. However, there was still a region of slightly lower pressure magnitude at the ears. At higher frequencies, there were only minor differences between the two models.

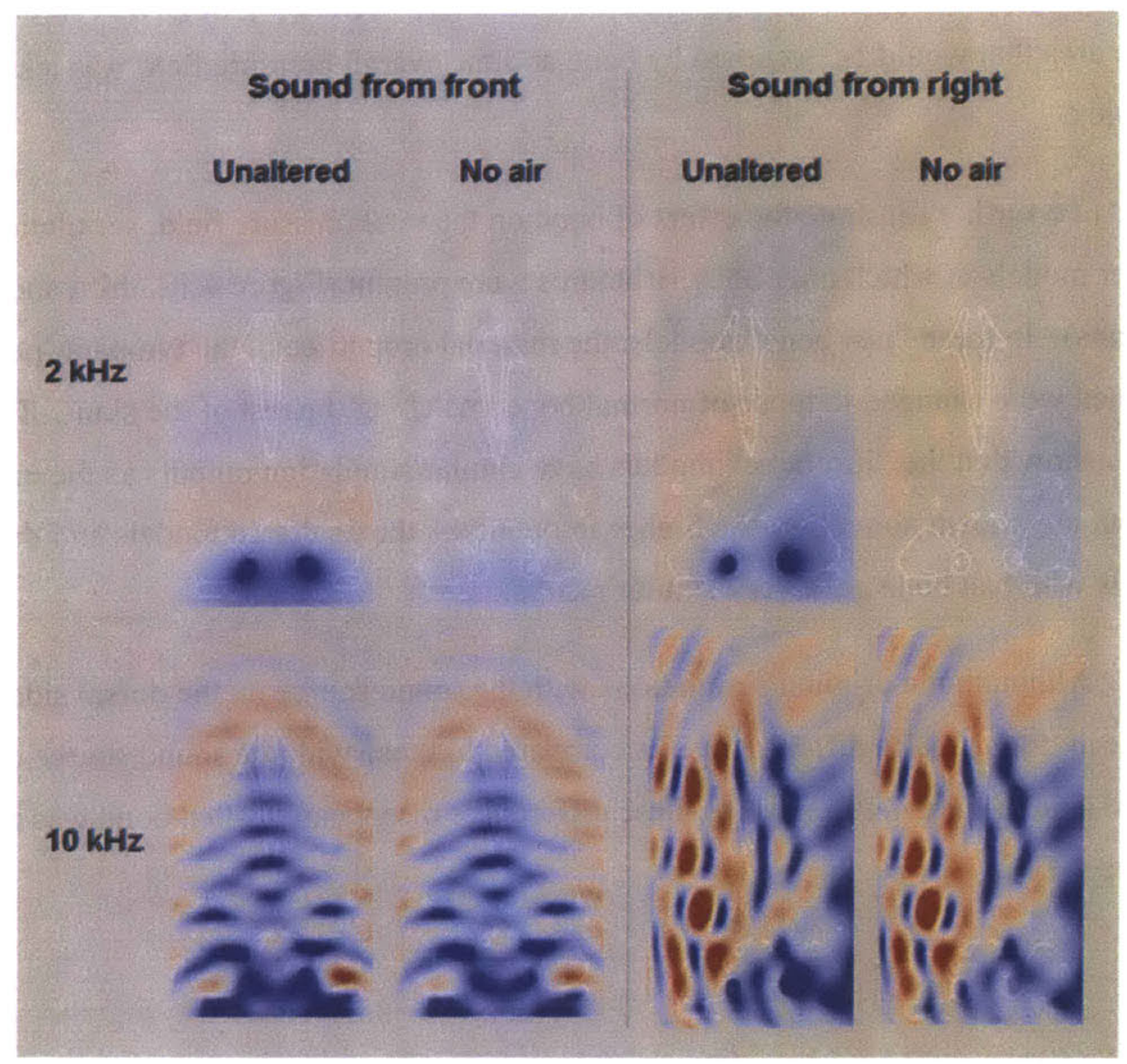

Figure 4.11. Comparisons between the basic, unaltered models and models in which air spaces were removed. Red indicates high total pressure magnitude and blue indicates low total pressure magnitude. 


\subsubsection{The effect of bony structures}

Figure 4.12 compares the unaltered models with the models in which all bony structures, including the skull and tympano-periotic complex, were removed, as well as models that included just bone. The simulations run with lower frequencies (below 2 $\mathrm{kHz}$ ) were not strongly affected by the lack of bone, except that the region of low pressure magnitude extended over a larger area around the air space when bone was removed. In contrast, the simulations with higher frequencies produced dramatically different results when bones were removed. There were generally higher total pressures in the area that would be occupied by bone and the overall pressure field was less complex.

To further illustrate the effect of bone on the total pressure field, simulations were run for models in which only bony structures were present (Figure 4.12 , third and sixth columns). In these "just bone" models, the material properties of the tympano-periotic complex were changed to those of normal bone, matching the rest of the skull. The results show that the "just bone" models have similar simulation outputs as the models without air, shown above. At the higher frequencies, the unaltered models and the models with just bone gave very similar results.

Although the original simulations with the sound source on the dorsal side produced dramatically different results compared to those with the sound source on the ventral side (Figure 4.10), most of these differences disappeared when bone was removed (Figure 4.13). 


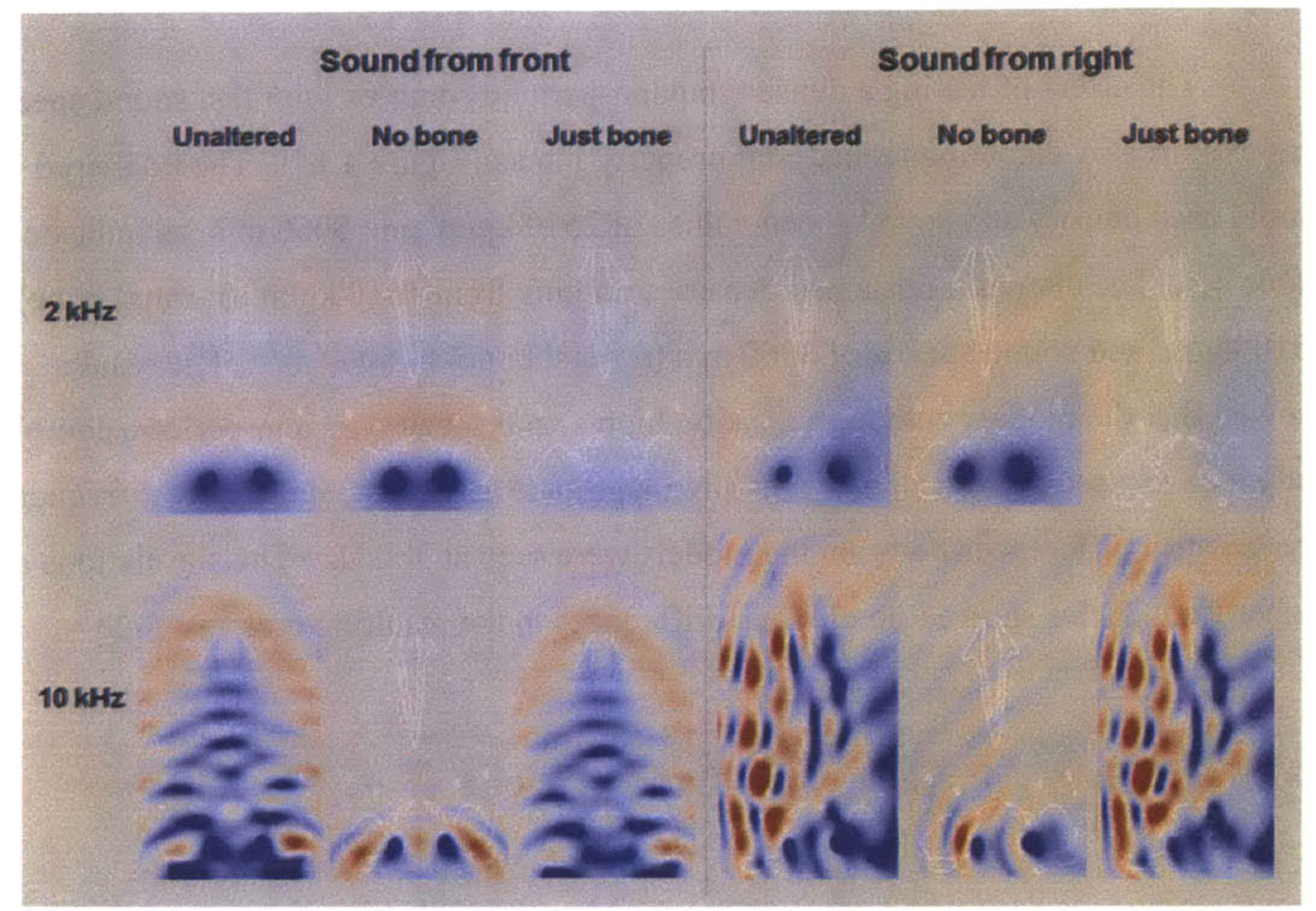

Figure 4.12. Comparisons between the basic, unaltered models and models in which bones and tympano-periotic complexes were removed, as well as models consisting of only bony structures. Red indicates high total pressure magnitude and blue indicates low total pressure magnitude.

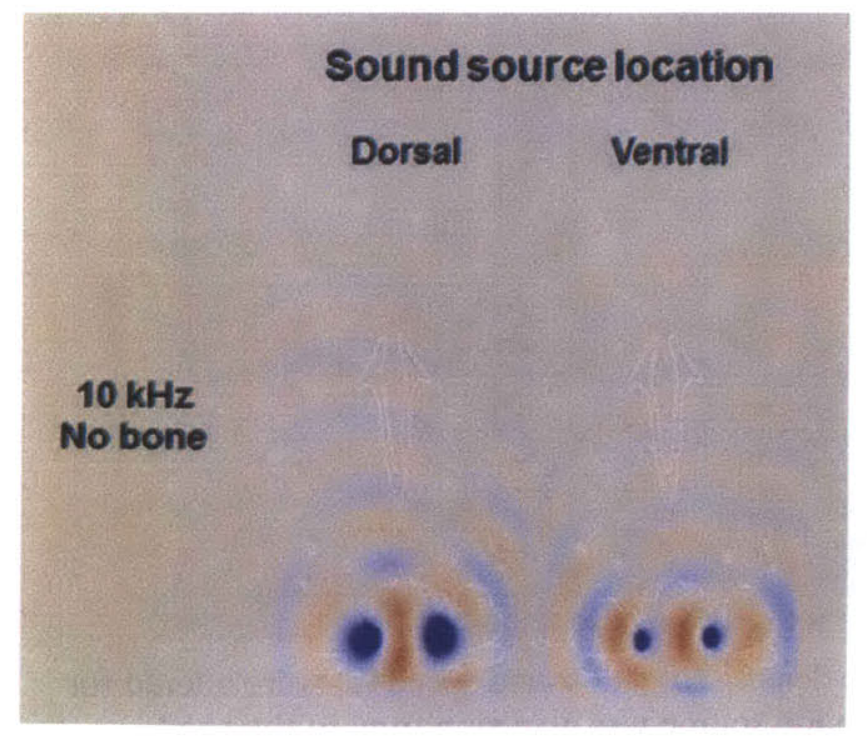

Figure 4.13. Simulation outputs for models in which bony structures, including the tympano-periotic complex, were removed. A $10 \mathrm{kHz}$ sound source was placed on the dorsal or ventral side of the head. Red indicates high total pressure magnitude and blue indicates low total pressure magnitude. 
The effect of having a dense tympano-periotic complex with fast sound speeds was explored by changing its material property inputs (Figure 4.14). The unaltered model used density and sound speed values of $2510 \mathrm{~kg} / \mathrm{m}^{3}$ and $5060 \mathrm{~m} / \mathrm{s}$, as indicated in Table 4.1. The altered models had densities ranging from $1610 \mathrm{~kg} / \mathrm{m}^{3}$ (normal bone) to $3510 \mathrm{~kg} / \mathrm{m}^{3}$ and sound speeds of $3060 \mathrm{~m} / \mathrm{s}$ (normal bone) to $6060 \mathrm{~m} / \mathrm{s}$. The results showed that the models with high density, high sound speed tympano-periotic complexes had more focused regions of low pressure magnitude at the ears at the lowest frequencies. The greatest differences between the models were seen at $300 \mathrm{~Hz}$. The simulations at higher frequencies showed no obvious differences in the resulting pressure field.

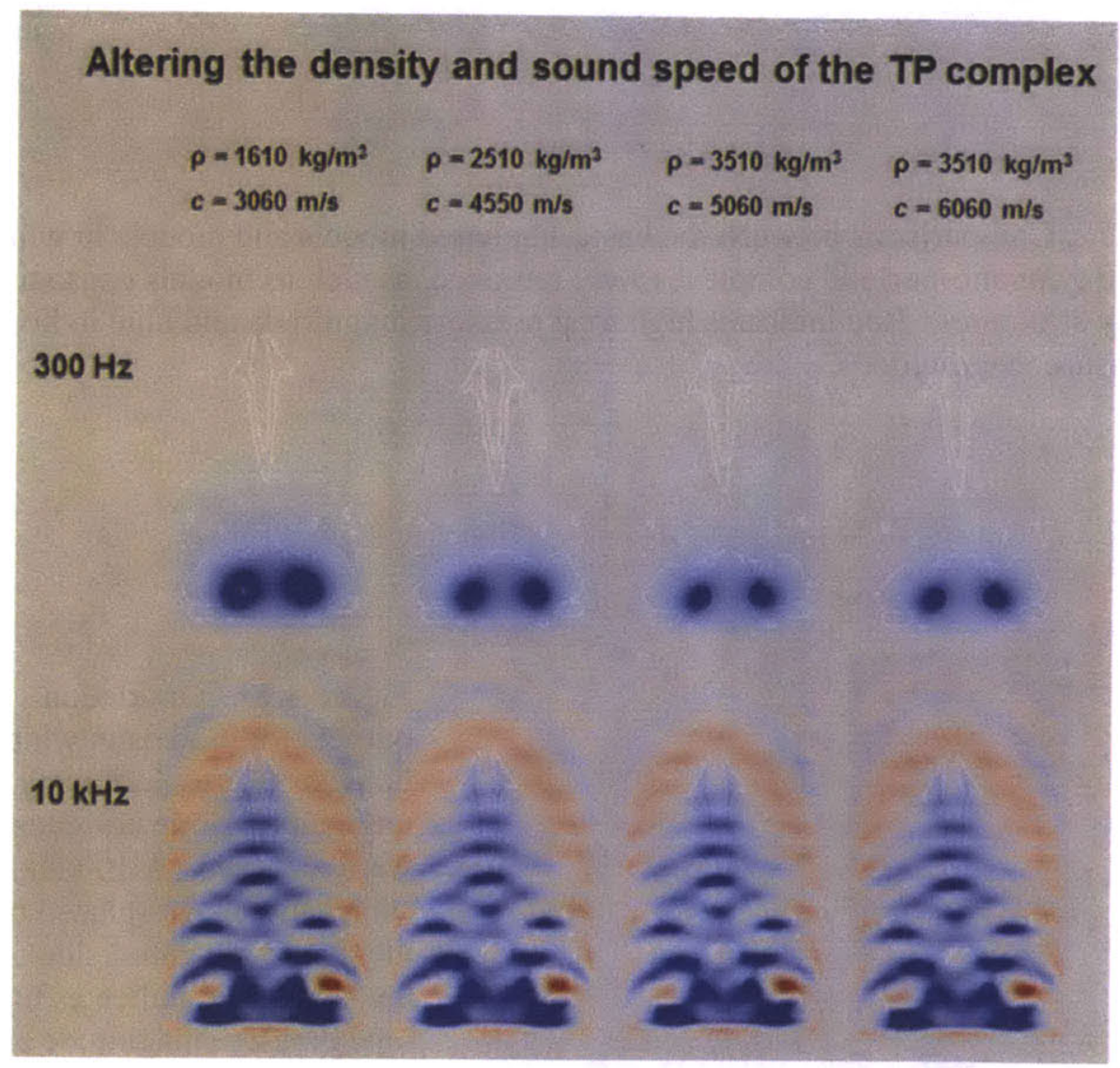

Figure 4.14. Simulations in which the density $(\rho)$ and sound speed (c) were altered for the tympano-periotic complex. The sound source was placed in front of the head. 


\subsubsection{The role of ear fat}

In the unaltered simulations, the ear fat had a density of $970 \mathrm{~kg} / \mathrm{m}^{3}$, which was the average measured density of our ear fat samples (including the more fibrous regions), and a sound speed of $1430 \mathrm{~m} / \mathrm{s}$, which is the published in-vivo value for pig fat (Duck, 1990). To understand the potential role of the ear fat, these material properties were changed to match those of muscle $\left(1040 \mathrm{~kg} / \mathrm{m}^{3}\right.$ and $\left.1600 \mathrm{~m} / \mathrm{s}\right)$, water $\left(1030 \mathrm{~kg} / \mathrm{m}^{3}\right.$ and $\left.1500 \mathrm{~m} / \mathrm{s}\right)$, and fats with lower densities and sound speeds $\left(900 \mathrm{~kg} / \mathrm{m}^{3}\right.$ and $\left.1300 \mathrm{~m} / \mathrm{s}\right)$. Although the latter values may be unlikely for the mysticete ear fat, they have been found in other fatty tissues including the odontocete acoustic fats. Duck (1990) states that the density of adipose tissue is $916 \mathrm{~kg} / \mathrm{m} 3$ and Soldevilla et al. (2005) reported that the density of a neonate beaked whale perimandibular fats is $890 \mathrm{~kg} / \mathrm{m}^{3}$. Although the range of sound speeds for typical mammalian fats at physiological temperatures is $1412-1471 \mathrm{~m} / \mathrm{s}$, there are published values of $975-1225 \mathrm{~m} / \mathrm{s}$ for subcutaneous canine fat (Duck, 1990). Solevilla et al. (2005) reported that the perimandibular fats of the neonate beaked whale had a sound speed of $1350 \mathrm{~m} / \mathrm{s}$ at $37^{\circ} \mathrm{C}$, and sound speeds as low as $1273 \mathrm{~m} / \mathrm{s}$ has been reported through lipids from the central core of the odontocete fatty melon (Norris and Harvey, 1974).

The results indicated that there was a slight increase in total pressure magnitude at the ear fats when the sound speed and density of the ear fats were progressively reduced from values matching muscle to odontocete-like fats. These effects were visible for the simulations above $2 \mathrm{kHz}$. This trend was minor for the simulations in which the sound source was placed in front of the head (Figure 4.15), but was very clear for simulations in which the sound source was placed to the right (Figure 4.16) or on the ventral side of the head (Figure 4.17). One exception was the $10 \mathrm{kHz}$ simulation from the ventral side, where there was a slightly larger area of high total pressure magnitude by the ears when the ear fat material properties were matched with muscle (Figure 4.17).

For the $5 \mathrm{kHz}$ ventral simulations, the presence of ear fat as originally modeled resulted in a $7 \%$ increase in total pressure magnitude at the ear fat compared to 
simulations in which the ear fats were removed. The difference in total pressure magnitude between models with ear fat composed of muscle vs. the unaltered model was $13 \%$. When the ear fat was changed from muscle to odontocete-like fats, there was a $31 \%$ increase in total pressure magnitude.

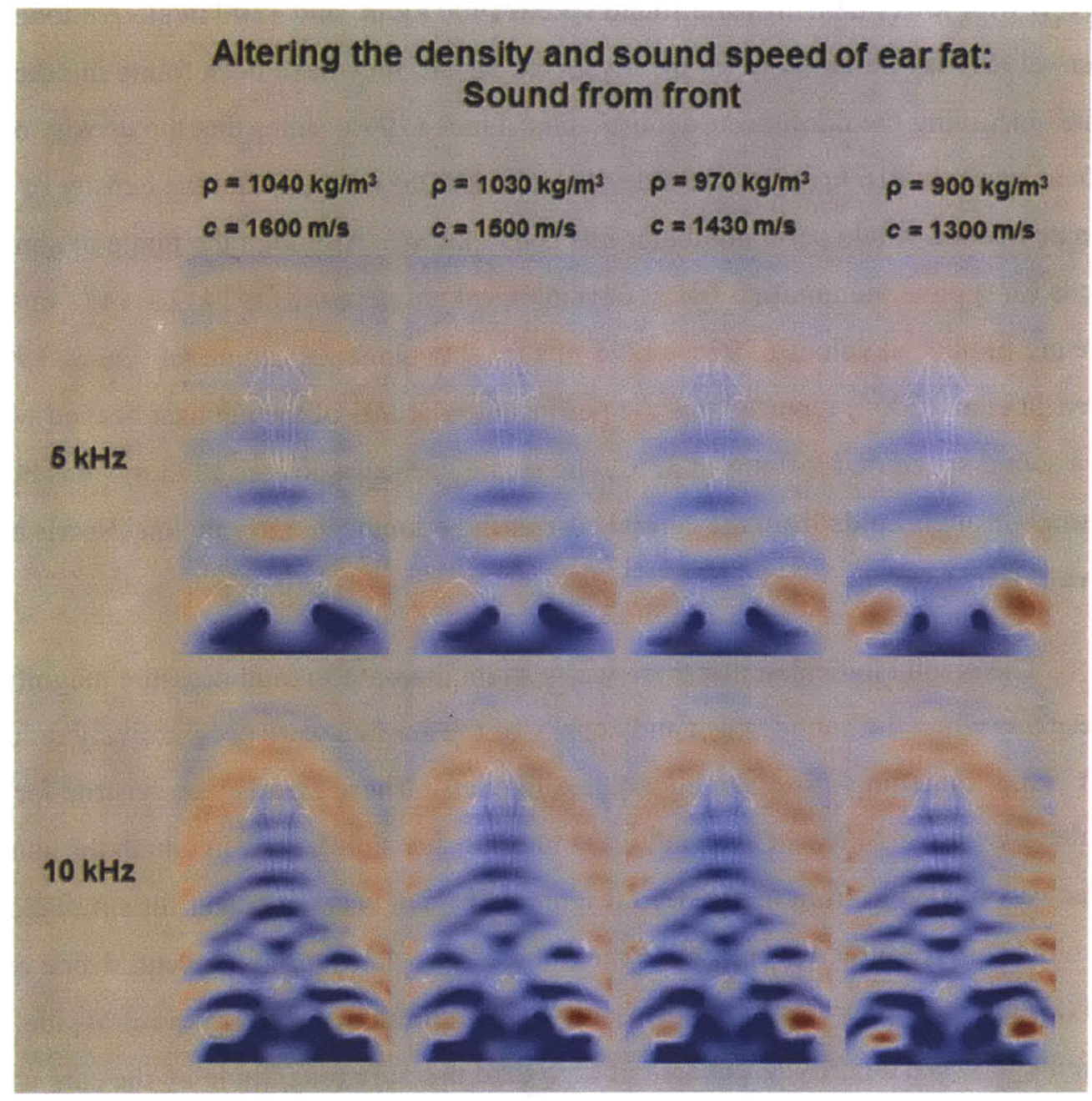

Figure 4.15. Simulations in which the density ( $\rho$ ) and sound speed (c) were altered for the ear fat. The sound source was placed in front of the head. Red indicates high total pressure magnitude and blue indicates low total pressure magnitude. 


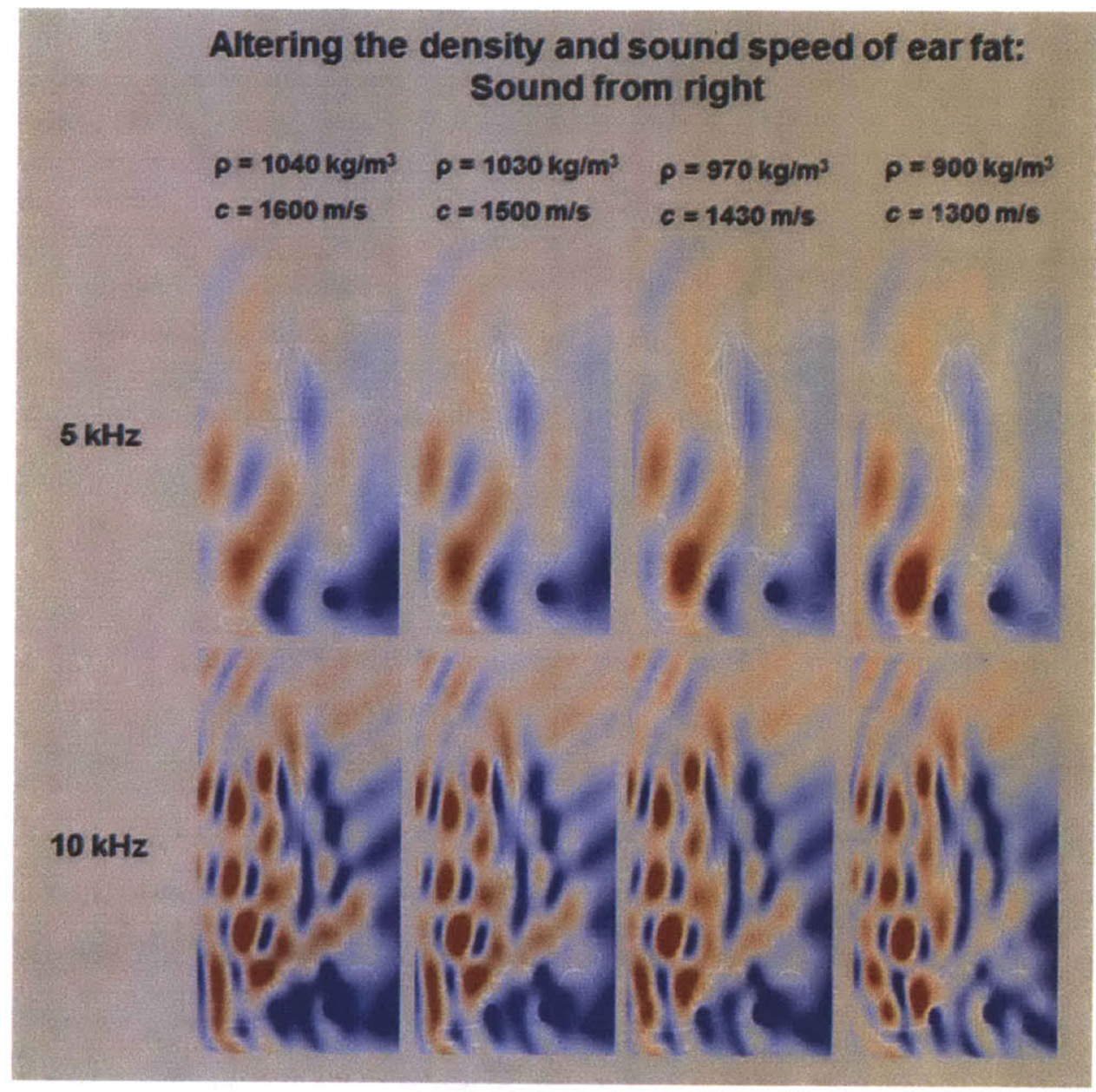

Figure 4.16. Simulations in which the density $(\rho)$ and sound speed (c) were altered for the ear fat. The sound source was placed to the right of the head (left side of the page). Red indicates high total pressure magnitude and blue indicates low total pressure magnitude. 


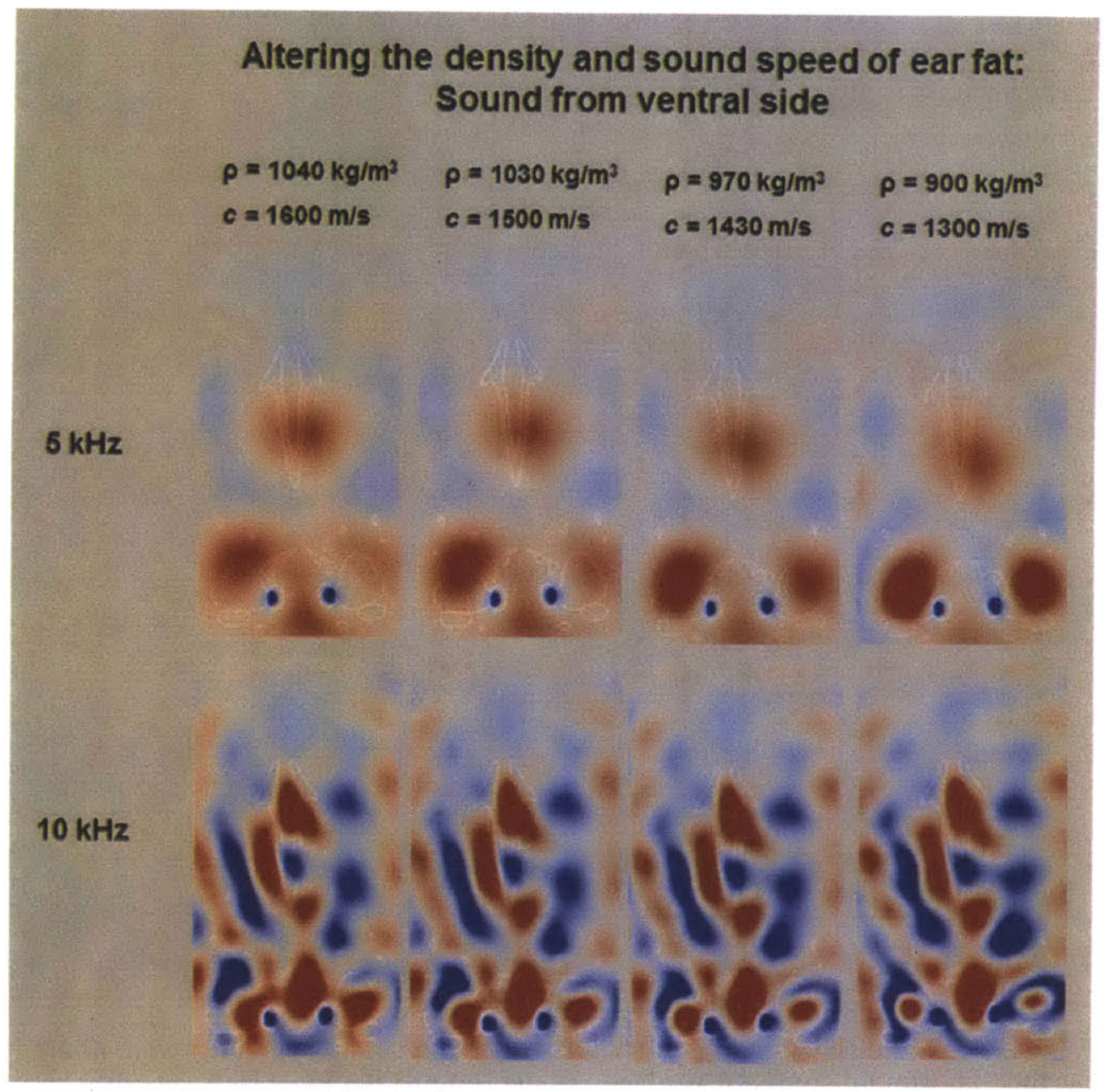

Figure 4.17. Simulations in which the density $(\rho)$ and sound speed (c) were altered for the ear fat. The sound source was placed on the ventral side of the head. Red indicates high total pressure magnitude and blue indicates low total pressure magnitude. 
The unaltered simulations indicated that regions of high total pressure magnitude did not develop at the ear fats when the sound source was placed on the dorsal side of the head (Figure 4.10). However, at $5 \mathrm{kHz}$, it appeared that the ear fats experienced a slightly higher total pressure magnitude when their sound speed and density were reduced (Figure 4.18). Such differences were not noticeable for $10 \mathrm{kHz}$ simulations.

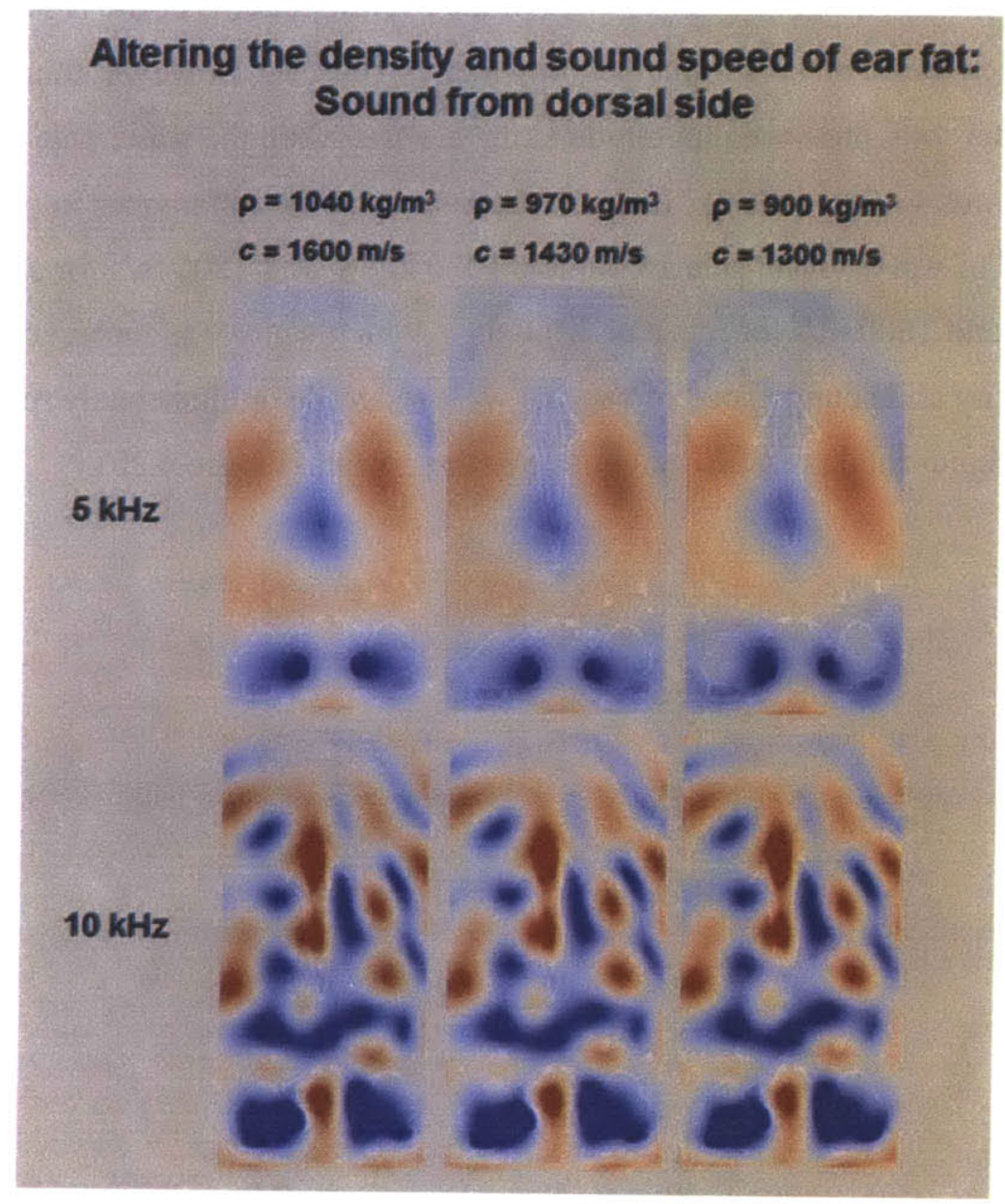

Figure 4.18. Simulations in which the density $(\rho)$ and sound speed (c) were altered for the ear fat. The sound source was placed on the dorsal side of the head. Red indicates high total pressure magnitude and blue indicates low total pressure magnitude. 


\subsubsection{Immersing the head in soft tissues}

In the above models, the bones, ears, air spaces, and ear fats were immersed in sea water and the rest of the soft tissues were lumped with the surrounding sea water. We also modeled the other extreme of replacing this surrounding water with muscle, which may be a closer approximation of how sound would behave once it was inside the head (Figure 4.19). There was little difference in the overall patterns of the resulting pressure fields between the structures immersed in water vs. muscle. However, there was a slightly higher total pressure magnitude at the ear fats when the water was replaced with muscle (Figures 4.19 and 4.20). It should be noted that the differences in density and sound speed of water vs. muscle are minor: $1030 \mathrm{~kg} / \mathrm{m}^{3}$ and $1500 \mathrm{~m} / \mathrm{s}$ for sea water, and $1040 \mathrm{~kg} / \mathrm{m}^{3}$ and $1600 \mathrm{~m} / \mathrm{s}$ for muscle. Models in which water was replaced with muscle and the density and sound speed of ear fats were reduced simultaneously resulted in a noticeably higher total pressure magnitude at the ear fats (Figure 4.20). 


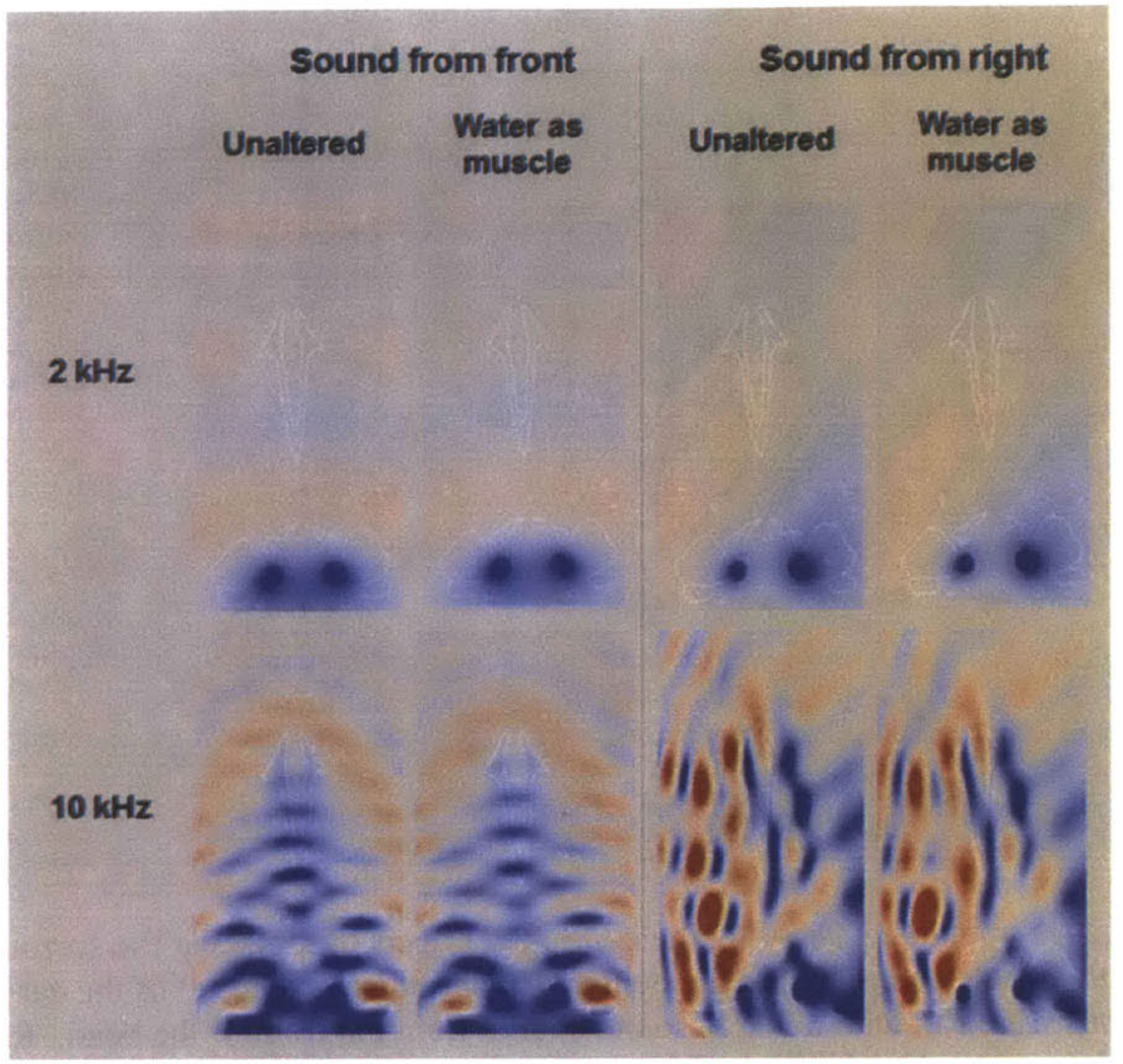

Figure 4.19. Comparisons between the basic, unaltered models and models in which the surrounding water was replaced with muscle. Red indicates high total pressure magnitude and blue indicates low total pressure magnitude. 


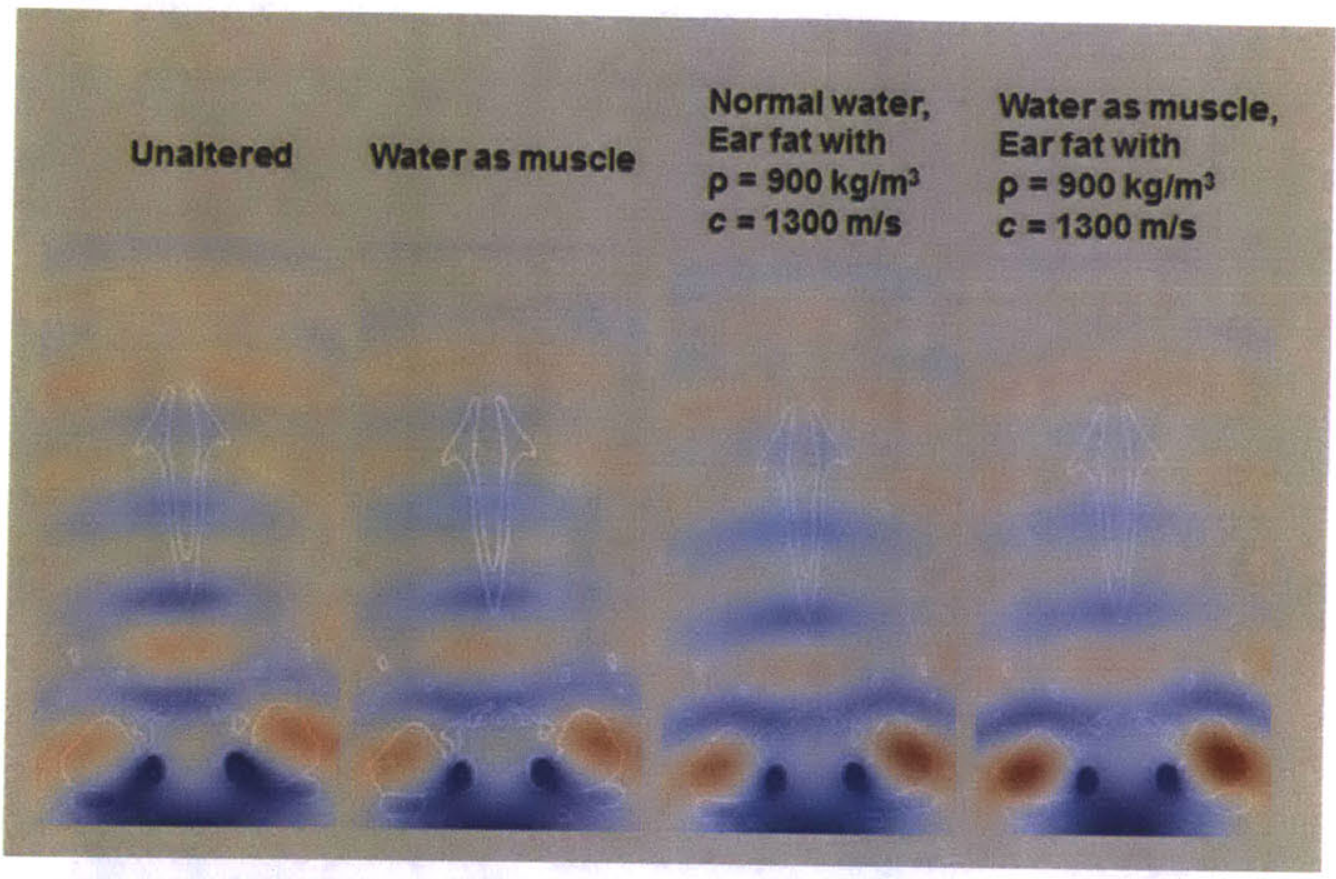

Figure 4.20. Simulations showing the combined effects of replacing the surrounding water with muscle and reducing the density $(\rho)$ and sound speed (c) of the ear fat. The simulations were run with a $5 \mathrm{kHz}$ sound source from the front of the head. Red indicates high total pressure magnitude and blue indicates low total pressure magnitude.

\subsection{Discussion}

\subsubsection{Density of ear fat samples}

The average density of the ear fat samples, $967 \mathrm{~kg} / \mathrm{m}^{3}$, is slightly higher than the reported density for animal fat, $916 \mathrm{~kg} / \mathrm{m}^{3}$ to $950 \mathrm{~kg} / \mathrm{m}^{3}$ (Duck, 1990; Mast, 2000), and previously reported values for acoustic fats. Soldevilla et al. (2005) found a very low average density of $890 \mathrm{~kg} / \mathrm{m}^{3}$ for the perimandibular fat bodies and $937 \mathrm{~kg} / \mathrm{m}^{3}$ for the melon tissue in a neonate beaked whale. Varanasi et al. (1975) reported that the density of extracted melon lipids was between $900-930 \mathrm{~kg} / \mathrm{m}^{3}$ in the spotted dolphin (Stenella attenuata). It should be noted that the density of the whole tissue are likely higher than 
the extracted lipids because the tissue includes structural components, which are denser than the pure lipid. Accordingly, the higher average density value for the ear fats may be because of the inclusion of fibrous regions representing the transition to the fibrous attachment to the squamosal bone, as well as the mandible. In fact, the regions of the ear fat with higher lipid contents had lower densities (Figures 4.4 and 4.5).

There was a linear relationship between CT number and density of the tissues, which is consistent with assumptions and measurements from previous works (Aroyan, 2001; Soldevilla et al., 2005). However, each study arrived at a different best fit equation for describing this linear relationship (Table 4.2). Our finding that the linear slope of the solid samples is smaller than the slope for the ear fat is consistent with Henson et al.'s (1987) finding that two separate regressions are necessary for describing the CT number vs. density relationship of soft tissue and bone, and that the slope of the line for soft tissues is steeper.

In some previous studies, these best fit equations have been used to derive densities of tissues based on CT number (e.g., Krysl et al., 2006) or to indirectly derive sound speeds based on Hounsfield Units (e.g., Aroyan, 2001). Therefore, each equation was used to derive the density for theoretical samples with various CT numbers (Table 4.2). Based on the resulting values, it appears that soft tissues with low CT numbers will result in relatively similar densities. However, bony structures with higher CT numbers will have more varied results. For example, tissues with a CT number of $1500 \mathrm{HU}$ will have an estimated density of $1804 \mathrm{~kg} / \mathrm{m}^{3}$ according to our equation from the solid standards, whereas the same sample will have an estimated density of $2527 \mathrm{~kg} / \mathrm{m}^{3}$ if the equation from Soldevilla et al. (2005) is used. These differences may be caused by the calibration and settings used on the CT device as well as the tissue type. Because samples with similar densities can have very different CT numbers, conversions from CT number to estimates of density should be conducted with caution. While large differences in material property values have little effect in some simulations, they can result in noticeably different results under some circumstances (discussed below). 
Table 4.2. CT number to density conversions based on data from different studies.

\begin{tabular}{|l|l|l|l|l|}
\hline Study & $\begin{array}{l}\text { Best fit equation } \\
\text { (for density in } \mathbf{k g} / \mathrm{m}^{3} \text { ) }\end{array}$ & $\begin{array}{l}\text { Density if } \\
\mathbf{H U}=-\mathbf{1 0 0}\end{array}$ & $\begin{array}{l}\text { Density if } \\
\mathbf{H U}=\mathbf{1 0 0 0}\end{array}$ & $\begin{array}{l}\text { Density if } \\
\mathbf{H U}=\mathbf{1 5 0 0}\end{array}$ \\
\hline $\begin{array}{l}\text { Our study: } \\
\text { solids }\end{array}$ & Density $=0.518 \mathrm{HU}+1027$ & $975.2 \mathrm{~kg} / \mathrm{m}^{3}$ & $1545 \mathrm{~kg} / \mathrm{m}^{3}$ & $1804 \mathrm{~kg} / \mathrm{m}^{3}$ \\
\hline $\begin{array}{l}\text { Our study: } \\
\text { ear fat }\end{array}$ & Density $=0.684 \mathrm{HU}+1007$ & $938.6 \mathrm{~kg} / \mathrm{m}^{3}$ & $1691 \mathrm{~kg} / \mathrm{m}^{3}$ & $2033 \mathrm{~kg} / \mathrm{m}^{3}$ \\
\hline $\begin{array}{l}\text { Aroyan } \\
(2001)^{*}\end{array}$ & Density $=0.835 \mathrm{HU}+1000$ & $916.5 \mathrm{~kg} / \mathrm{m}^{3}$ & $1835 \mathrm{~kg} / \mathrm{m}^{3}$ & $2253 \mathrm{~kg} / \mathrm{m}^{3}$ \\
\hline $\begin{array}{l}\text { Soldevilla } \\
\text { et al. (2005) }\end{array}$ & Density $=1.000 \mathrm{HU}+1027$ & $926.5 \mathrm{~kg} / \mathrm{m}^{3}$ & $2027 \mathrm{~kg} / \mathrm{m}^{3}$ & $2527 \mathrm{~kg} / \mathrm{m}^{3}$ \\
\hline
\end{tabular}

*Best fit equation estimated from given data.

\subsubsection{Simulations}

Our simulations showed that the finite element method is a promising approach for understanding hearing mechanisms in the minke whale. Our relatively simple model is a first step towards understanding both the composite and isolated effects of the various structures found within the head. The model also allowed us to perform "virtual experiments" (Cranford et al., 2008) by altering sound source frequencies and locations while introducing structural and material differences.

In each simulation except when the sound source was placed dorsally, total pressure magnitudes at the ear fats were much higher than pressure levels inside of the tympano-periotic complex. Structures in the ear could potentially harness such differences in pressure to induce pressure-driven motions in the cochlea. For a given sound source condition (source frequency and location), higher total pressure levels adjacent to the ears could lead to more favorable conditions for hearing. However, Figure 4.9 should not be interpreted to mean that the minke whale hears better at $10 \mathrm{kHz}$ than at $300 \mathrm{~Hz}$ because the model did not include middle and inner ear structures, which are critical for determining frequency sensitivity. 
The patterns in total pressure magnitude for lower frequencies were primarily driven by the small amount of air within the middle ear. The air produced a region of very low pressure magnitude, perhaps from the pressure-release effect of the air space (Aroyan, 2001). While water is not very compressible, air is highly compressible and may act to relieve pressures in the air space. However, the effects of bony structures were greater than the effects of air spaces for higher frequency simulations (Figures 4.114.12).

The bony structures were important for creating a sound shadow effect at the higher frequencies. Figure 4.10 shows that the location of the sound source had a strong effect on the resulting pressure fields for frequencies above $5 \mathrm{kHz}$. In contrast, the results from simulations with sound sources from the dorsal side and the ventral side were much more similar when the bones were removed (Figure 4.13).

The differences in pressure (and intensity) caused by variations in sound source location may provide localization cues for vocalizations of conspecifics or predators; minke whale vocalizations span from $50 \mathrm{~Hz}-9.4 \mathrm{kHz}$ (Edds, 1997; Mellinger et al., 2000; Gedamke et al., 2001) and killer whale vocalizations range from approximately $100 \mathrm{~Hz}-60 \mathrm{kHz}$ (Wartzok and Ketten, 1999; Au et al., 2004). The mechanism for localizing lower frequency sounds below $5 \mathrm{kHz}$ is unclear from our modeling results, but may involve binaural time or phase differences. According to Heffner and Heffner (1992), binaural phase differences are physiologically useful when the frequency is below $1 /$ [ $6(a / C) \sin \theta]$ where $a=$ radius of the head, $C=$ speed of sound, and $\theta=$ angle of the sound source from the animal's midline. If $a=25 \mathrm{~cm}$ for a small minke whale head such as ours, $C=1500 \mathrm{~m} / \mathrm{s}$, and $\Theta=30$ degrees, this frequency cutoff would be at $2 \mathrm{kHz}$.

The tympano-periotic complexes of cetaceans are composed of particularly dense bones with higher sound speeds than other types of bone, excluding some tooth material (Lees et al., 1983; Lees et al., 1996). Lees et al. (1996) speculated that the high density, high sound speed, and consequently high specific acoustic impedance of the tympanoperiotic complex helps to isolate the cochlea from "body noise" by increasing the 
acoustical contrast with soft tissues and the rest of the skull. We investigated the effects of altering the density and sound speed of the tympano-periotic complex in our models (Figure 4.14). Our results indicate that a higher density, higher sound speed tympanoperiotic complex could potentially help to isolate the ears at lower frequencies, focusing the effect of the air space to a smaller region just at the ears. However, these effects were minor and not discernible at the higher frequencies. A more refined model incorporating elastic properties of the bone may help resolve this issue in future studies.

Compared to the dramatic effects of removing the air spaces or bony structures from the model, removal of the ear fats did not greatly affect the overall patterns in total pressure fields (Figures 4.15-4.18). This was to be expected, given that the material properties of ear fat are much closer to the surrounding sea water compared to air or bone (Table 4.1). Removal of the ear fats resulted in a minor decrease in total pressure magnitude by the ears (7\% for $5 \mathrm{kHz}$ ventral simulations; Figures 4.15-4.18), suggesting that the ear fats, as modeled, could be somewhat helpful in increasing sound pressures at the ears. The focusing effect of the ear fats increased when the density and sound speed of the ear fats were decreased, indicating that placing a low density, low sound speed tissue by the ears may be helpful for sound reception. Conversely, increasing the density and sound speed of ear fat to match those of muscle resulted in decreased total pressure magnitudes at the ears ( $13 \%$ for $5 \mathrm{kHz}$ ventral simulations; Figures $4.15-4.18)$. The differences in total pressures were very noticeable when comparing the models at each extreme. For the ventral simulations at $5 \mathrm{kHz}$, the lowest density, lowest sound speed ear fat models resulted in $31 \%$ higher total pressures at the ear fats compared to the high density, high sound speed ear fat models.

Of typical mammalian soft tissues, fat has the lowest density and sound speed, especially at physiological temperatures (Bamber and Hill, 1979; Duck, 1990). It may not be a coincidence that odontocetes acoustic fats are composed of unique lipids with even lower sound speeds and densities compared to typical mammalian fats (Varanasi and Malins, 1970; Hustad et al., 1971; Varanasi and Malins, 1971; Litchfield et al., 1975; 
Varanasi and Malins, 1975; Guow and Vlugter, 1976). The focusing effect of the ear fats was stronger when the head was immersed in muscle instead of water (Figure 4.20). This is likely because of the greater difference in sound speeds between muscle and fat compared to water and fat.

The effects of altering the ear fat's material properties were most evident above 2 $\mathrm{kHz}$. Simulations involving frequencies below $2 \mathrm{kHz}$ were not strongly affected by the ear fat with or without altered material properties. This may be because the wavelengths of the sound are much larger than the ear fat itself at these lower frequencies. The wavelengths of a $300 \mathrm{~Hz}, 1 \mathrm{kHz}, 2 \mathrm{kHz}, 5 \mathrm{kHz}$, and $10 \mathrm{kHz}$ sound traveling through water are $5 \mathrm{~m}, 1.5 \mathrm{~m}, 0.75 \mathrm{~m}, 0.3 \mathrm{~m}$, and $0.15 \mathrm{~m}$. The minke whale head used in this simulation was from a juvenile and was approximately $1 \mathrm{~m}$ long, with ear fats dimensions of approximately $0.15 \mathrm{~m}$ (left-right) x $0.15 \mathrm{~m}$ (anterior-posterior) x .12 m (dorsal-ventral).

According to Neuweiler (2000), a pinna functions as a directional antenna when $k a>1.25$, where $\mathrm{k}=2 \pi / \lambda$ and $a=$ radius of the pinna opening. If the ear fat were acting as an internal pinna for our model minke whale, $k a$ would be greater than 1.25 for wavelengths of less than $0.3 \mathrm{~m}$, or for frequencies greater than about $5 \mathrm{kHz}$. The relevant frequencies would be lower for models of larger species, such as the fin whale or blue whale. However, the land-based pinnae referenced by Neuweiler are composed of soft tissues (including cartilage), whose material properties are more different from the surrounding air than the ear fats are from the surrounding water, limiting the ability to make such comparisons. It is possible that the large squamosal shield surrounding the dorsal aspect of the ear fats and constraining some of its dimensions may be a more effective pinna-like component for the mysticetes. The bowl-like shape of the squamosal shield is somewhat reminiscent of the "scoop-shaped" (Fleischer, 1976) bony complex including the nasal bones, maxilla, and premaxilla of some odontocetes. These bones are located on the ventral and posterior side of the melon, and have been suggested to function as an "acoustic mirror" helping to focus outgoing echolocation beams (Evans et al., 1964; Fleischer, 1976; Aroyan et al., 1992). 
Thus, the emerging hypothesis for mysticete sound reception is that sound arrives at the tympano-periotic complex through the ear fats, which directly leads from the blubber region to the ossicles, but is guided by multiple components of the head, including air and bone. This may be analogous to the situation in land mammals, in which the head and torso play a large role in hearing and sound localization by causing sounds to diffract in ways that are frequency-dependent (Heffner and Heffner, 1992). In land mammals, the soft tissues also play a large role in shaping the sound pressure fields around the head because they have very different material properties compared to air.

We propose that in mysticetes, the ear fats have replaced the ear canal in providing a pathway for sound to get from the environment to the middle ear. The low density and sound speed of the ear fats seem to help focus sound towards the ears, as the sound refracts towards regions of minimum sound speed. The focusing effect was most pronounced for frequencies above $2 \mathrm{kHz}$ in our model of a small, juvenile minke whale. However, it is important to keep in mind that sound reception is a complex process in reality, which cannot be fully described by a simple model such as ours. For instance, we know that the human auditory system is capable of detecting sounds with wavelengths up to $17 \mathrm{~m}$, which is much larger than any component of the human ear or body itself (Rosowski, 1996). The question of if and how the ear fats may be useful for lower frequency reception should be addressed in future studies.

This study represents the first application of FEM techniques to explore sound reception in a baleen whale. While we were able to obtain potentially informative results, we suggest several improvements for future studies. As noted above, our model did not include any elastic structures, and the mesh sizes limited our ability to run simulations at higher frequencies. Furthermore, we only modeled a subset of the structures present in the minke whale head. Lumping most of the soft tissues, such as muscle, with the surrounding water seemed to be an acceptable simplification, since the material properties of sea water and muscle are close. Figure 4.19 shows that immersing the whole head in muscle instead of sea water did not affect the overall patterns in total 
pressure magnitude. However, there are other soft tissues besides muscle that were not modeled, such as the cartilaginous padding described in Yamato et al. (2012). This thick, hard, mutli-layerd padding encompasses the entire tympanic bone except at its dorsal side, where the periotic bone is, and its lateral side, at the insertion of the ear fat into the tympano-periotic complex. Such structures may particularly affect the simulations with ventral sound sources, and should be included in more refined models of the ear region.

A major question relevant to models of sound reception in baleen whales or any diving mammal is the extent of air present in the head at depth. Our model included the minimum amount of air that is presumed to exist in the peribullar sinus while the animal is diving (Fraser and Purves, 1960). The simulation results show that these air spaces play a major role in shaping the pressure field in the head at lower frequencies. Since the actual amount of air retained at depth is uncertain, the outputs of our models should be compared with additional models incorporating varied amounts of air in the peribullar sinuses, pterygoid sinuses, and the nares.

Validation experiments are necessary for any attempt at modeling complex phenomena. Previous studies have attempted validation in several ways. Aroyan et al. (1992) and Aroyan (2001) compared modeling results with data available for the bottlenose dolphin, and Cranford et al. (2008) incorporated simulations of outgoing echolocation sounds from the phonic lips, which converged into beam patterns matching experimental results. However, minke whales are not thought to produce vocalizations from the nasal region, the laryngeal area was not included in our models, and there are limited experimental data with which to compare simulation results. One possibility is to implant small hydrophones into several different locations within a fresh dead head and measure received levels while ensonifying it, similar to the work done by Norris and Harvey (1974) on a bottlenose dolphin. 


\subsection{Conclusions}

In this chapter, we modeled sound propagation through the various components of a minke whale head using the Finite Element Method. Based on the simulation results, we hypothesize that air plays an important role in the interaction of sound waves with the head at lower frequencies. However, the effects of bony structures seem to be dominant at higher frequencies and contribute greatly to the sound shadow effect of the head.

In contrast to bone and air, which are dramatically different from the surrounding aquatic medium, the ear fats have relatively similar material properties as sea water. Consequently, their effect on the total pressure field through the whale head is not as extreme as the effect of bone and air. However, the ear fats did slightly increase the total pressure magnitude by the ears. The significance of placing a fat body adjacent to the ears was investigated by altering the material properties of the ear fat. Fat has lower sound speeds and densities compared to other types of soft tissues (Duck, 1990), and decreasing these parameters in our model led to slightly greater total pressure magnitudes at the ears. In contrast, increasing the density and sound speed of the ear fat to match those of muscle led to a decreased total pressure magnitude at the ears. Thus, the incorporation of fat bodies into the sound reception system seems to help focus sounds towards the ears in the minke whale. 


\subsection{Acknowledgements}

This project would not have been possible without Dr. Gonzalo Feijoo, who kindly provided me with his time and access to his software while mentoring me throughout this study. Dr. Dennis Freeman provided me with insightful feedback and was especially good at explaining difficult concepts in an intelligible way. Dr. Ted Cranford and Dr. Petr Krysl provided me with inspiring conversations at conferences and meetings. The ear fat samples were CT scanned by Dr. Darlene Ketten, Julie Arruda, and Scott Cramer.

Funding to pursue this work came from the Ocean Ventures Fund Award, National Science Foundation Graduate Research Fellowship, WHOI Ocean Life Institute Fellowship, MIT Student Assistance Fund, and the WHOI Academic Programs Office. 


\subsection{References}

Aroyan JL, Cranford TW, Kent J, Norris KS. 1992. Computer Modeling of Acoustic Beam Formation in Delphinus-Delphis. Journal of the Acoustical Society of America 92:2539-2545.

Aroyan JL. 2001. Three-dimensional modeling of hearing in Delphinus delphis. Journal of the Acoustical Society of America 110:3305-3318.

Ashman RB, Corin JD, Turner CH. 1987. Elastic properties of cancellous bone: Measurement by an ultrasonic technique. Journal of Biomechanics 20:979-986.

Au WWL, Ford JKB, Horne JK, Allman KAN. 2004. Echolocation signals of freeranging killer whales (Orcinus orca) and modeling of foraging for chinook salmon (Oncorhynchus tshawytscha). The Journal of the Acoustical Society of America 115:901909.

Babuska I, Aziz AK. 1973. The Mathematical Foundations of the Finite Element Method-with Applications to Partial Differential Equations. New York: Academic Press.

Bamber JC, Hill CR. 1979. Ultrasonic attenuation and propagation speed in mammalian tissues as a function of temperature. Ultrasound in medicine \& biology 5:149-157.

Brill RL, Sevenich ML, Sullivan TJ, Sustman JD, Witt RE. 1988. Behavioral Evidence for hearing through the lower jaw by an echolocating dolphin (Tursiops truncatus). Marine Mammal Science 4:223-230.

Bullock T H, Grinnell AD, Ikezono E, Kameda K, Katsuki Y, Nomoto M, Sato O, Suga N, Yanigasawa K. 1968. Electrophysiological studies of central auditory mechanisms in cetaceans. Zeitschrift fur vergleichende Physiologie 59:117-156.

Campbell-Malone R. 2007. Biomechanics of North Atlantic right whale bone:

mandibular fracture as a fatal endpoint for blunt vessel-whale collision modeling. Doctor of Philosophy thesis for the Biology Department, MIT-WHOI Joint Program. 257 pages.

Cranford TW, Amundin M, Norris KS. 1996. Functional morphology and homology in the odontocete nasal complex: Implications for sound generation. Journal of Morphology 228:223-285.

Cranford TW, Krysl P, Hildebrand JA. 2008. Acoustic pathways revealed: Simulated sound transmission and reception in Cuvier's beaked whale (Ziphius cavirostris). Bioinspiration \& Biomimetics 3. 
Dietzen G. 2008. Acoustic Scattering from Sand Dollars (Dendraster excentricus): Modeling as High Aspect Ratio Oblate Objects and Comparison to Experiment. Master of Science thesis for the Applied Ocean Science and Engineering Department, MITWHOI Joint Program. 160 pages.

Duck FA. 1990. Physical Properties of Tissue. A Comprehensive Reference Book. San Diego: Academic Press.

Edds-Walton PL. 1997. Acoustic communication signals of mysticete whales. Bioacoustics 8(1-2): 47-60.

Eiber A. 1999. Mechanical Modeling and Dynamical Behavior of the Human Middle Ear. Audiology and Neurotology 4(3-4): 170-177.

Evans WE, Sutherland WW, Beil RG. 1964. The directional characteristics of delphinid sounds. In: Travolga WN, editor. Marine Bio-acoustics. Oxford: Pergamon Press. p 353370.

Fitzgerald ER, Ackerman E, Fitzgerald JW. 1957. Preliminary Measurements on the Viscoelastic Properties of Animal Tissues at Audio-Frequencies. The Journal of the Acoustical Society of America 29:61-64.

Fleischer G. 1976. Hearing in Extinct Cetaceans as Determined by Cochlear Structure. Journal of Paleontology 50:133-152.

Fraser FC, Purves PE. 1960. Anatomy and Function of the Cetacean Ear. Proceedings of the Royal Society of London. Series B, Biological Sciences 152:62-77.

Frizzell LA, Carstensen EL, Dyro JF. 1976. Shear properties of mammalian tissues at low Megahertz frequencies. The Journal of the Acoustical Society of America 60:1409-1411.

Gedamke J, Costa DP, Dunstan A. 2001. Localization and visual verification of a complex minke whale vocalization. Journal of the Acoustical Society of America 109:3038-3047.

Gouw IRTH, Vlugter IRJC. 1967. Physical Properties of Triglycerides III: Ultrasonic Sound Velocity. Fette, Seifen, Anstrichmittel 69:159-164.

Heffner RS, Heffner. HE. 1992 Evolution of sound localization in mammals. In: D. B. Webster RRF, A. N. Popper, editor. The Evolutionary Biology of Hearing New York: Springer-Verlag. p 691-715.

Koike T, Wada H, Kobayashi H. 2002. Modeling of the human middle ear using the finite element method. Journal of the Acoustical Society of America 111: 1306-1317. 
Krysl P, Cranford TW, Wiggins SM, Hildebrand JA. 2006. Simulating the effect of highintensity sound on cetaceans: Modeling approach and a case study for Cuvier's beaked whale (Ziphius cavirostris). J. Acoust. Soc. Am. 120:2328-2339.

Krysl P, Cranford TW, Hildebrand JA. 2008. Lagrangian finite element treatment of transient vibration/acoustics of biosolids immersed in fluids. In. p 754-775.

Henson PW, Ackland T, Fox RA. 1987. Tissue density measurement using CT scanning. Australasian Physical \& Engineering Sciences in Medicine 10:162-166.

Hewitt P. 1998. Conceptual Physics, Eighth Edition. New York: Addison-Wesley.

Hustad GO, Richardson T, Winder WC, Dean MP. 1971. Acoustic properties of some lipids. Chemistry and physics of lipids 7:61.

Lane H. 2009. Variation in the nutritional value of Atlantic Herring (Clupea harengus) from the Bay of Fundy, Canada. Master of Science thesis for the Department of Biology and Marine Biology, University of North Carolina Wilmington. 104 pages.

Lee C-F, Chen P-R, Lee W-J, Chen J-H, Liu T-C. 2006. Three-Dimensional Reconstruction and Modeling of Middle Ear Biomechanics by High-Resolution Computed Tomography and Finite Element Analysis. Laryngoscope 116:711-716.

Lees S, Ahern JM, Leonard M. 1983. Parameters influencing the sonic velocity in compact calcified tissues of various species. The Journal of the Acoustical Society of America 74:28-33.

Lees S, Hanson DB, Page EA. 1996. Some acoustical properties of the otic bones of a fin whale. J. Acoust. Soc. Am. 99:2421-2427.

Litchfield C, Greenberg AJ, Caldwell DK, Caldwell MC, Sipos JC, Ackman RG. 1975. Comparative lipid patterns in acoustical and nonacoustical fatty tissues of dolphins, porpoises and toothed whales. Comparative Biochemistry and Physiology Part B: Comparative Biochemistry 50:591-597.

Mast TD. 2000. Empirical relationships between acoustic parameters in human soft tissues. Acoustics Research Letters Online 1:37-42.

McKenna MF, Goldbogen JA, St. Leger J, Hildebrand JA, Cranford TW. 2007. Evaluation of postmortem changes in tissue structure in the bottlenose dolphin (Tursiops truncatus). The Anatomical Record: Advances in Integrative Anatomy and Evolutionary Biology 290:1023-1032. 
Mellinger DK, Carson CD, Clark CW. 2000. Characteristics of minke whale (Balaenoptera acutorostrata) pulse trains recorded near Puerto Rico. Marine Mammal Science 16:739-756.

Mohl B, Au WWL, Pawloski J, Nachtigall PE. 1999. Dolphin hearing: Relative sensitivity as a function of point of application of a contact sound source in the jaw and head region. J. Acoust. Soc. Am. 105:3421-3424.

Neuweiler G. 2000. The Biology of Bats. New York: Oxford University Press.

Norris KS. 1964. Some problems of echolocation in cetaceans. In: Tavolga WN, editor. Marine bioacoustics. New York: Pergamon Press. p 317-336.

Norris KS, Harvey GW. 1974. Sound transmission in the porpoise head. The Journal of the Acoustical Society of America 56:659-664.

Pickard GL, Emery WJ. 1990. Descriptive Physical Oceanography: An Introduction, 5th Enlarged Edition. Oxford: Butterworth-Heinemann.

Rosowski JJ. 1996. Models of External- and Middle-Ear Function. In: Hawkins HL, McMullen TA, Popper AN, Fay RR, editors. Auditory Computation: Springer Verlag. p $15-61$.

Soldevilla MS, McKenna MF, Wiggins SM, Shadwick RE, Cranford TW, Hildebrand JA. 2005. Cuvier's beaked whale (Ziphius cavirostris) head tissues: physical properties and CT imaging. The Journal of Experimental Biology 208:2319-2332.

Strang WG, Fix G. 1973. An Analysis of the Finite Element Method. Upper Saddle River: Prentice-Hall.

Varanasi US, Malins DC. 1970. Unusual wax esters from the mandibular canal of the porpoise (Tursiops gilli). Biochemistry 9:3629-3631.

Varanasi U, Malins DC. 1971. Unique lipids of the porpoise (Tursiops gilli): Differences in triacyl glycerols and wax esters of acoustic (mandibular canal and melon) and blubber tissues. Biochimica et Biophysica Acta (BBA) - Lipids and Lipid Metabolism 231:415418.

Varanasi U, Feldman HR, Malins DC. 1975. Molecular basis for formation of lipid sound lens in echolocating cetaceans. Nature 255:340-343.

Wartzok D, Ketten DR. 1999. Marine Mammal Sensory Systems. In: Biology of Marine Mammals. J. Reynolds and S. Rommel (eds.), Smithsonian Institution Press, pp. 117-175 
Yamato M, Ketten DR, Arruda J, Cramer S, Moore K. The Auditory Anatomy of the Minke Whale (Balaenoptera acutorostrata): A Potential Fatty Sound Reception Pathway in a Baleen Whale. The Anatomical Record: Advances in Integrative Anatomy and Evolutionary Biology 295:991-998. 
Chapter 5: Conclusions 
Although hearing in odontocetes is well-studied, very little is known about mysticete hearing. This thesis explored sound reception in the minke whale (Balaenoptera acutorostrata), one of the smallest and most abundant baleen whale species, using an interdisciplinary approach combining anatomical, biochemical, and modeling techniques.

Dissections and biomedical imaging of minke whale heads in Chapter 2 revealed that there is a large, well-formed fat body extending from the blubber region to the tympano-periotic complex, or the ears. This "ear fat" inserts into the tympano-periotic complex and attaches to the ossicles, which leads to the fluid-filled cochlea. Odontocetes are thought to use specialized "acoustic fats" for underwater sound reception (Norris, 1964; Bullock et al., 1968; Brill et al., 1988; Mohl et al., 1999). These acoustic fats are associated with their derived mandibles and also attach to the tympano-periotic complex. Based on the anatomical observations from the minke whale, it was hypothesized that fatty sound reception pathways may not be an exclusively odontocete phenomenon amongst marine mammals, as previously believed.

The morphology and lipid composition of the ear fats were compared to the acoustic fats of odontocetes in Chapter 3. Odontocete acoustic fats are comprised of endogenously synthesized short, branched chain fatty acids and fatty alcohols within triacylglycerols and wax esters (Varanasi and Malins, 1970), whereas typical mammalian fats contain fatty acids with longer chain lengths of $14-22$ carbons found within triacylglycerols (Pond, 1998). We found that the ear fats are made up of these typical mammalian lipids and also do not have a multi-lobed structure or fill the mandibular canals like odontocete acoustic fats. However, acoustic fats and ear fats shared several potentially important characteristics, such as retaining their lipids even during starvation, containing fewer dietary signals compared to blubber, and having reduced sound speeds compared to surrounding non-fatty tissues. Furthermore, the acoustic fats of odontocetes are incredibly diverse in both morphology and lipid composition. Thus, fatty tissues may 
not be restricted to a certain type of lipid composition or morphological form to have an acoustic function.

The functional significance of placing fatty tissues adjacent to the ears was examined using the Finite Element Method (FEM) in Chapter 4. A model of the minke whale head was created based on CT data from Chapter 2, combined with material property values from measurements and published data, and ensonified by a plane wave sound source between $300 \mathrm{~Hz}$ and $10 \mathrm{kHz}$. We found that the resulting patterns in total pressure magnitude were shaped by multiple components of the head, including air spaces and bony structures. For simulations above $2 \mathrm{kHz}$, the presence of the ear fats slightly increased the total pressure magnitude by the ears compared to a model without ear fats. When the density and sound speed of the ear fats were decreased, the sound was more focused towards the ears. Conversely, when the density and sound speed of the ear fats were increased to match the properties of muscle, sound was less focused at the ears. For the simulations using a $5 \mathrm{kHz}$ source from the ventral source, the addition of the ear fat resulted in a $7 \%$ increase in total pressure magnitude adjacent to the ears. The addition of the ear fat, compared to a scenario where the ear fat was composed of muscle, increased pressures by $13 \%$. When the ear fat was changed from muscle to odontocetelike fats, there was a $31 \%$ increase in total pressure magnitude. Thus, the presence of fatty tissues with low densities and low sound speeds seems to be beneficial in guiding sound towards the ears.

In odontocete acoustic fats, the topographical arrangement of specific lipids is thought to help channel sound towards the ears (Koopman et al., 2006). This is because the lipids with lowest sound speeds are found at the central core of the fat body and at the regions closest to the ears, allowing incoming sound to bend towards these regions of minimum sound speed (Guow and Vlugter, 1967; Hustad et al., 1971; Flewellen and Morris, 1978; Koopman et al., 2006). Although we did not see spatial variability in the identity of lipids within the mysticete ear fats, we propose that the ear fats represent spatial variability in sound speeds on a grosser scale, consistent with the longer 
wavelength sounds presumably used by these animals. By having a lower sound speed than the surrounding, non-fatty tissue, the ear fats may be helping to focus sound towards the ears in baleen whales. Fatty tissues are known to have lower densities and sound speeds than other types of soft tissue (Duck, 1990), which may explain why they are an important component of the auditory system in odontocetes, and perhaps in mysticete cetaceans as well.

In summary, we described a novel potential fatty sound reception pathway in a mysticete cetacean. The morphology and biochemical composition of this "ear fat" was compared with the acoustic fats of odontocete cetaceans. As expected, we identified major differences between the mysticete ear fats and odontocete acoustic fats. However, the ear fats and acoustic fats share several potentially important features. Furthermore, a FE model of the minke whale head showed that the presence of ear fats slightly increases sound pressure magnitudes at the ears. In contrast, increasing the density and sound speed of ear fat to match those of muscle resulted in lower sound pressure magnitudes at the ears. In an aquatic habitat where the pinna and air-filled ear canal is no longer effective at collecting and focusing sound towards the ears, we propose that both odontocete and mysticete cetaceans have evolved to incorporate fatty tissues into their auditory systems for aquatic sound reception. 


\subsection{References}

Brill RL, Sevenich ML, Sullivan TJ, Sustman JD, Witt RE. 1988. Behavioral Evidence for hearing through the lower jaw by an echolocating dolphin (Tursiops truncatus). Marine Mammal Science 4:223-230.

Bullock T H, Grinnell AD, Ikezono E, Kameda K, Katsuki Y, Nomoto M, Sato O, Suga N, Yanigasawa K. 1968. Electrophysiological studies of central auditory mechanisms in cetaceans. Zeitschrift fur vergleichende Physiologie 59:117-156.

Duck FA. 1990. Physical Properties of Tissue. A Comprehensive Reference Book. San Diego: Academic Press.

Flewellen CG, Morris RJ. 1978. Sound velocity measurements on samples from the spermaceti organ of the sperm whale (Physeter catodon). Deep Sea Research 25:269-277.

Gouw IRTH, Vlugter IRJC. 1967. Physical Properties of Triglycerides III: Ultrasonic Sound Velocity. Fette, Seifen, Anstrichmittel 69:159-164.

Hustad GO, Richardson T, Winder WC, Dean MP. 1971. Acoustic properties of some lipids. Chemistry and physics of lipids 7:61.

Koopman HN, Budge SM, Ketten DR, Iverson S. 2006. Topographic distribution of lipids inside the mandibular fat bodies of odontocetes: Remarkable complexity and consistency. IEEE Journal of Oceanic Engineering 31:95-106.

Mohl B, Au WWL, Pawloski J, Nachtigall PE. 1999. Dolphin hearing: Relative sensitivity as a function of point of application of a contact sound source in the jaw and head region. J. Acoust. Soc. Am. 105:3421-3424.

Norris KS. 1964. Some problems of echolocation in cetaceans. In: Tavolga WN, editor. Marine bioacoustics. New York: Pergamon Press. p 317-336.

Pond CM. 1998. The fats of life. Cambridge: Cambridge University Press.

Varanasi US, Malins DC. 1970. Unusual wax esters from the mandibular canal of the porpoise (Tursiops gilli). Biochemistry 9:3629-3631. 
Appendix: CT scanning and three-dimensional visualization of the minke whale head: non-auditory structures 
The primary goal of CT scanning and dissecting the minke whale heads was to examine the auditory anatomy. However, it also provided a unique opportunity to examine additional anatomical features of the minke whale head. This appendix provides a brief description of five different structures that could be seen clearly on the CT images and dissection: rostral fat, ventral fibrocartilage, baleen, pharyngo-tympanic (Eustachian) tube, and olfactory structures. CT datasets of whole baleen whale heads are incredibly rare and would be beneficial for future studies of mysticete cephalic anatomy.

\section{A.1. Rostral fat ("Melon")}

In the CT scans of the minke whale, there was a structure anterior to the blowholes that had Hounsfield units (HU) of $-30 \sim-100$, which is within the range of ear fat HU (Figure A.1). Interestingly, the rostral fat is in a similar location of the head as the odontocete melon, connecting with the nares and blowhole region posteriorly. Dissections revealed that the structure is made of fatty tissues as well (Figure A.2).

This structure has been referred to as the mysticete "melon" in Heyning and Mead (1990). According to them, the mysticete melon is "rather small compared to that of odontocetes, but is of the same consistency of adipose tissue and located in exactly the same position as the melon of toothed whales". However, they acknowledge that mysticete melons are not likely to be involved in sound production as in odontocetes. Instead, they speculate that the fatty tissue plays a role during respiration, assisting in movements of the nasal plugs as the nasal plug muscles contract and relax. Harper et al. (2010) came to similar conclusions while investigating the collagen fiber architecture of the rostral material in a right whale.

The three-dimensional reconstructions show that the rostral fat consists of two separate fatty cores originating at blowhole, which join together anteriorly. This fatty structure sits in the mesorostral groove and extends almost to the anterior edge of the 
premaxilla. The minke whale rostral fat does not show any obvious morphological asymmetry, unlike the melon of some odonotocetes. For example, the bottlenose dolphin melon extends much farther posteriorly on the right side compared to the left side (Figure A.3).

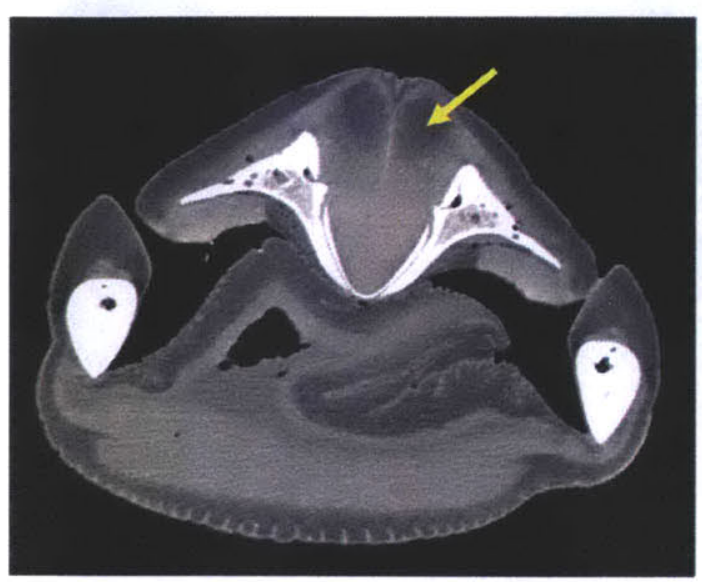

Figure A.1. CT image of the rostral material in B-acu13, indicated by yellow arrow.

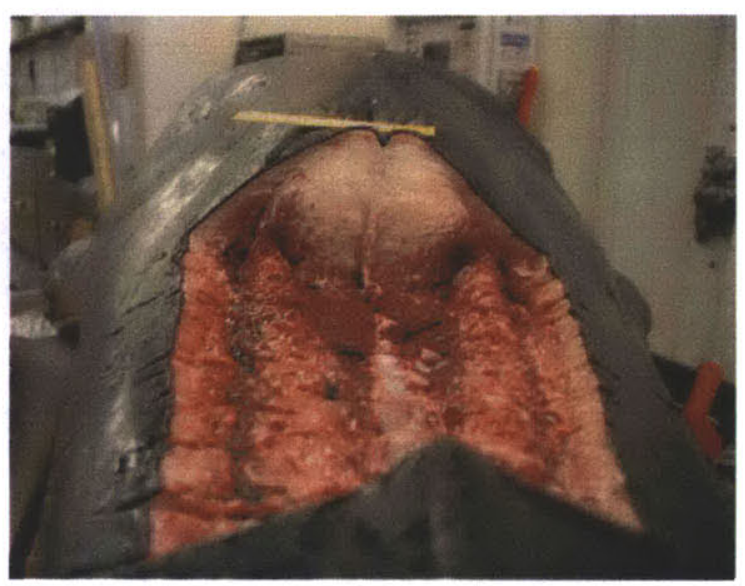

Figure A.2. Rostral material of B-acu22. Photo courtesy of Cally Harper. 


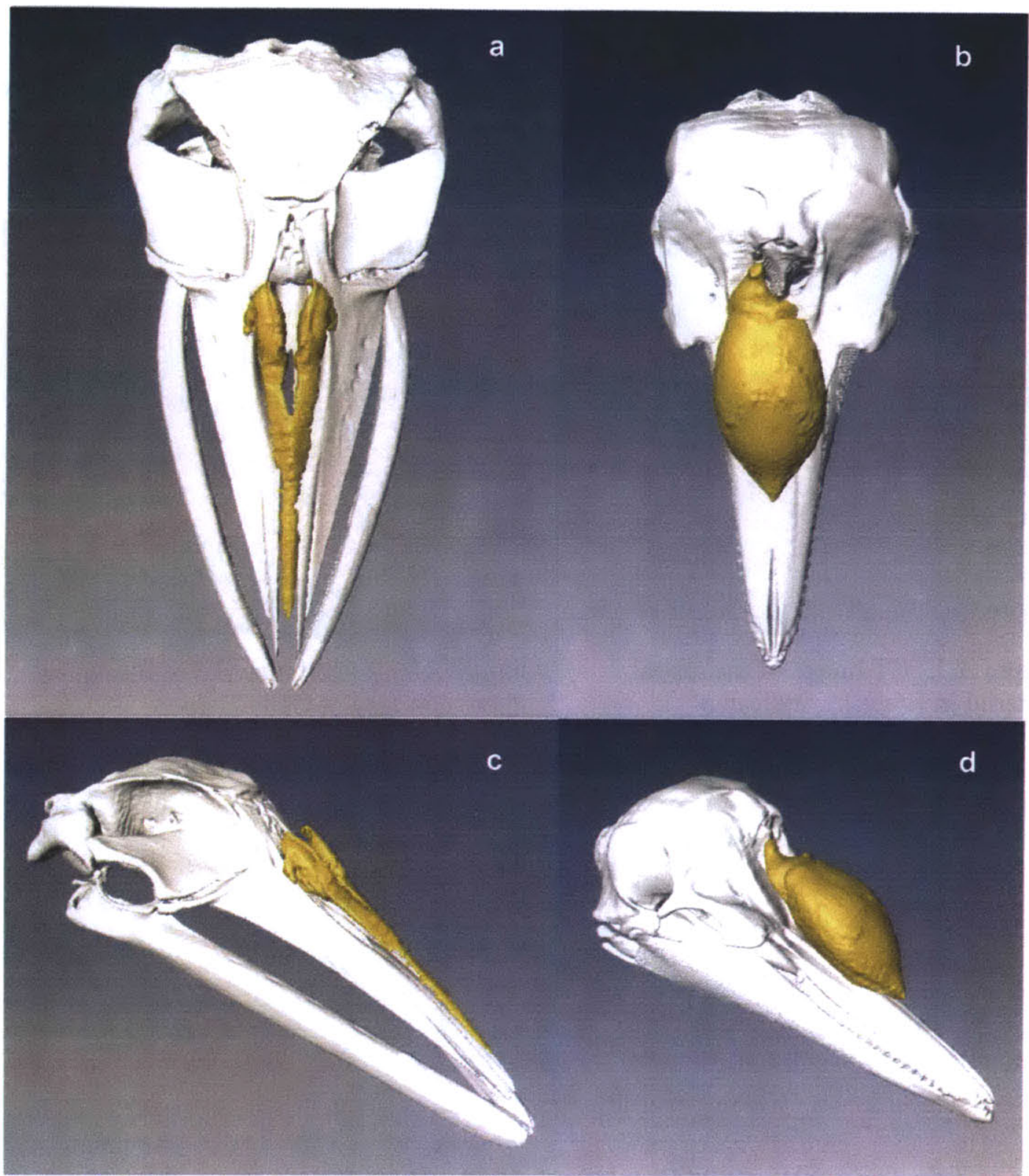

Figure A.3. The rostral material of the minke whale $(\mathrm{a}, \mathrm{c})$ compared to the melon of a bottlenose dolphin (b, d). (a, b), Dorsal view; (c, d), lateral view. 


\section{A.2. Ventral fibrocartilage}

Rorqual whales possess a unique feeding mechanism, lowering their jaws by almost 90 degrees and engulfing prey-laden seawater into their massive elastic throat pouch. Brodie (1993) has claimed that this represents the "greatest biomechanical action in the animal kingdom". The unique Y-shaped fibrocartilage structure located ventral to the mandibles most likely provides additional support for the elastic throat pouch during feeding (Pivorunas, 1977). Pivorunas (1977) provides a more in-depth description of this structure, noting that it connects to the mandibular symphyseal fibrocartilage mass at the anterior end.

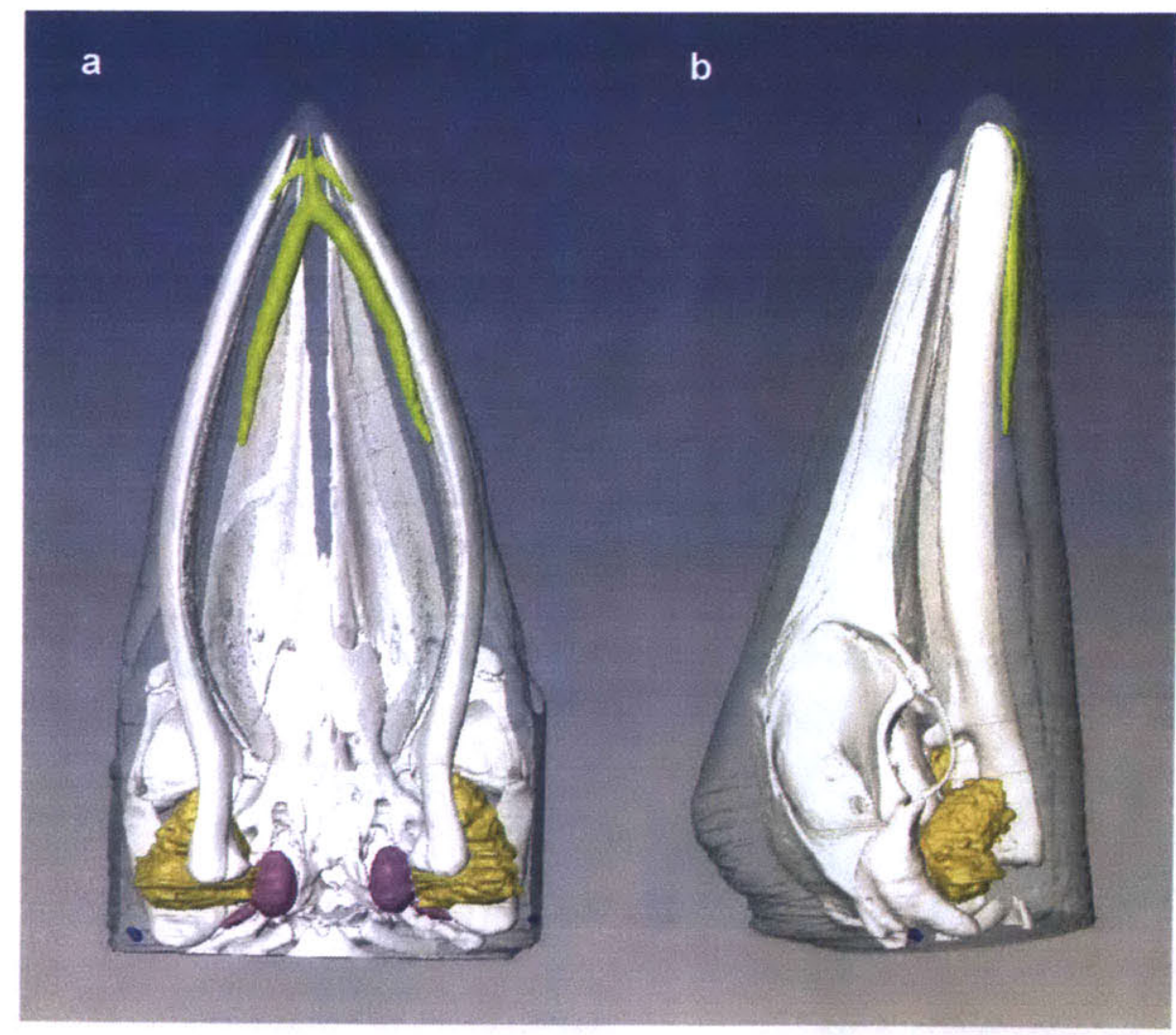

Figure A.4.. Ventral fibrocartilage of the minke whale, shown in green. White, bone; purple, tympano-periotic complex; dark blue, external auditory canal; yellow, ear fats. a) Ventral view, b) lateral view. 


\section{A.3. Baleen}

The baleen of Mysticetes is made of keratin, which is an epidermal tissue also found in the hair, nails, hoofs, and horns of mammals (Pautard, 1963). The length, shape, and number of baleen plates vary considerably across families and species. For example, the bowhead whale (Balaena mysticetes) can have baleen that is up to $4.5 \mathrm{~m}$ long, while rorqual whales such as the minke whale have much shorter baleen (Tinker, 1988; Figure A.5). According to Werth (2001), Balaena baleen is so long that they must fold posteriorly for the mouth to close properly. The three-dimensional reconstructions of minke whale baleen indicate that the baleen is able to fit in to the mouth without major deformations (Figure A.6). The question of how Mysticetes remove prey trapped in baleen has not yet been resolved (Werth, 2001).

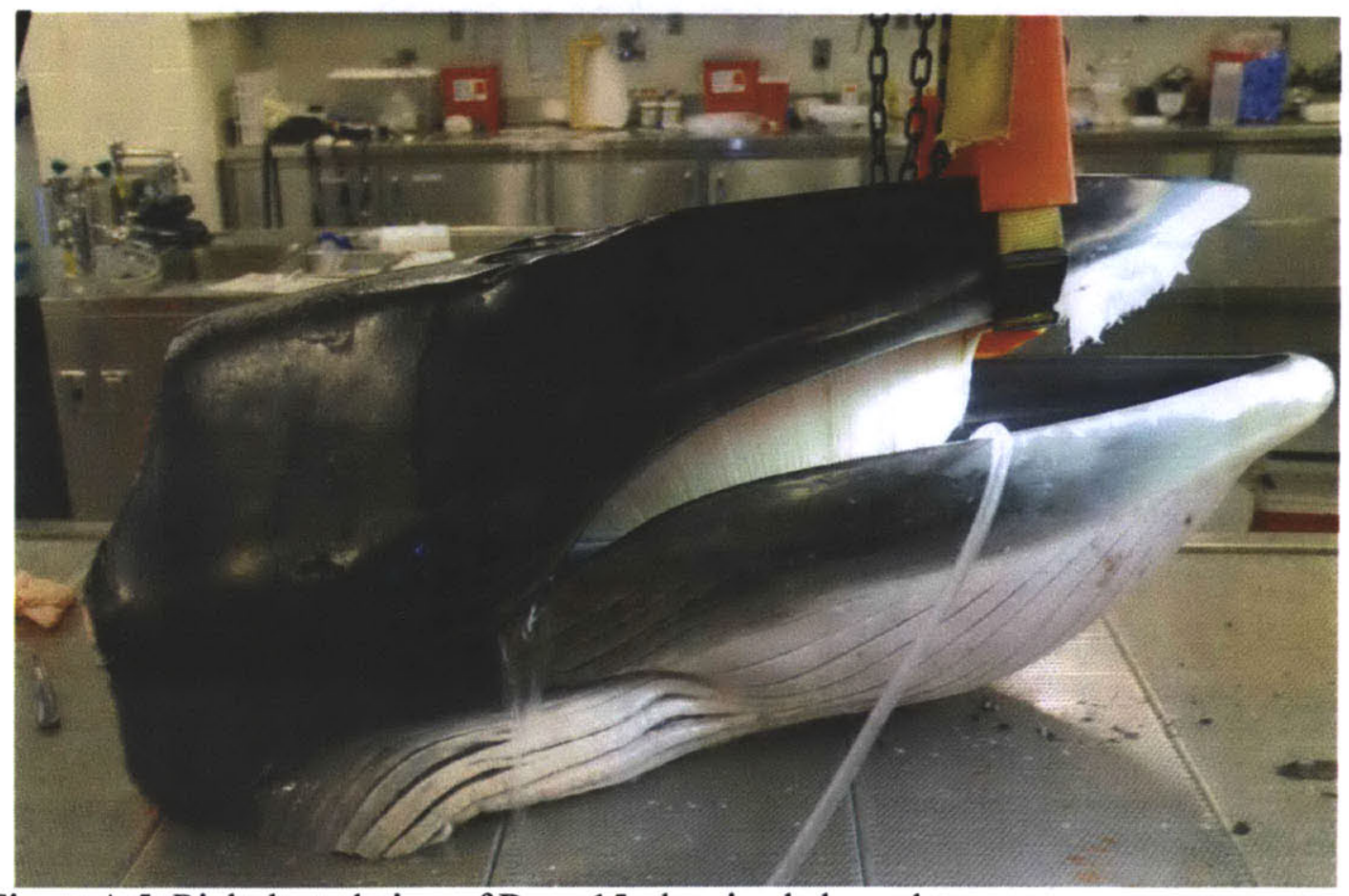

Figure A.5. Right lateral view of B-acu15, showing baleen plates. 
Figure A.6. Baleen of B-acu13. a) Axial CT image. b) Three-dimensional reconstruction, ventral view. Baleen, black; skull, white; soft tissues, transparent. c) Lateral view with transparent skull. d) Anterior view with transparent skull. e) Lateral view of baleen. f) Anterior view of baleen.
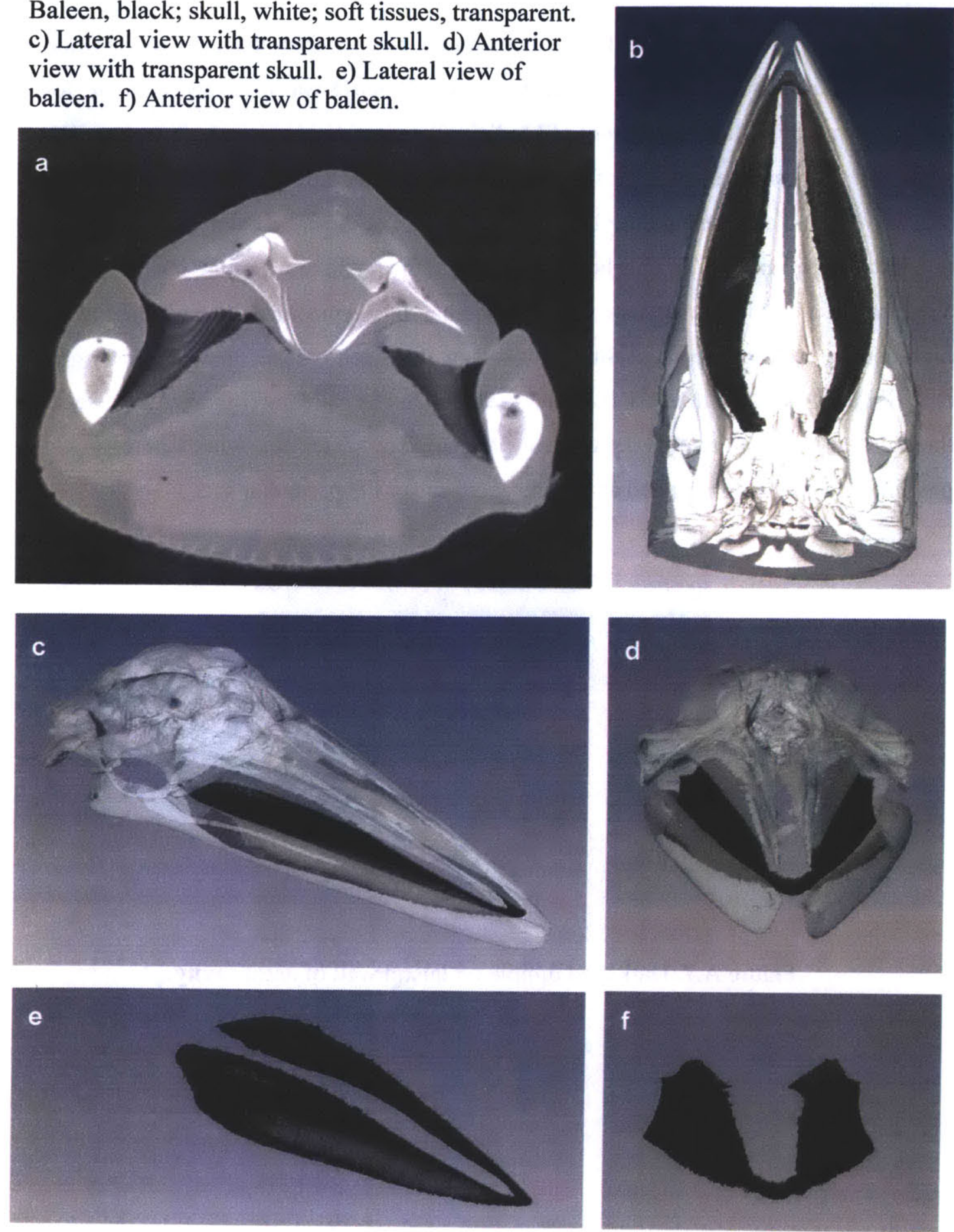


\section{A.4. Pharyngo-tympanic (Eustachian) tube}

Lillie (1910) states that the Eustachian tube extends from the nares to the floor of the pterygoid sinus in the larger mysticete species. B-acu18 was dissected with Dr. Joy Reidenberg of the Mt. Sinai School of Medicine, an expert on cetacean air spaces. We were able to locate the opening of the pharyngo-tympanic tube from the ventral aspect, where we found a darkened dimple in the lateral wall of the nasal cavity on both the right and left side (Figure A.7). This hole connected to the medial wall of the pterygoid sac. We inserted a hollow plastic tube through the pharyngo-tympanic tube and filled it with a high-density contrast media, sealing both ends with silicone rubber cement and surgical tape (Figure A.8). We then CT the head to visualize this pathway (Figure A.9). Because the right ear had been removed previously, we could not determine whether the pharyngo-tympanic tube ended at the pterygoid sac or the peribullar sac.

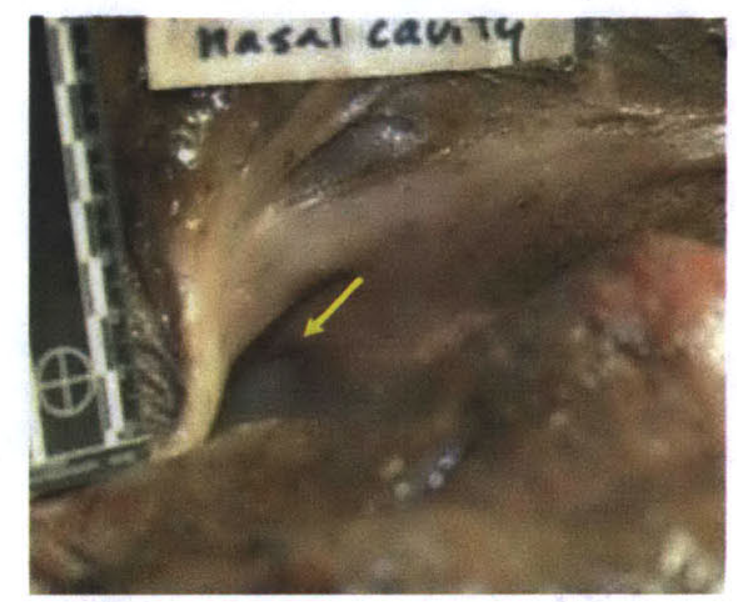

Figure A.7. Darkened dimple on lateral wall of nasal cavity. 


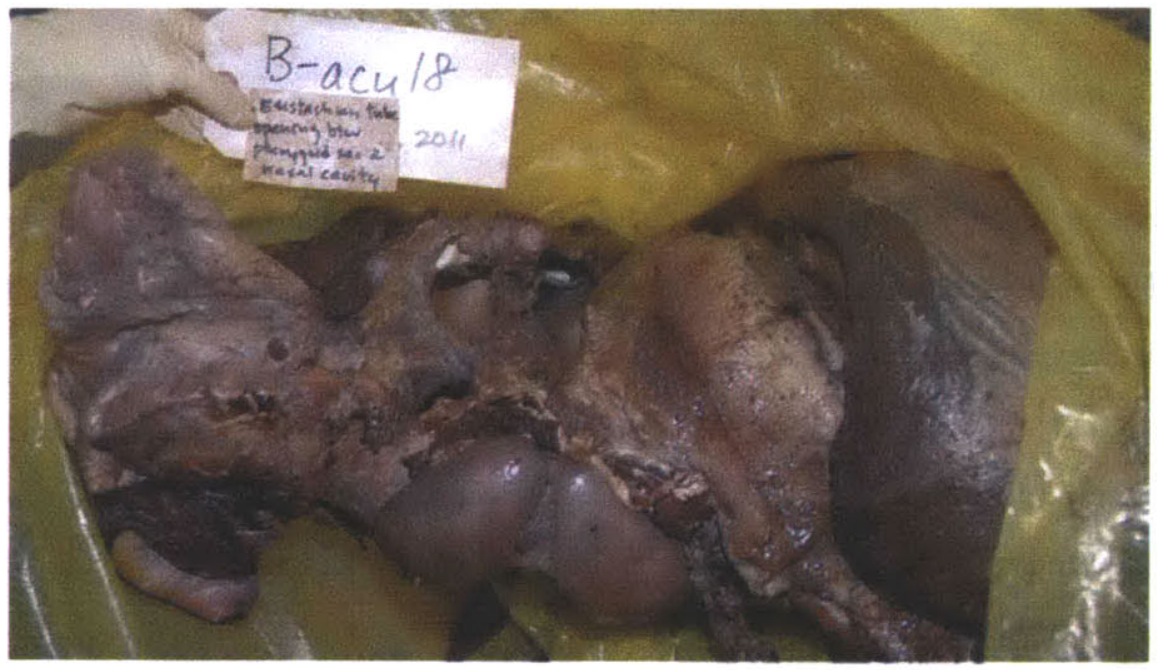

Figure A.8. Plastic tube filled with high-density contrast media and inserted through pharyngo-tympanic tube.
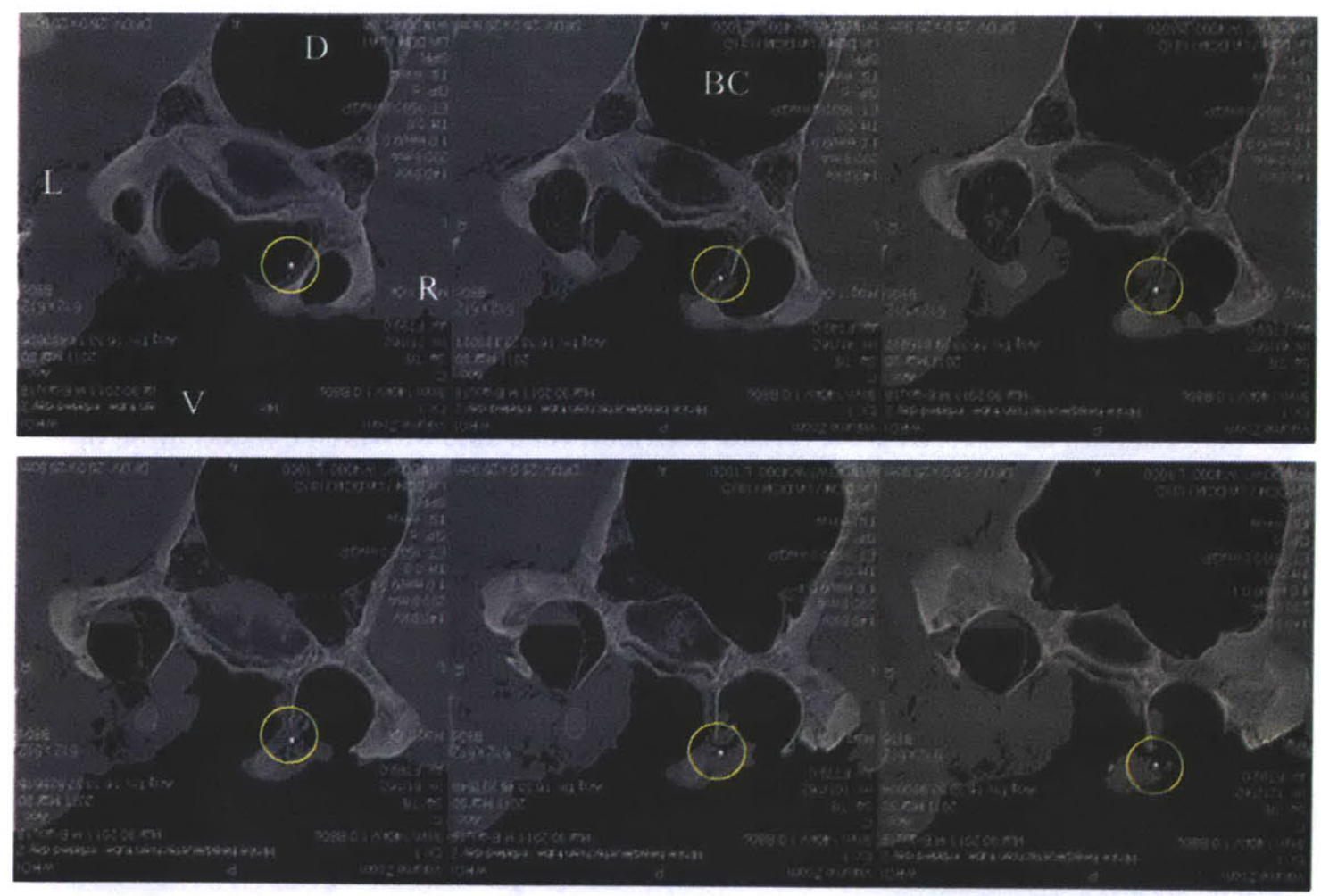

Fig. A.9. CT scan images at $10 \mathrm{~mm}$ intervals (rostral to caudal) showing the plastic tube with high-density contrast media going through the right pharyngo-tympanic tube (circled). The images have been rotated 180 degrees for visualization. D, dorsal; V, ventral; R, right; L, left; $\mathrm{BC}$, brain case. 


\section{A.5. Olfactory structures}

Historically, it has been widely thought that cetaceans do not have a good sense of smell. This is based on both anatomical and genetic evidence: the olfactory bulbs of cetaceans are reduced or absent (Breathnach, 1960), and the olfactory receptor genes contain significantly higher numbers of non-functional pseudogenes compared to their terrestrial relatives (Kishida et al., 2007). However, while it may be true that odontocetes do not use olfaction, there is increasing evidence that mysticetes may have a functional olfactory system. The proportion of olfactory receptor pseudogenes is much lower in mysticetes compared to odontocetes; $58 \%$ and $49 \%$ in the minke whale and bowhead whale, respectively, compared to $77 \%$ and $78 \%$ in the dwarf sperm whale and Dall's porpoise (Kishida et al., 2007; Theiwissen et al., 2011). Theiwissen et al. (2011) also found well-developed olfactory bulbs in the bowhead whale (Balaena mysticetus) and speculated that Bowhead whales may use olfaction to locate aggregations of krill.

We opportunistically examined the olfactory region while dissecting two of the specimens, B-acu18 and B-acu23. After extracting the brain, the dura was removed and the tissue lining was scraped off on the left side to expose the cribriform plate (Figures A.10 and A.11). Carte and Macalister (1868) noted that the cribriform plate of minke whales "presented a median plate (crista-galli), on each side of which existed three or four deep depressions perforated by foramina for the exit of the olfactory nerves." The olfactory bulbs were not present in either of our specimen, most likely because of postmortem decomposition.

The space where the olfactory bulbs are presumably located is clearly visible on the CT images of the minke whale, while it was not obvious in the bottlenose dolphin (Figure A.13, a-c). Another structure that may be relevant to the olfactory system is the inter-turbinate air spaces within the ethmoid bones. These irregularly shaped air spaces are located just anterior to the olfactory bulbs and lead to the nasal passage (Figure A.12). We could not assess whether these spaces were lined with olfactory epithelium, but these inter-turbinate air spaces are not present in the bottlenose dolphin (Figure A.13). 


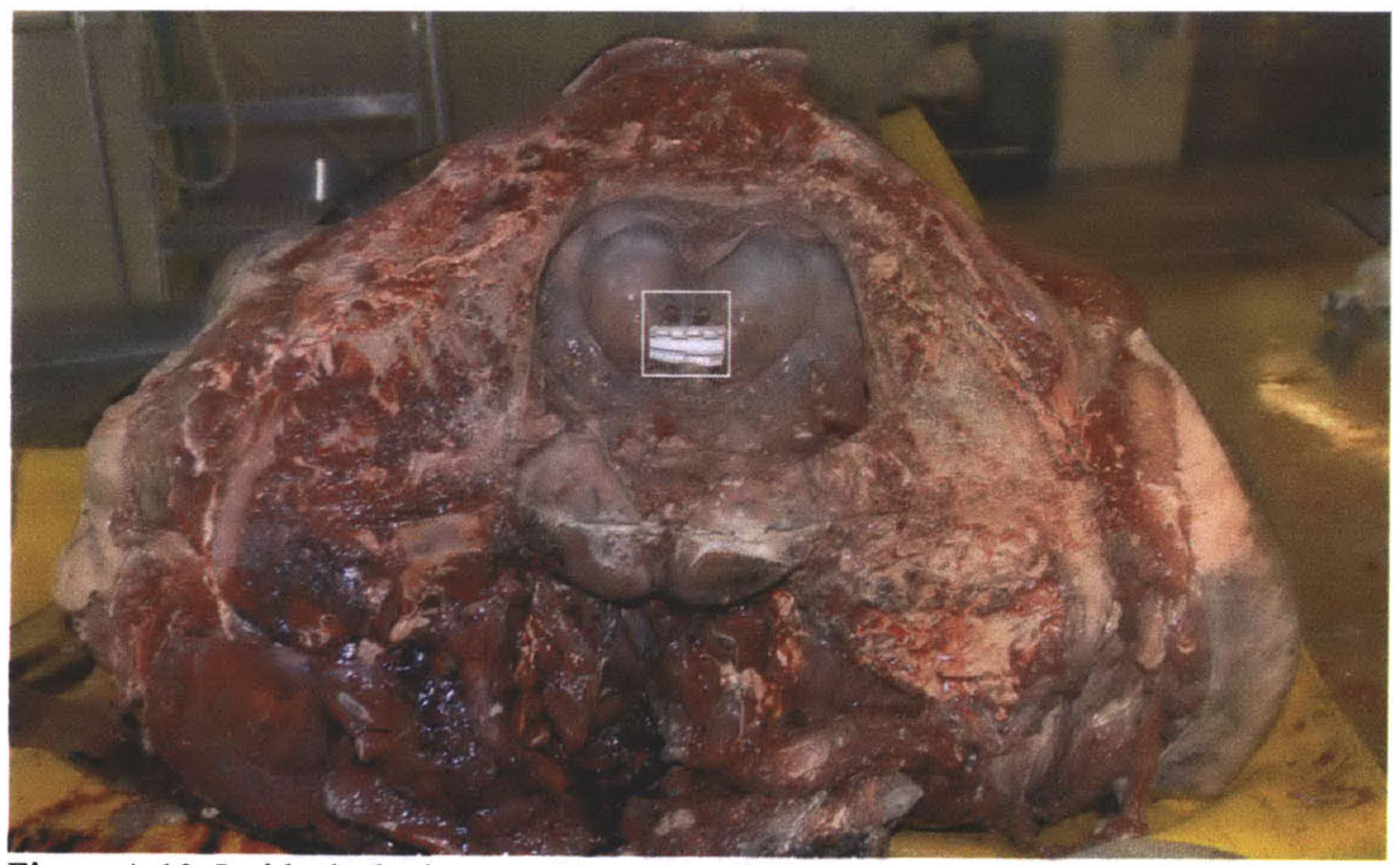

Figure A.10. Inside the braincase of B-acu23. The location of the olfactory bulbs is indicated by the white box.

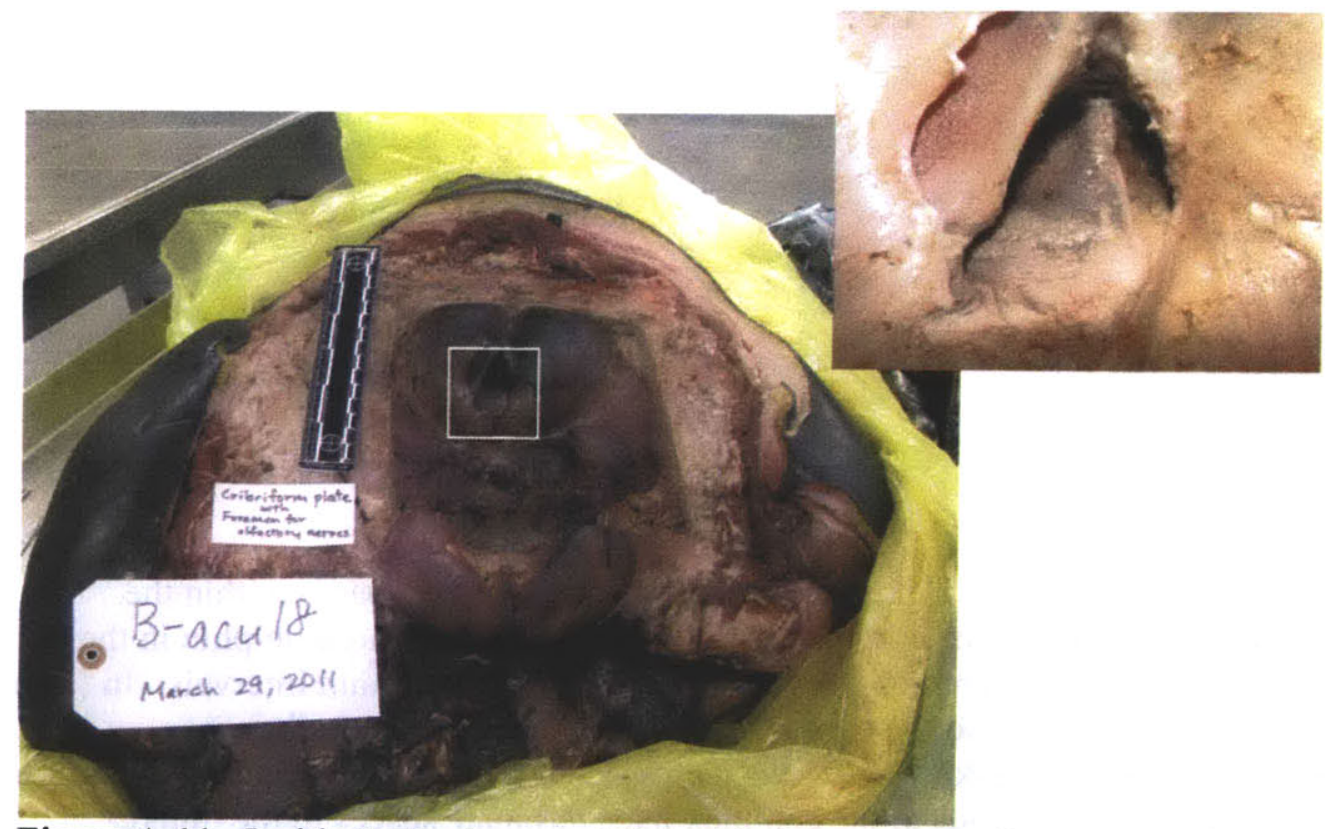

Figure A.11. Inside the braincase of B-acu18. The dura has been removed to expose the cribriform plate. The area indicated by white box is enlarged to the right. 


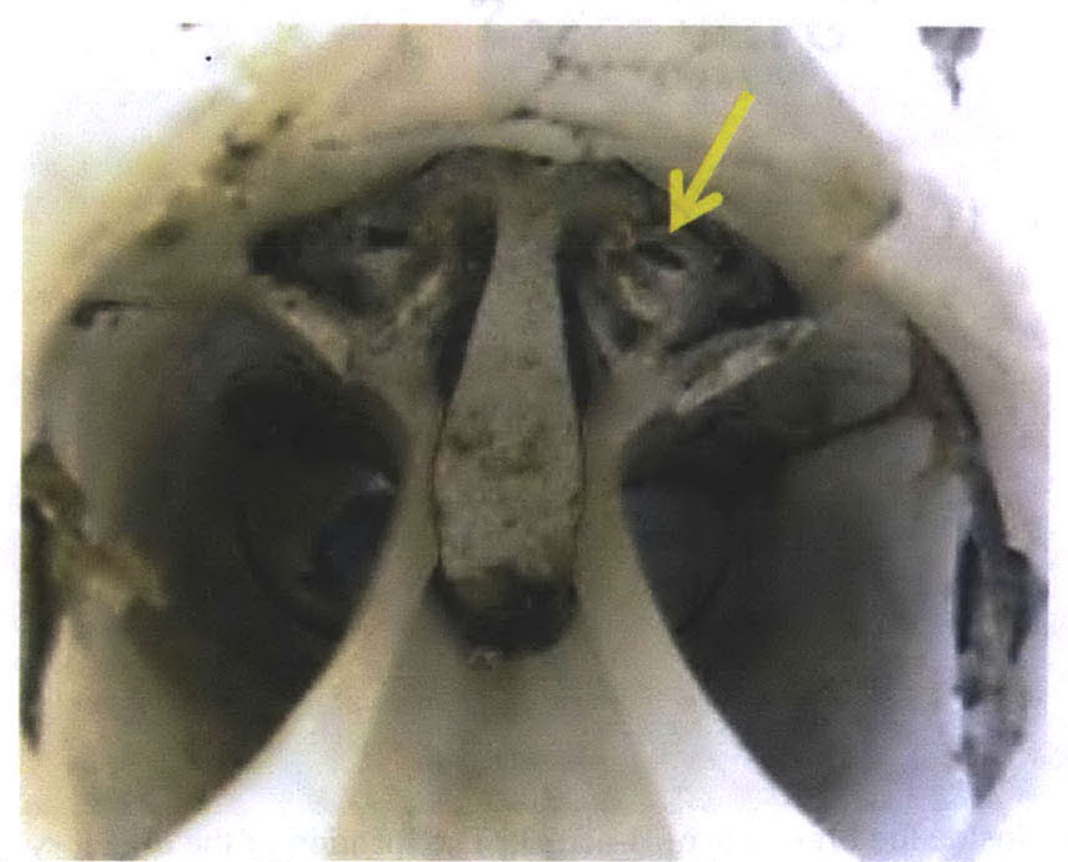

Figure A.12. Dried bone of B-acu11 showing inter-turbinate spaces within the ethmoid bones, which connect to the nasal passage.

Figure A.13. (Next 5 pages). CT images of the inter-turbinate air spaces within the ethmoid bones in the minke whale in the left column and the bottlenose dolphin in the right column. The series progresses from posterior to anterior at $3 \mathrm{~mm}$ intervals. In (a-c), the braincase is visible dorsal to the empty space where the olfactory bulbs are presumably located in the minke whale. No such space is evident in the bottlenose dolphin. This empty space leads to the complex inter-turbinate spaces in the minke whale, while these inter-turbinate spaces are also not found in the bottlenose dolphin. In (l-n), the inter-turbinate spaces are shown connecting to the nasal passage in the minke whale. The nasal passage leads to the blowhole further anteriorly. 

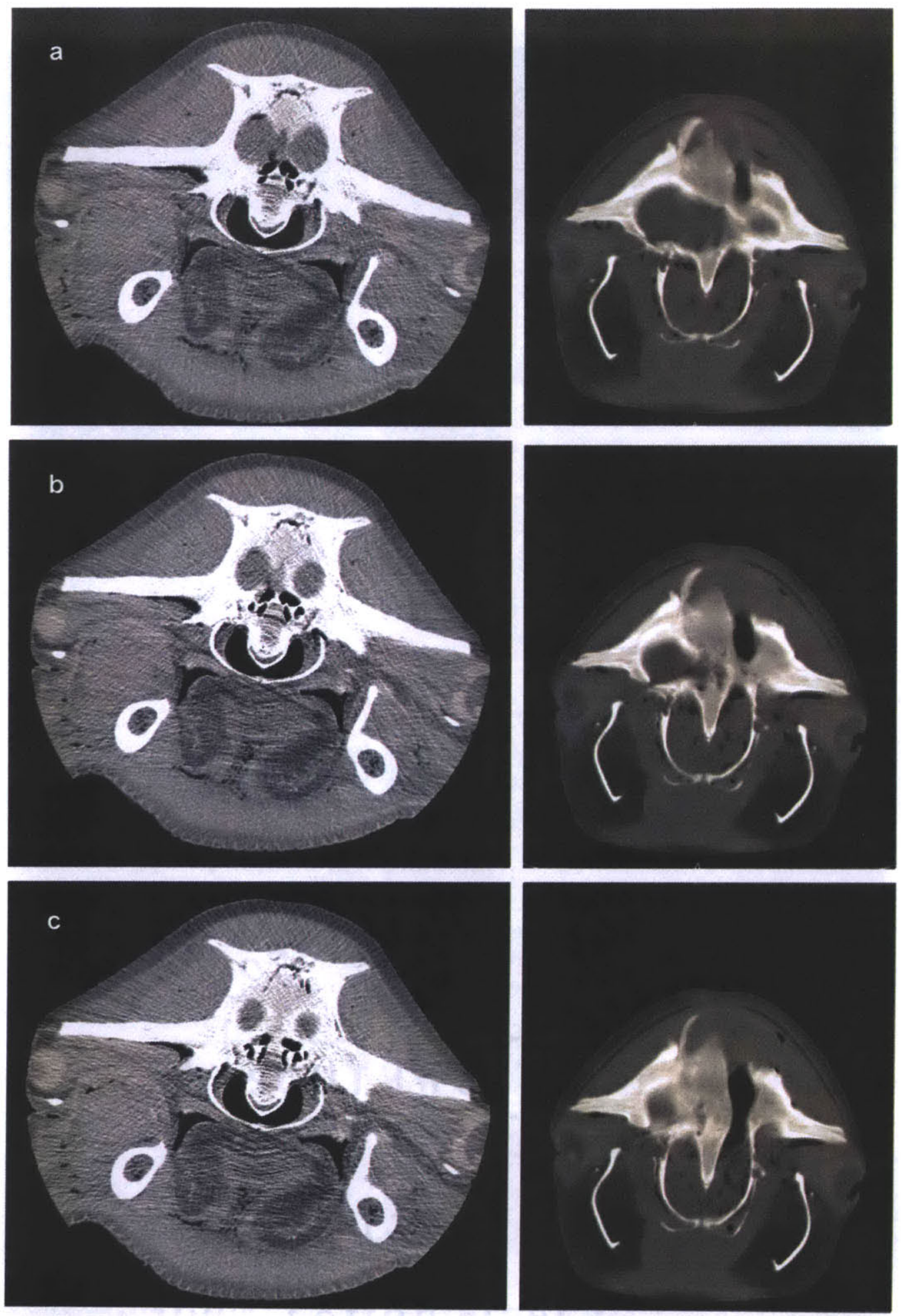

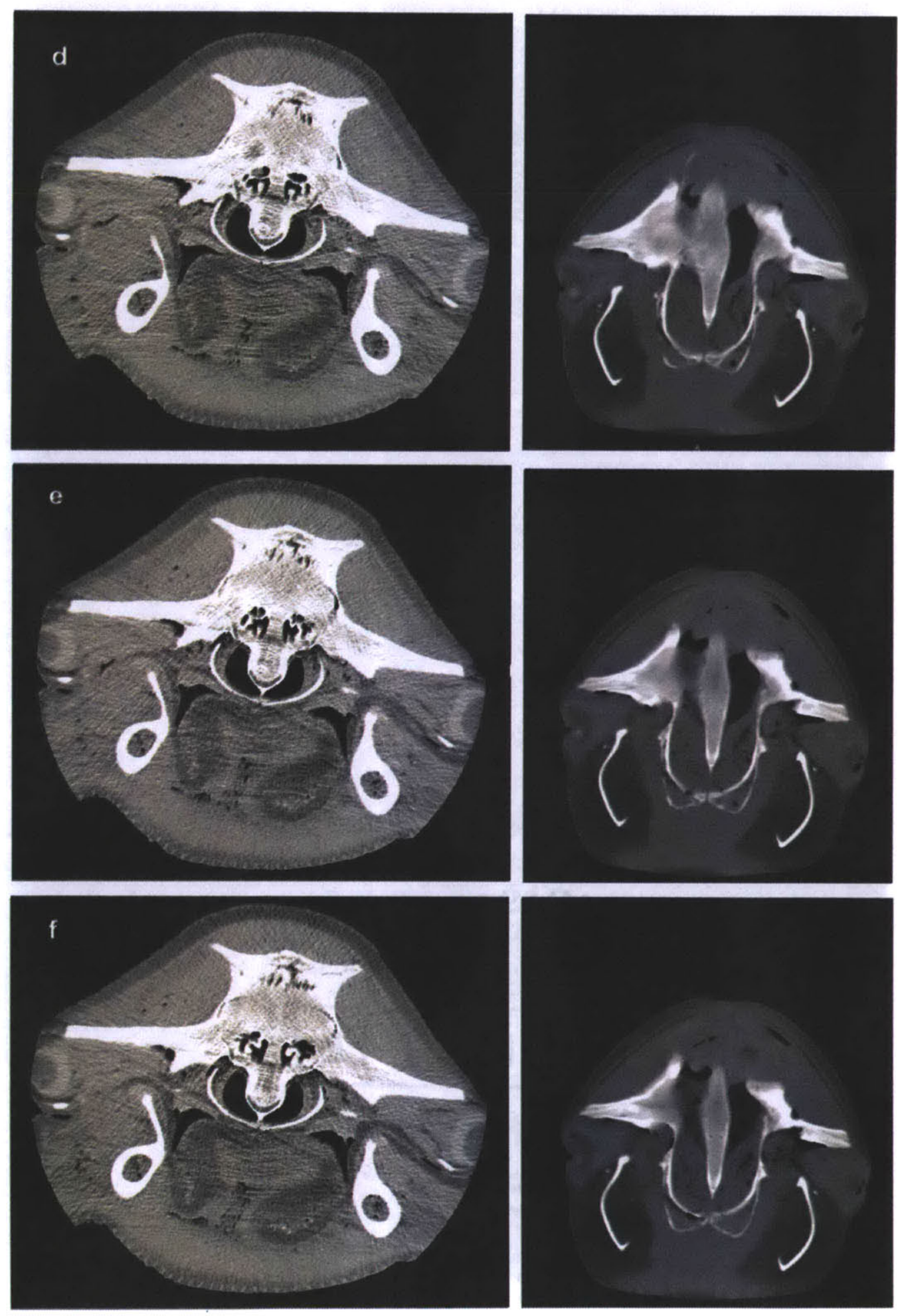

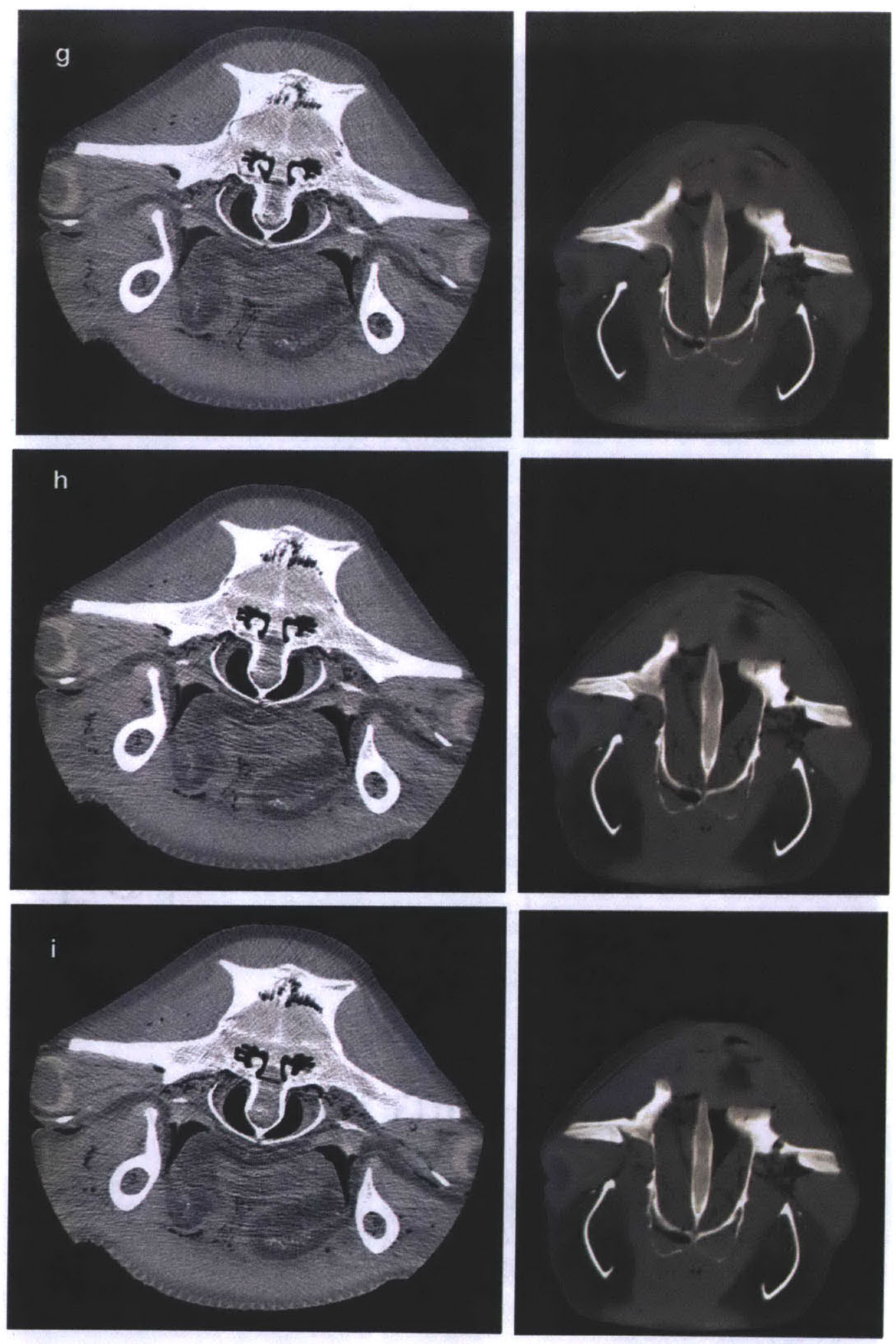

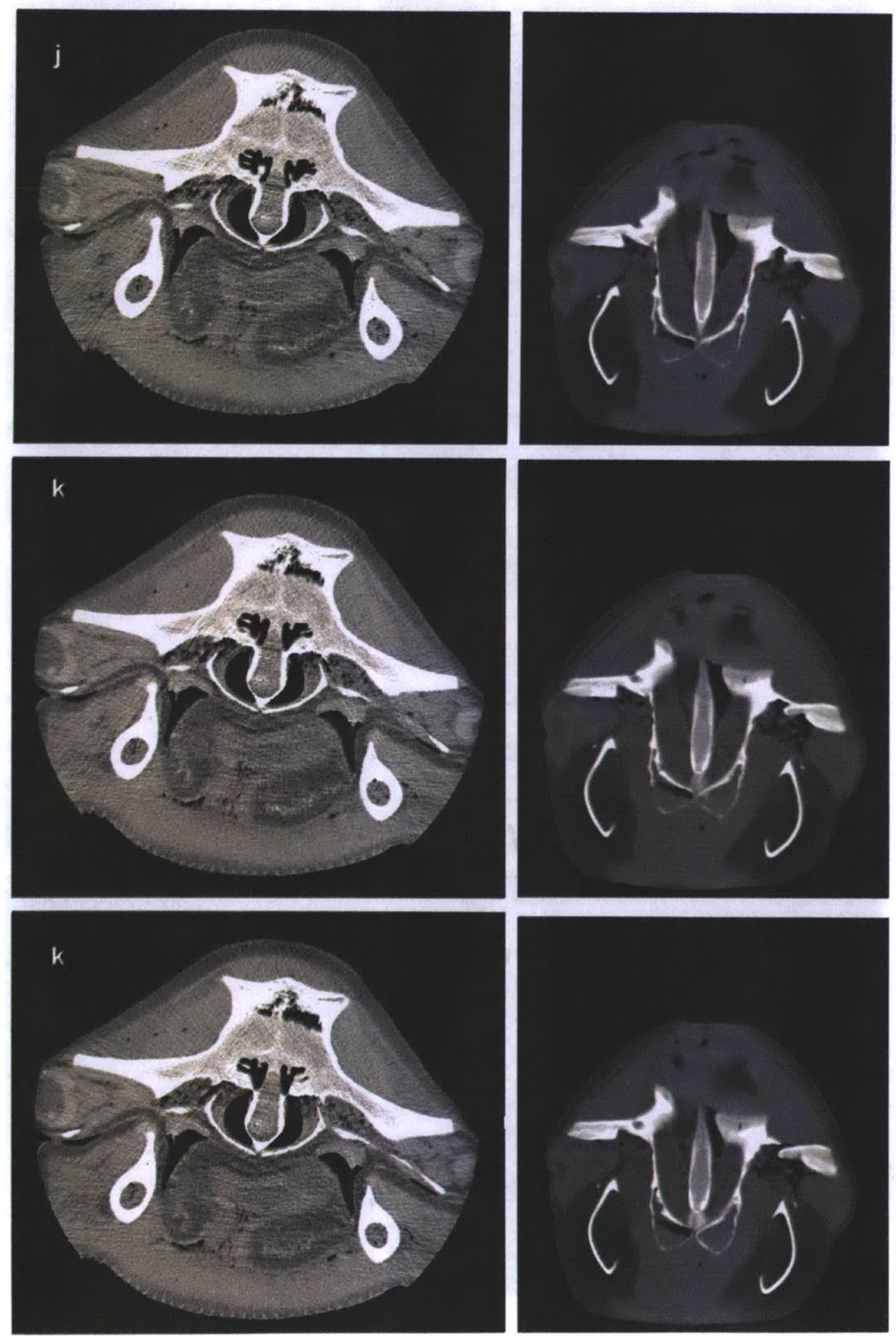

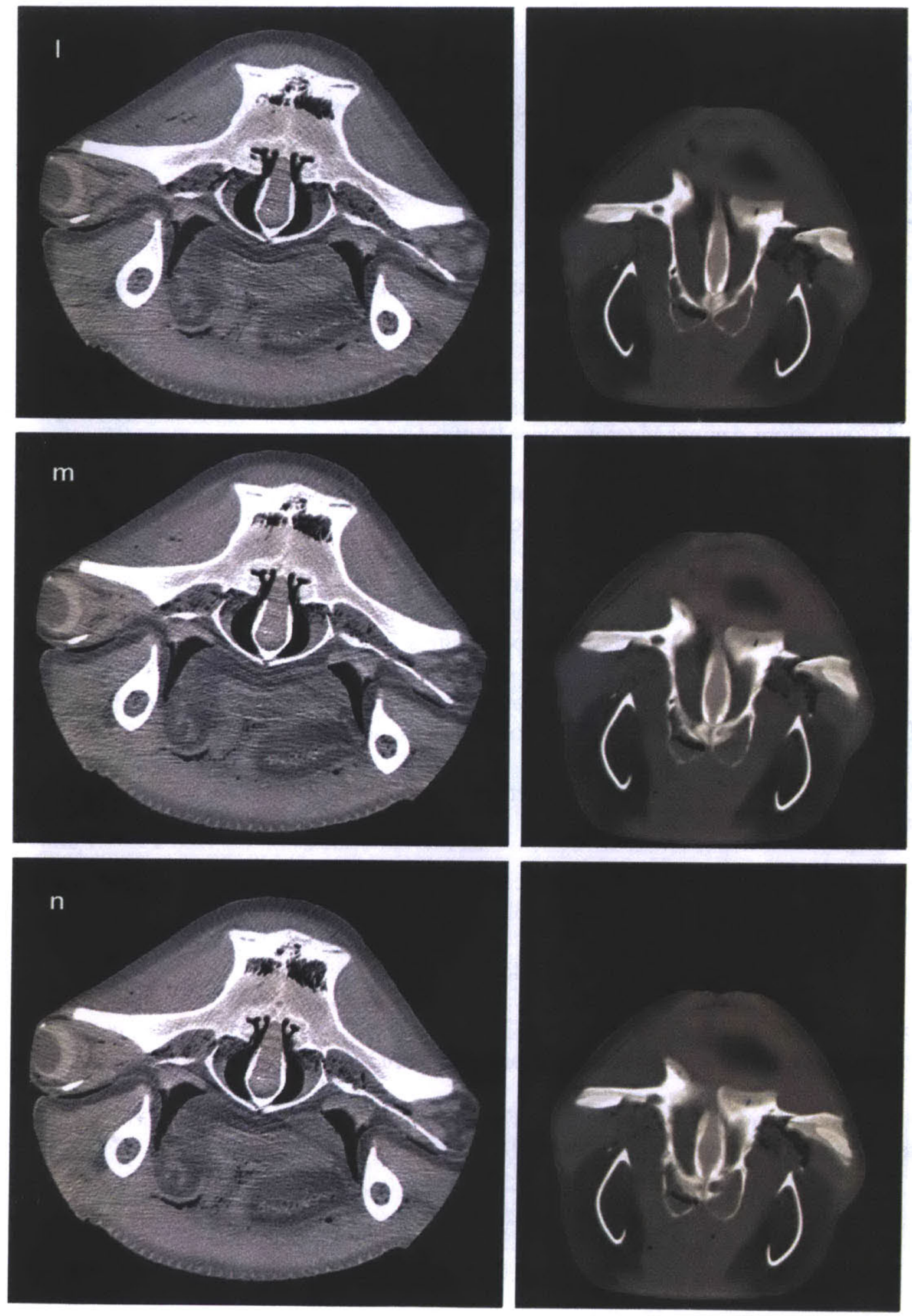


\section{A.6. References}

Breathnach AS. 1960. The cetacean central nervous system. Biological Reviews 35:187230.

Brodie PF. 1993. Noise generated by the jaw actions of feeding fin whales. Canadian Journal of Zoology 71:2546-2550.

Carte A, Macalister A. 1868. On the Anatomy of Balaenoptera rostrata. Phil. Trans. 158:201-261.

Harper CJ, McLellan WA, Barco S, Pabst DA. 2010. The Gross Morphology of the Melon in a Neonate Right Whale (Eubalaena glacialis). In: North Atlantic Right Whale Consortium Annual Meeting. New Bedford.

Heyning JE, Mead JG. 1990. Evolution of the nasal anatomy of cetaceans. In: Thomas J, Kastelein R, editors. Sensory abilities of cetaceans. New York: Plenum. p 67-79.

Kishida T, Kubota S, Shirayama Y, Fukami H. 2007. The olfactory receptor gene repertoires in secondary-adapted marine vertebrates: evidence for reduction of the functional proportions in cetaceans. Biology Letters 3:428-430.

Lillie DG. 1910. Observations on the Anatomy and General Biology of some Members of the Larger Cetacea. Proceedings of the Zoological Society of London 80:769-792.

Pautard FGE. 1963. Mineralization of Keratin and its Comparison with the Enamel Matrix. Nature 199:531-535.

Pivorunas A. 1977. The fibrocartilage skeleton and related structures of the ventral pouch of Balaenopterid whales. Journal of Morphology 151:299-313.

Tinker SW. 1988. Whales of the world. Honolulu: Bess Press, Inc.

Thewissen JGM, George J, Rosa C, Kishida T. 2011. Olfaction and brain size in the Bowhead whale (Balaena mysticetus). Marine Mammal Science 27:282-294.

Werth A. 2001. How do mysticetes remove prey trapped in baleen? Bulletin of the Museum of Comparative Zoology 156:189-203. 